\title{
Analyses of the PM-2 Aquifer Test Using Multiple Observation Wells
}
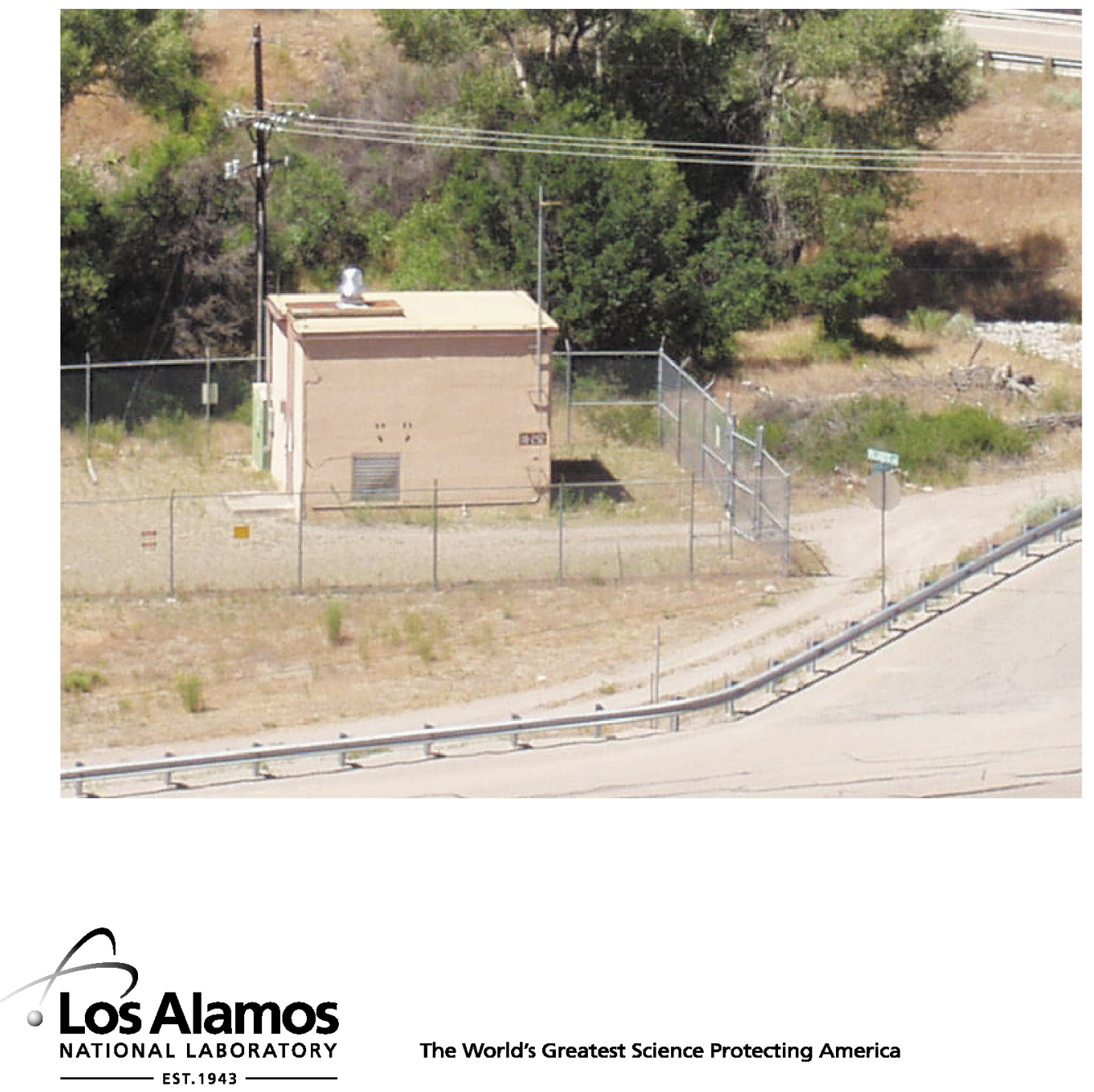

The World's Greatest Science Protecting America 
Edited by Faith J. Harp, Comforce, for Group IM-1

Photocomposition by Teresa Hiteman, Group ENV-ECO

About the Covers: (Front) PM-2 well house located in Pajarito Canyon. Los Alamos County recently renamed it PW-2. (Back) The venerable CM-55 coring drill rig in Valles Grande (circa 1948).

Los Alamos National Laboratory, an affirmative action/equal opportunity employer, is operated by the University of California for the United States Department of Energy under contract W-7405-ENG-36.

This report was prepared as an account of work sponsored by an agency of the United States Government. Neither the Regents of the University of California, the United States Government nor any agency thereof, nor any of their employees make any warranty, express or implied, or assume any legal liability or responsibility for the accuracy, completeness, or usefulness of any information, apparatus, product, or process disclosed, or represent that its use would not infringe privately owned rights. Reference herein to any specific commercial product, process, or service by trade name, trademark, manufacturer, or otherwise does not necessarily constitute or imply its endorsement, recommendation, or favoring by the Regents of the University of California, the United States Government, or any agency thereof. The views and opinions of authors expressed herein do not necessarily state or reflect those of the Regents of the University of California, the United States Government, or any agency thereof. Los Alamos National Laboratory strongly supports academic freedom and a researcher's right to publish; as an institution, however, the Laboratory does not endorse the viewpoint of a publication or guarantee its technical correctness. 
LA-14225-MS

Issued: July 2005

Analyses of the PM-2 Aquifer Test Using Multiple Observation Wells

Stephen G. McLin

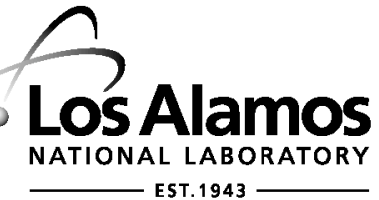

The World's Greatest Science Protecting America 



\section{CONTENTS}

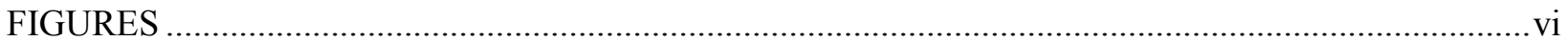

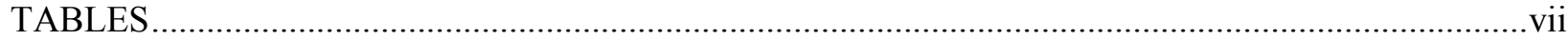

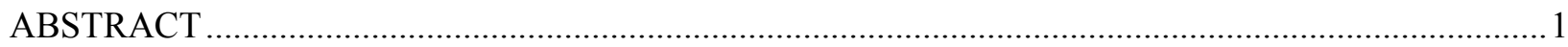

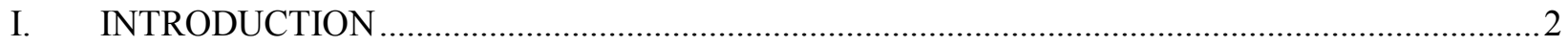

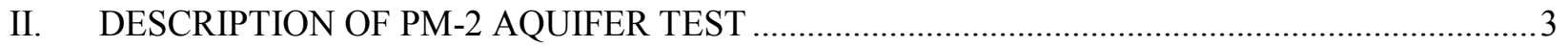

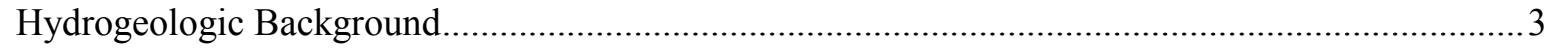

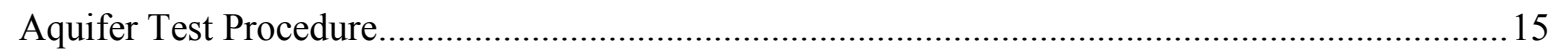

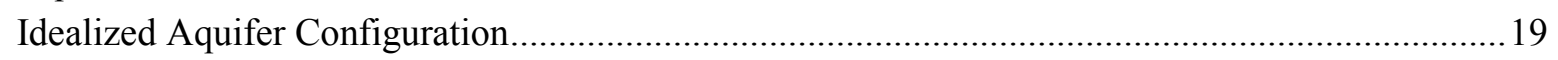

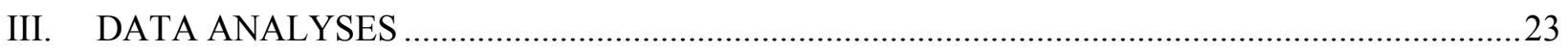

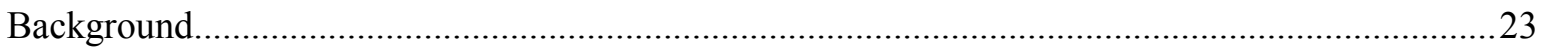

Distance-Drawdown Analysis ..................................................................................................2 27

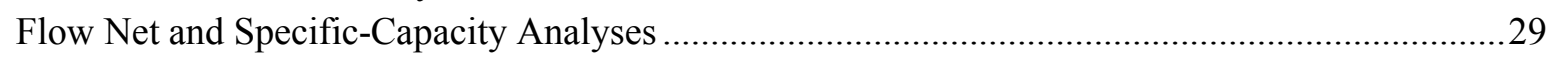

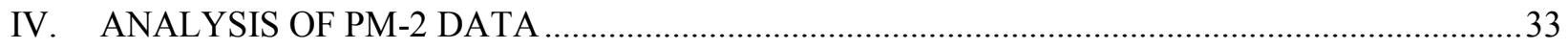

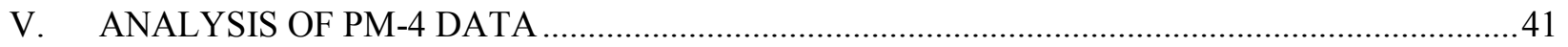

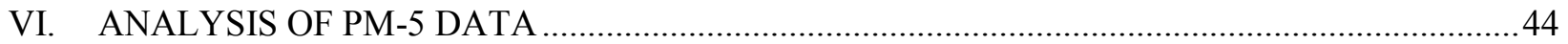

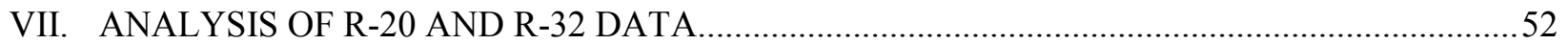

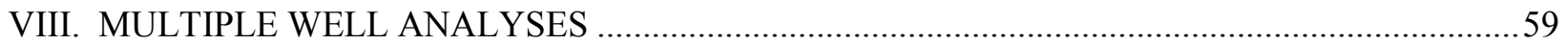

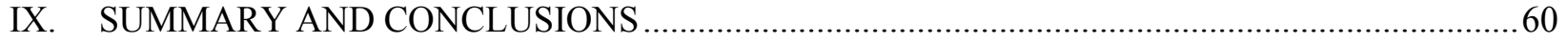

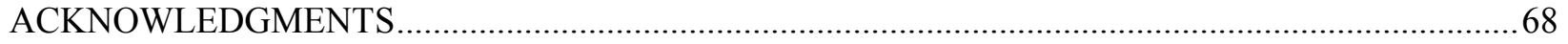

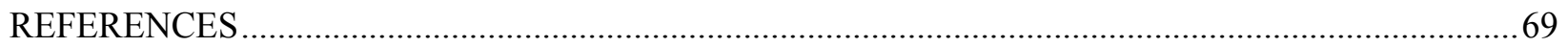

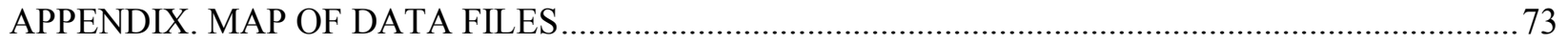




\section{FIGURES}

1. Location of wells on Pajarito Plateau. Note the location of geologic cross-section $\mathrm{A}-\mathrm{A}^{\prime}$...................4

2. Geological cross-section A-A' through well PM-2 and the central plateau area..............................5

3. Location of wells surrounding the PM-2 aquifer test................................................................. 6

4. Geologic cross-section B-B' through well PM-2 and the adjacent observation wells.......................8

5. Well completion diagram for PM-5 showing geologic units penetrated........................................9

6. Well completion diagram for PM-4 showing geologic units penetrated. ..................................... 10

7. Well completion diagram for PM-2 showing geologic units penetrated......................................... 11

8. Well completion diagram for R-20 showing geologic units penetrated........................................ 12

9. Well completion diagram for R-32 showing geologic units penetrated.....................................13

10. Well completion diagram for R-22 showing geologic units penetrated......................................14

11. Discharge and water-level response at well PM-2 during the aquifer test. ................................... 17

12. Drawdown in several wells in response to pumping at well PM-2. ............................................ 18

13. Drawdown at wells R-20 (a) and R-32 (b) in response to pumping at well PM-2........................ 18

14. Graphical results of (a) the dynamic spinner log at well PM-4; (b) interpretative results showing the derivative of water velocity with respect to borehole depth; and (c) the geologic log opposite the PM-4 well screen (from Figure 6).

15. Idealized representation of the regional aquifer along the geologic cross-section B-B' shown in

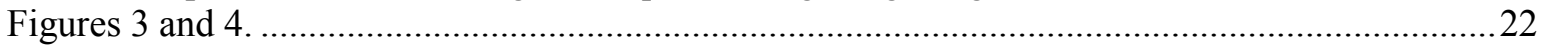

16. Distance-drawdown analysis from the PM-2 aquifer test using the data listed in Table 5..............28

17. Regional aquifer flow net analysis for central Pajarito Plateau using all available well data (modified after Purtymun and Johansen 1974).

18. Theis confined-aquifer analysis using PM-2 data from (a) drawdown, (b) recovery, and (c) residual recovery. In (a) and (b) the anisotropy ratio is 1.

19. Anisotropy ratio as a function of transmissivity from the Theis analysis for PM-2 drawdown data.

20. Leaky-aquifer analysis using PM-2 drawdown data for the (a) Hantush-Jacob, (b) the NeumanWitherspoon, and (c) the Moench models.

21. Anisotropy ratio as a function of transmissivity from the Hantush-Jacob method of leaky-aquifer analysis for PM-2 drawdown data.

22. Theis confined-aquifer analysis using PM-4 data from (a) drawdown, (b) recovery, and (c) residual recovery.

23. Leaky-aquifer analysis using PM-4 drawdown data for the (a) Hantush-Jacob, (b) the NeumanWitherspoon, and (c) the Moench models.

24. Theis confined-aquifer analysis using PM-5 data from (a) drawdown, (b) recovery, (c) residual recovery, and (d) a wedge-shaped aquifer.....

25. Idealized representation of the wedge-shaped regional aquifer along the geologic cross-section B-B' shown in Figures 3 and 4. Compare this figure with Figure 15.

26. Leaky-aquifer analysis using PM-5 drawdown data for the (a) Hantush-Jacob, (b) the NeumanWitherspoon, and (c) the Moench models.

27. Theis confined-aquifer analysis using R20-3 data from (a) drawdown, (b) recovery, and (c) residual recovery.....

28. Leaky-aquifer analysis using R20-3 drawdown data for the (a) Hantush-Jacob , (b) NeumanWitherspoon, and (c) Moench models.

29. Multiple-well analyses using PM-2, PM-4, and PM-5 drawdown data for (a) Theis confined-aquifer, (b) Hantush-Jacob leaky-aquifer, (c) Neuman-Witherspoon leaky-aquifer analyses, and (d) Moench leaky-aquifer (case 1).

30. Drawdown at wells (a) R-20, (b) R-32, and (c) R-22 following the aquifer test at well PM-2...............62

31. Monthly water production for Los Alamos County during 2003. 


\section{TABLES}

1. Water-Level Measurements and Elevations in Wells used during the PM-2 Aquifer Test..............15

2. Instantaneous and Average Discharge Rates Measured at Well PM-2 ...........................................17

3. Summary of PM-4 Production Zone Characteristics from the Dynamic Spinner Log in

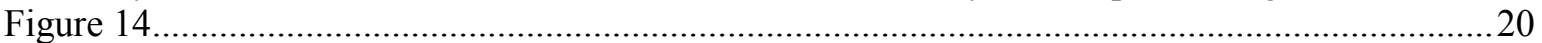

4. Aquifer Configuration Dimensions in Pumping and Observation Wells .....................................20

5. Data Used in Distance-Drawdown Analysis Shown in Figure 16 .................................................28

6. Hydraulic Conductivity Ratios Derived from the Flow Net Shown in Figure 17 ..........................32

7. Transmissivity Estimated from Specific Capacity Data ..................................................................32

8. Summary of Aquifer Parameters from PM-2 Aquifer Test ............................................................37

9. Comparison of Hydraulic Conductivity Ratios from Various Analytical Techniques ......................45

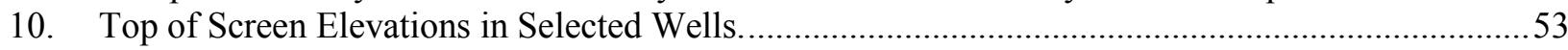

11. Maximum Water-Level Changes in Selected Observation Wells .................................................64

12. Distance of Various Water Supply Wells from Well R-32 ........................................................65

A-1. Data Files Contained on the CD-ROM Included with This Report...............................................73 



\title{
Analyses of the PM-2 Aquifer Test Using Multiple Observation Wells
}

by

\author{
Stephen G. McLin
}

\begin{abstract}
A 25-day aquifer test was conducted at municipal water supply well PM-2 at a constant discharge rate of $1,249 \mathrm{gpm}$. This pumping interval was immediately followed by a 25day recovery period. Surrounding observation wells were used to record both drawdown and recovery. These data reveal horizontal propagation of drawdown in the regional aquifer beyond $8,800 \mathrm{ft}$ from well PM-2 but show a pronounced resistance to vertical drawdown propagation at shallower depths. Hydraulically, the regional aquifer behaves like a semiconfined aquifer with leaky units located above a highly conductive layer that averages about $850 \mathrm{ft}$ in thickness. Classical distance-drawdown and fully confined aquifer behavior of early-time drawdown data (i.e., less than 4 days) from individual observation wells suggest that the highly conductive layer in the regional aquifer between wells PM-2 and PM-4 has a transmissivity of about $4,235 \mathrm{ft}^{2} /$ day and a storage coefficient of about 0.00035 . The corresponding hydraulic conductivity is about 5.0 $\mathrm{ft} /$ day. The aquifer thins between wells PM-4 and PM-5 to an effective thickness of about $490 \mathrm{ft}$, whereas the aquifer transmissivity increases to about $6,246 \mathrm{ft}^{2} /$ day and the storage coefficient increases to about 0.00069 . The corresponding hydraulic conductivity near well PM-5 is about $12.7 \mathrm{ft} /$ day. Comparisons of late-time drawdown data (i.e., more than 4 days), using leaky-confined aquifer models, suggest a gradual transition from confined to leaky-confined aquifer behavior because the storage coefficient slowly increases to about 0.00180 after this time.
\end{abstract}

The test demonstrated a remarkably complex aquifer response over space and time that is not easily interpreted without a combination of fully penetrating and multiple-screened observation wells, a dynamic spinner log from well PM-4, and water-level data from selected observation wells for about one year following the aquifer test. These data also suggest the possibility that two competing conceptual models may be used to represent the regional aquifer in the central plateau area. First and more likely, aquifer drawdown data suggest that a traditional leaky-confined aquifer model is appropriate. In this model, leaky source beds in the regional aquifer are located above a highly conductive layer of variable thickness that extends between screen 3 of well R-20 and wells PM-2, PM-4, and PM-5. In a second possibility, the regional aquifer behaves like a leaky-confined model because it contains interbedded layers of alternating high and low hydraulic conductivities that are sandwiched together into a high-yielding zone. The overlying units at the top of the regional aquifer may not be a significant source of water to the municipal supply wells. This second conceptual model requires the low-conductivity layers within the alternating sequence to be leaking into the adjacent high-conductivity layers. These competing interpretations cannot be resolved without additional, deep, multiple-screened observation wells located near wells PM-4 and PM-5 that characterize vertical leakage between adjacent layers within the regional aquifer. This characterization has obvious implications for monitoring potential contaminant migration in the regional system. 


\section{INTRODUCTION}

An aquifer test generally has several objectives, depending on the test duration and number of observation wells that are used to record drawdown and recovery. First, a traditional aquifer test is undoubtedly the most reliable method for determining average hydraulic transmitting properties that characterize the saturated porous media surrounding the well screens in both pumping wells and observation wells. If drawdown is measured only in the pumping well, then we can determine aquifer transmissivity $(T)$. Charles Theis (1935) of the US Geological Survey's district office in Albuquerque, New Mexico, first defined $T$ for a confined aquifer. Here, $T$ represents the rate of flow to a pumping well in gallons per minute through a vertical crosssection of aquifer material one foot wide and extending the full saturated thickness of the aquifer that is subjected to a hydraulic gradient of one. We commonly express $T$ in equivalent units of length squared per unit of time $\left(L^{2} / \mathrm{T}\right)$. Hydraulic conductivity $(K)$ is determined by dividing $T$ by the aquifer thickness $(b)$. Values for $T$ and $K$ are important because they define how the aquifer will respond to stress (e.g., pumping, natural discharge, or recharge). If the well is completed into a geologic unit with a high $T$ value, then we will get less drawdown in response to pumping, but the cone of depression will propagate radially outward much farther. High $T$ values are generally more desirable than low $T$ values because wells have greater yields, show less drawdown, and generally cost less to pump.

Second, if an observation well is also available to simultaneously record drawdown and recovery in response to pumping, then an aquifer storage coefficient $(S)$ can also be obtained from the test. Here, $S$ is defined as the volume of water yielded to a pumping well per unit area of saturated aquifer material per unit of decline in water level. As such, $S$ is dimensionless. We can also write $S=S_{S} b$, where $S_{S}$ is the aquifer specific storage and has units of inverse length. This relationship is analogous to $T=K b$, which was defined above. Aquifer parameters like $T$ and $S$ were originally developed for confined-aquifer conditions assuming radial, two-dimensional (2-D), horizontal flow. However, in complex three-dimensional (3-D) groundwater representations, it is often best to use the parameters $K$ and $S_{s}$ because the influence of $b$ has been removed. This report documents estimated values for $T, K, b, S$, and $S_{s}$.

Third, if the test is long enough, the cone of depression may expand radially outward to intersect either a recharge boundary or a barrier boundary, if one is present. These boundary effects would typically be revealed by the differences between measured drawdown in an observation well and idealized drawdown predicted at the same time and location according to an appropriate analytical aquifer model (e.g., the Theis confined-aquifer model represented by the Theis typecurve).

Finally, if we have multiple observation wells that are optimally located, we can determine horizontal and/or vertical anisotropy effects on $K$. Horizontal anisotropy would be revealed by an elliptically shaped cone of depression rather than a circular one. This cone expands laterally away from the production well in response to pumping and requires at least two observation wells at different locations to physically verify the elliptical shape. Horizontal anisotropy is important because it tells us that water may preferentially move toward the well more easily in one horizontal flow direction than in another. However, it is the directional hydraulic gradient combined with anisotropic porous media characteristics that ultimately determines the precise groundwater flow direction. Vertical anisotropy would be similarly revealed as different 
drawdown values recorded in adjacent observation wells (or nested piezometers) completed at different vertical depths in the aquifer. Vertical anisotropy is important because it tells us that water generally moves more easily in the horizontal direction than in the vertical direction (i.e., parallel to sedimentary bedding planes rather than perpendicular to them). In addition, understanding vertical anisotropy helps us to characterize vertical hydraulic communication (e.g., leakage) between adjacent units that are located above or below the aquifer yielding water to the production well. These leaky source beds generally have lower $K$ values compared with units that yield water directly to the pumping well.

All of these properties are important because they reveal characteristics about the real 3-D expanding cone of depression that we cannot observe directly without numerous observation wells. In other words, drawdown is controlled by the 3-D nature of the hydraulic transmitting characteristics of the aquifer or adjacent saturated materials. This information, in turn, can help us predict complex aquifer responses to long-term seasonal pumping from multiple wells and help us understand the spread of potential contaminants that might eventually threaten the aquifer. These aquifer properties are also important because they give us an experimental method of measuring controlled stresses (i.e., pumping) and associated responses (i.e., drawdown and recovery), so that we can confidently estimate more complex aquifer behavior (e.g., anisotropy and leakage) with numerical models. These aquifer tests can also assist us in verifying data used in numerical models. Once verified, the aquifer parameters can be used to replicate and/or predict model responses to extremely complex stresses that cannot be duplicated in simple aquifer tests.

For example, if we have a numerical model that can reproduce the drawdown histories that were collected in individual observation wells during a controlled aquifer test like the one reported here, then we are likely to have added confidence in other complex model predictions of drawdown behavior from simulated long-term aquifer development or from potential contaminant movement that may eventually threaten the aquifer. Another way to build confidence is to accurately simulate observed long-term water-level declines in response to historical aquifer development like that documented on Pajarito Plateau starting in 1947 (e.g., McLin 1996; Rogers et al. 1996). These latter examples obviously represent important uses and justifications for model development and long-term water-level monitoring efforts. Less obvious, however, is the need to develop adequate aquifer tests with suitable observation wells that can help verify estimated model input data. This aquifer test partially fulfills these requirements for aquifer parameter identification that can be used for model verification.

\section{DESCRIPTION OF PM-2 AQUIFER TEST}

\section{Hydrogeologic Background}

Municipal water supply well PM-2 was completed in Pajarito Canyon in 1965 (Purtymun 1995), at a depth of 2,300 ft below ground surface ( $\mathrm{ft} \mathrm{bgs).} \mathrm{This} \mathrm{well} \mathrm{is} \mathrm{on} \mathrm{the} \mathrm{south} \mathrm{side} \mathrm{of} \mathrm{Pajarito}$ Road, approximately 2.56 miles northwest of White Rock (see Figure 1) and near the entrance to Technical Area 18. A number of observation wells (or R-wells) have also been installed over the past seven years as part of the Hydrogeologic Workplan (LANL 1998), in support of the Groundwater Protection Management Program (LANL 1996). Most of these wells are located in the central portions of Pajarito Plateau and also penetrate into the regional aquifer. This regional 


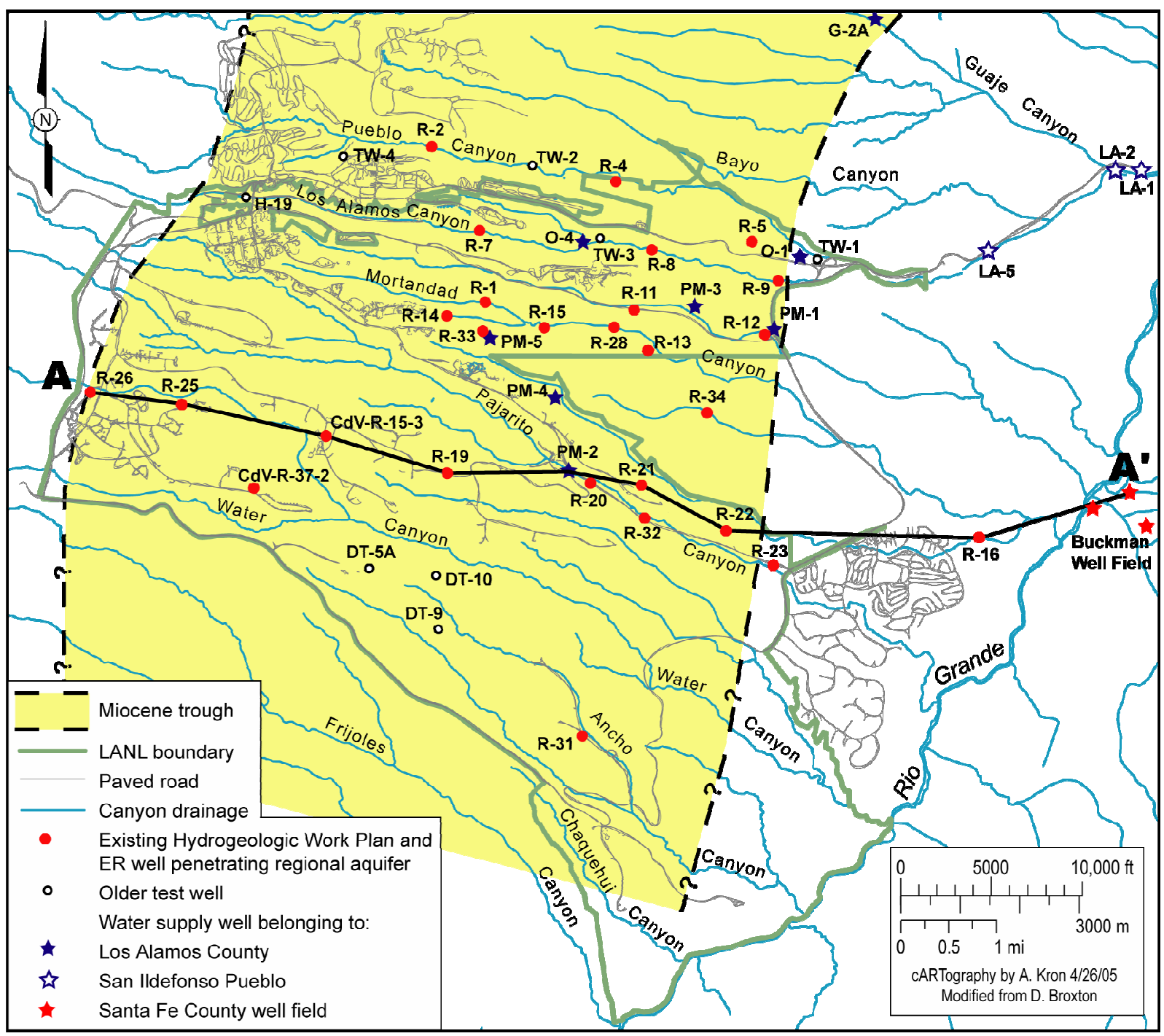

Figure 1. Location of wells on Pajarito Plateau. Note the location of geologic cross-section A-A'.

aquifer is the only source of potable drinking water for Los Alamos County, Los Alamos National Laboratory, and Bandelier National Monument. Historically, the highest-yielding water supply wells have penetrated into relatively thick sequences of the Puye fanglomerate (Griggs 1964; Purtymun and Stoker 1988), where axial deposits of ancestral Rio Grande gravels (i.e., the Totavi Lentil of Griggs) are commonly encountered. Locations of these and other high-yielding formations are generally defined according to the location of a Miocene trough (Figure 1). Although the areal extent of this trough has not been completely defined along the northern, western, and southern portions of the plateau, it has been clearly identified in numerous R-wells in the central plateau region where well PM-2 is located. Hence, some question marks along the trough perimeter are shown in Figure 1 because the presence of these units in the subsurface has not been fully verified by drilling. This trough has also been described by numerous authors (e.g., Broxton and Vaniman 2005; Broxton and Reneau 1996; Purtymun and Stoker 1988). Figure 1 also shows the location of geologic cross-section A-A' that runs west-to-east across Pajarito Plateau. This geologic section is shown in Figure 2 and is based on recent work by Broxton and Vaniman (2005). This cross-section is important because it shows a complex 


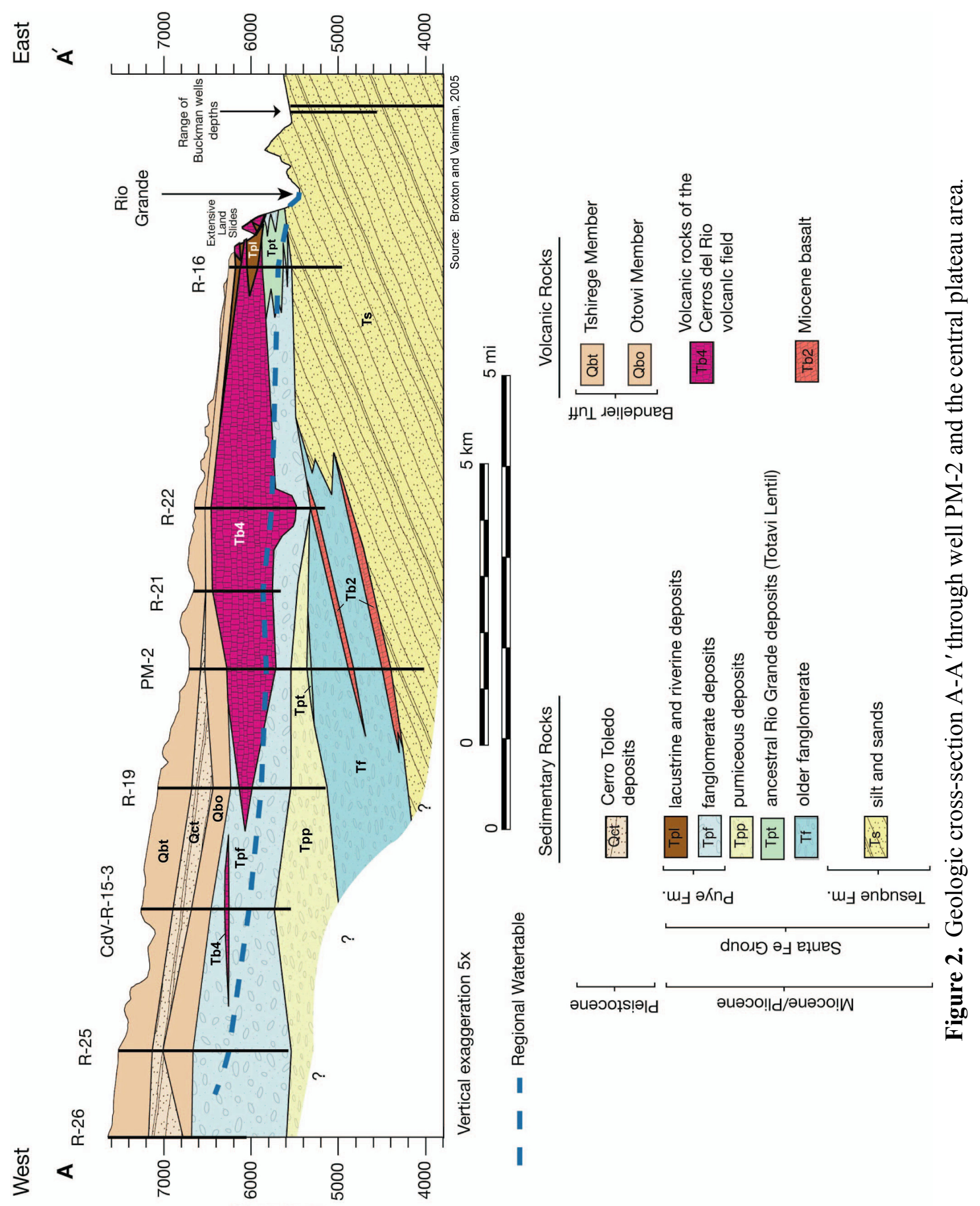

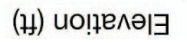


regional aquifer that can be characterized as an alluvial fan draped up against the Sierra de los Valles located west of well R-26, but the alluvial fan is also constrained by the Rio Grande on the east. Historical information for the regional aquifer below Pajarito Plateau was previously described (Cushman 1965; Griggs 1964; Theis and Conover 1962).

Figure 3 is an enlargement of the area surrounding well PM-2, where numerous observation wells are located. Figure 3 also shows an idealized radius of influence, or maximum extent of measured drawdown, that was observed in the 25-day aquifer test at PM-2. This radius is idealized because one must assume homogeneous and isotropic aquifer properties that generate concentric circles of equal drawdown in response to pumping at a constant rate. Several idealized concentric circles would actually represent these lines of equal drawdown at some time $t$. These contours would also decrease in value as the radial distance from the pumping well increases. In reality, we rarely see this idealized aquifer response. Instead, drawdown contours in response to pumping are typically shaped like concentric but distorted ellipses because the subsurface is not homogeneous and isotropic. These irregular shapes are revealed only when a sufficient number

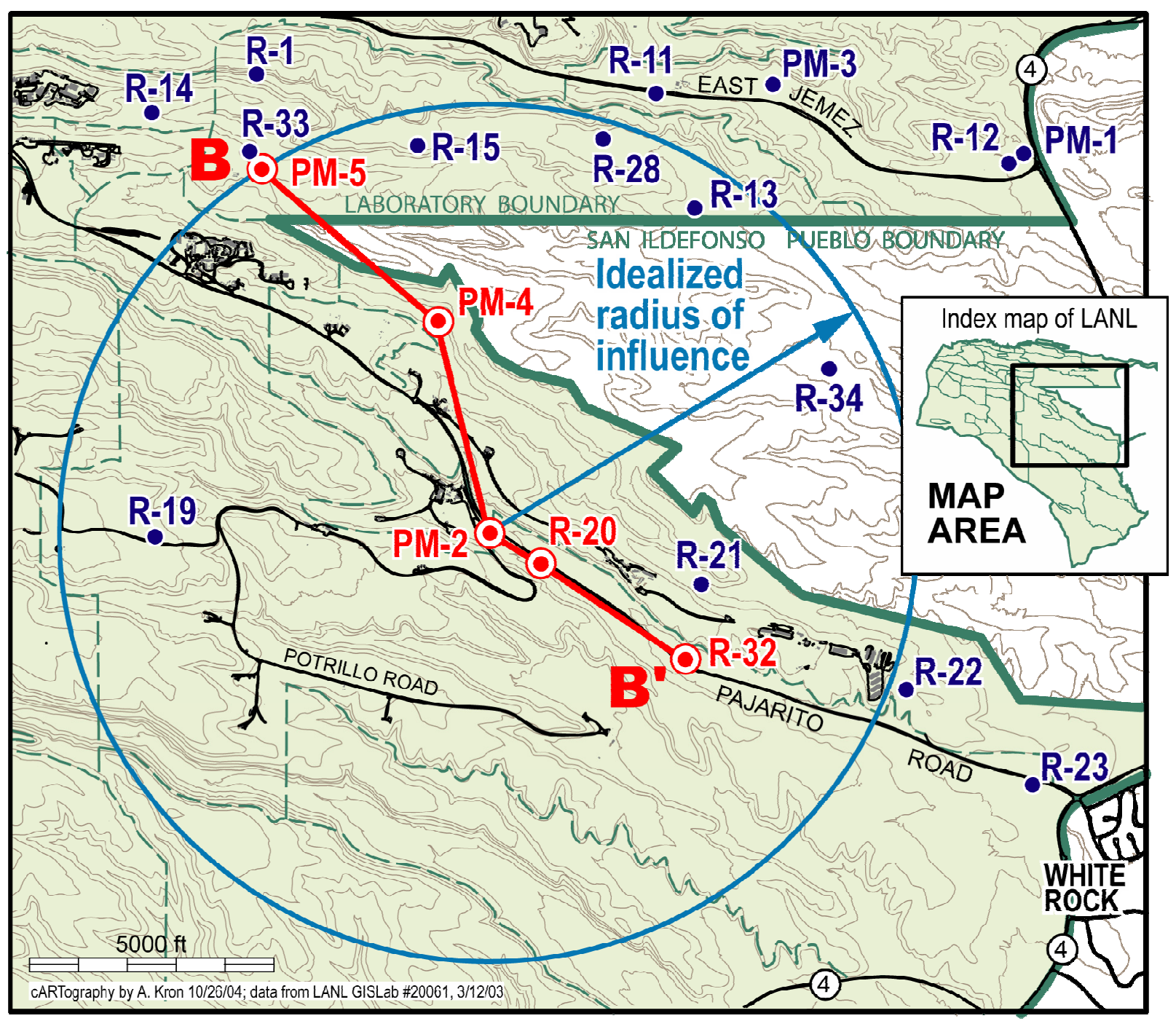

Figure 3. Location of wells surrounding the PM-2 aquifer test. Note the location of geologic cross-section B-B'. 
of observation wells are available to record spatial and temporal changes in drawdown. For the PM-2 aquifer test, drawdown was observed in wells PM-2, R-20, R-32, PM-4, and PM-5 (see Figure 3). However, no drawdown was observed in R-22, PM-1, or PM-3 because these deep wells are located too far from well PM-2 to be affected. In addition, no drawdown was observed in R-21, R-23, R-12, R-13, R-15, or R-14 because these wells are either too shallow and do not penetrate into the water-bearing units that yield water to PM-2, or these wells are located too far from PM-2 to be affected. This observation of drawdown in some wells and no drawdown in other wells immediately tells us that the saturated regional aquifer materials surrounding PM-2 are vertically anisotropic with respect to hydraulic transmitting characteristics. More is written about this behavior further on. Finally, no drawdown was recorded at R-19 because the recording transducer system for this well was not deployed during the PM-2 test period. On the basis of the hydraulic transmitting properties obtained from this test (as presented below) and the geologic cross-section shown in Figure 2, we would expect to see recordable drawdown in well R-19 during the 25-day pumping interval.

Figure 3 also shows a cross-sectional line labeled B-B' that runs between wells PM-5, PM-4, PM-2, R-20, and R-32. The corresponding geologic cross-section B-B' is shown in Figure 4. The geologic units penetrated by the pumping wells and the observation wells are represented in the latter figure. At well PM-2, these units include (in descending order) $30 \mathrm{ft}$ of alluvium, $103 \mathrm{ft}$ of the Tshirege Member of the Bandelier Tuff, $50 \mathrm{ft}$ of the Cerro Toledo interval, $249 \mathrm{ft}$ of the Otowi Member of the Bandelier Tuff, $268 \mathrm{ft}$ of the Cerros del Rio basalt, $34 \mathrm{ft}$ of the Puye Formation (fanglomerate), $36 \mathrm{ft}$ of Cerros del Rio basalt interbedded with the Puye fanglomerate, $570 \mathrm{ft}$ of the Puye fanglomerate, $70 \mathrm{ft}$ of axial Rio Grande deposits (i.e., the Totavi Lentil of Griggs 1964), $430 \mathrm{ft}$ of older fanglomerate deposits, $52 \mathrm{ft}$ of Miocene basalts, $326 \mathrm{ft}$ of older fanglomerate deposits, $92 \mathrm{ft}$ of Miocene basalts, and $288 \mathrm{ft}$ of Santa Fe Group sediments consisting of fine silty sands. Figure 4 also shows the respective screen locations for individual wells along the geologic cross-section B-B'. In general, we are more likely to see drawdown in a particular observation well if three conditions are met. These include the following: (1) the well screen in the observation well is located within at least a portion of the same horizontal interval as the production well screen; (2) the water-yielding units between the pumping wells and the observation wells are continuous; and (3) the observation well is relatively close to the pumping well.

Figure 2 shows that the regional aquifer is actually represented by a relatively complex stratigraphic sequence across the central portions of Pajarito Plateau. According to Figure 4, many individual units that are below the regional water table are present in several different observation wells (e.g., the Puye Formation), suggesting that many of these units were continuously deposited across the plateau. However, other units are clearly discontinuous between adjacent wells, or the saturated thickness of individual units varies considerably between adjacent wells (e.g., the Totavi Lentil or the Miocene basalts). The geologic crosssection represented by Figure 4 depicts only a small segment of a complex regional aquifer system located below Pajarito Plateau. Detailed well completion diagrams for each of the wells shown in Figure 4 are presented in Figures 5-9 and correspond to wells PM-5, PM-4, PM-2, R20, and R-32, respectively, that are along geologic cross-section B-B' (Purtymun 1995; Thompson et al. 2003; and Pearson 2003). Figure 10 also shows a well completion diagram for well R-22 (Ball et al. 2002). Well R-22 could easily have been included in the geologic crosssection B-B' depicted in Figure 4. However, no drawdown was recorded in any of the five 


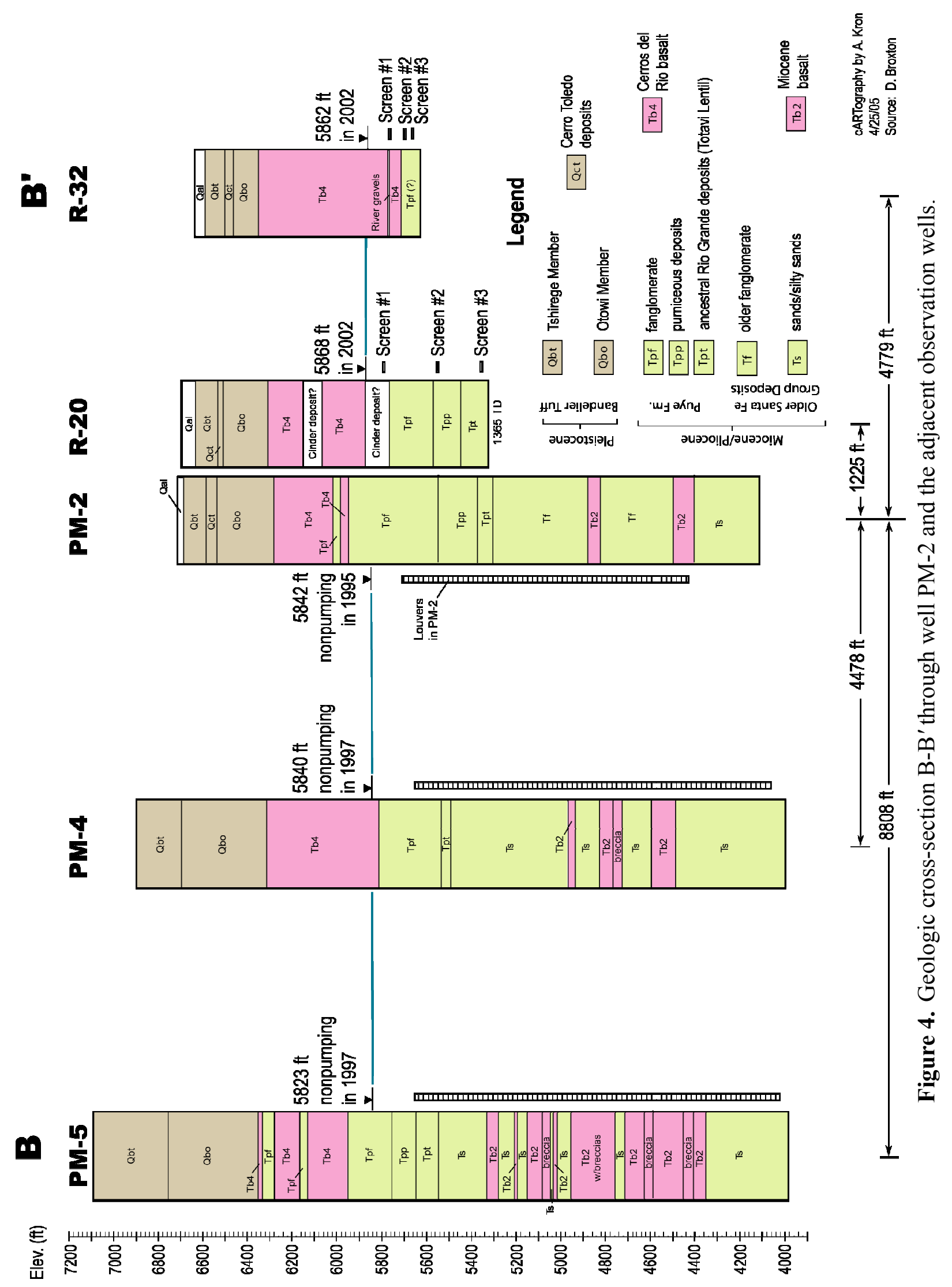




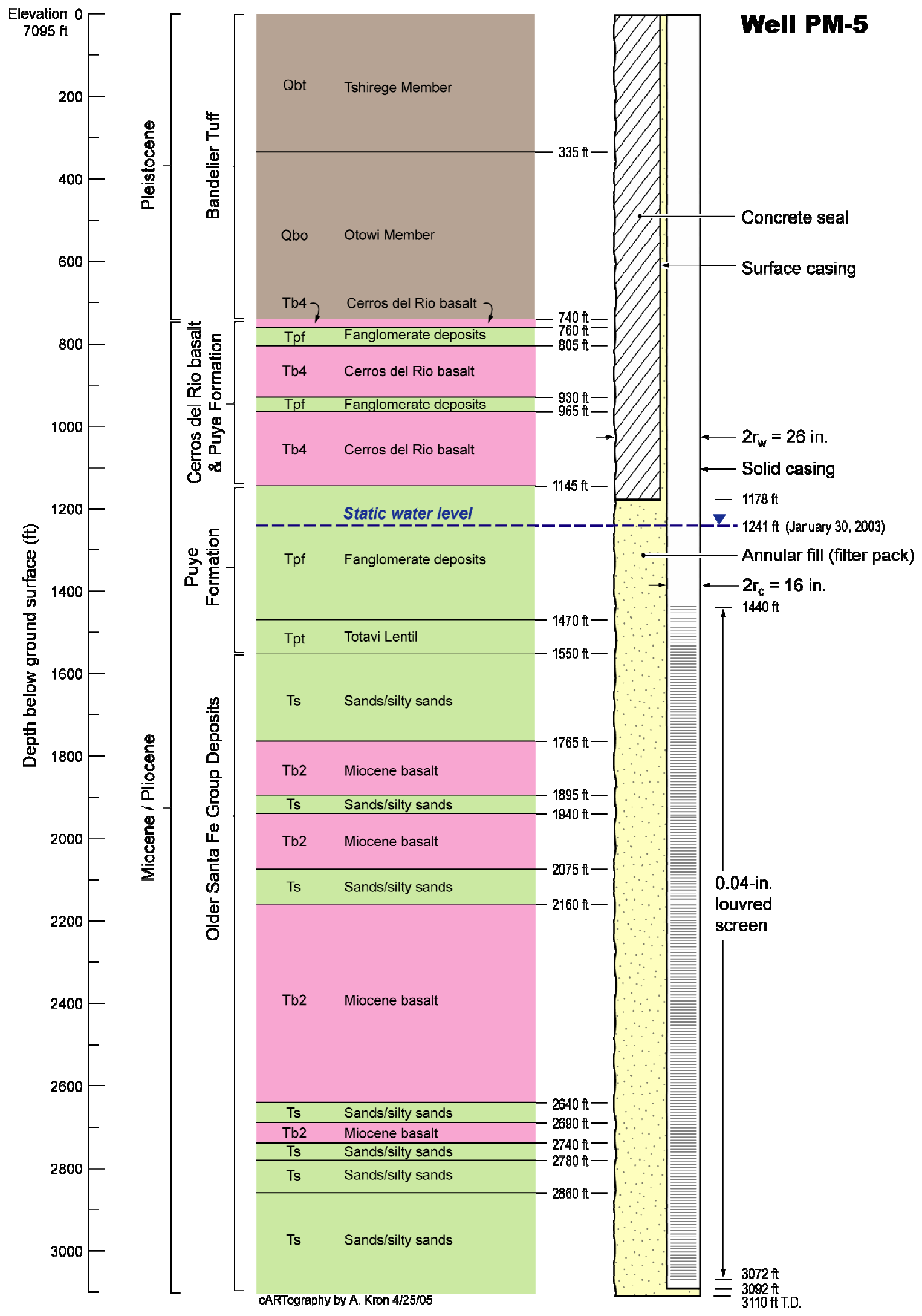

Figure 5. Well completion diagram for PM-5 showing geologic units penetrated. 


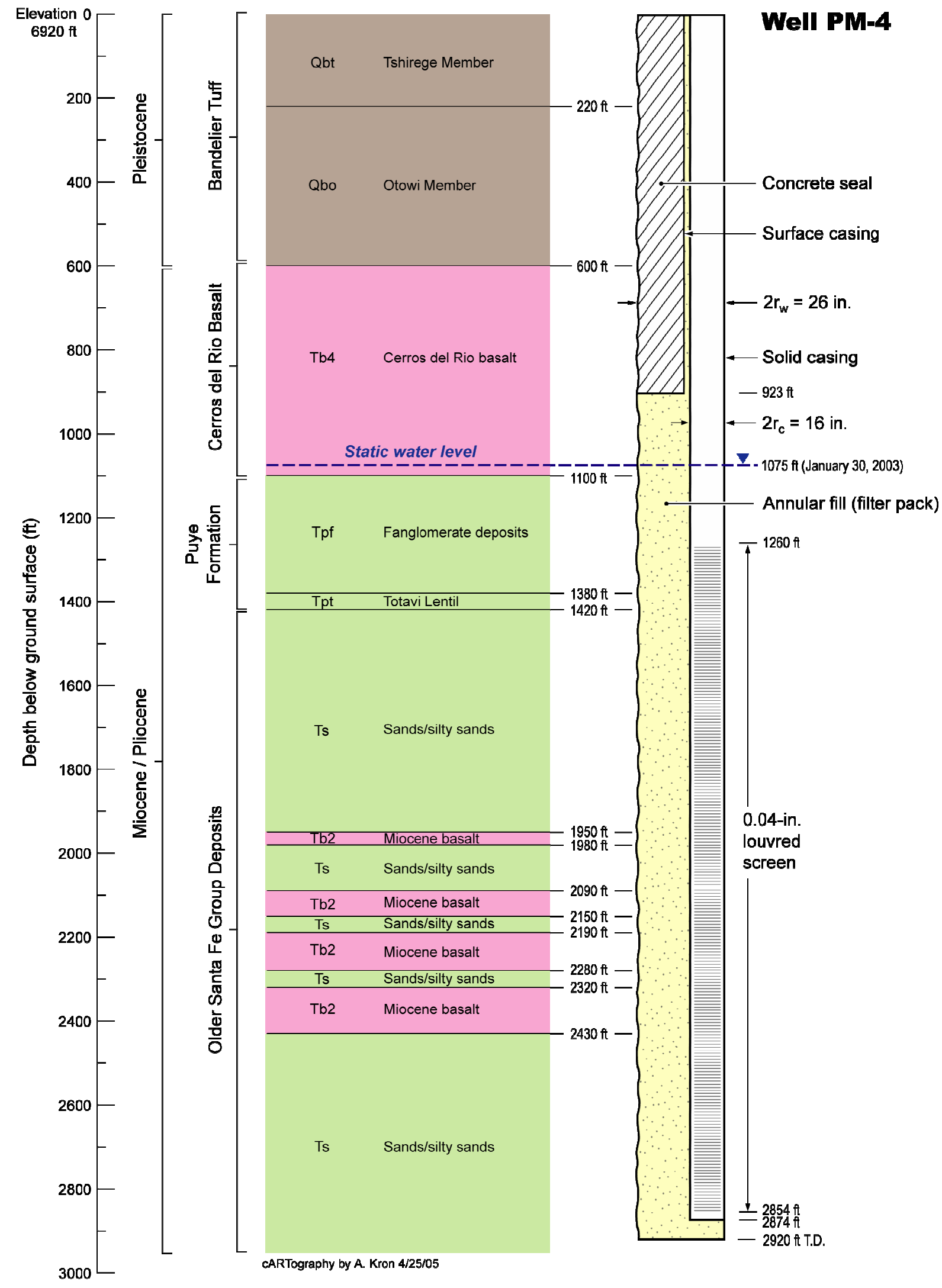

Figure 6. Well completion diagram for PM-4 showing geologic units penetrated. 


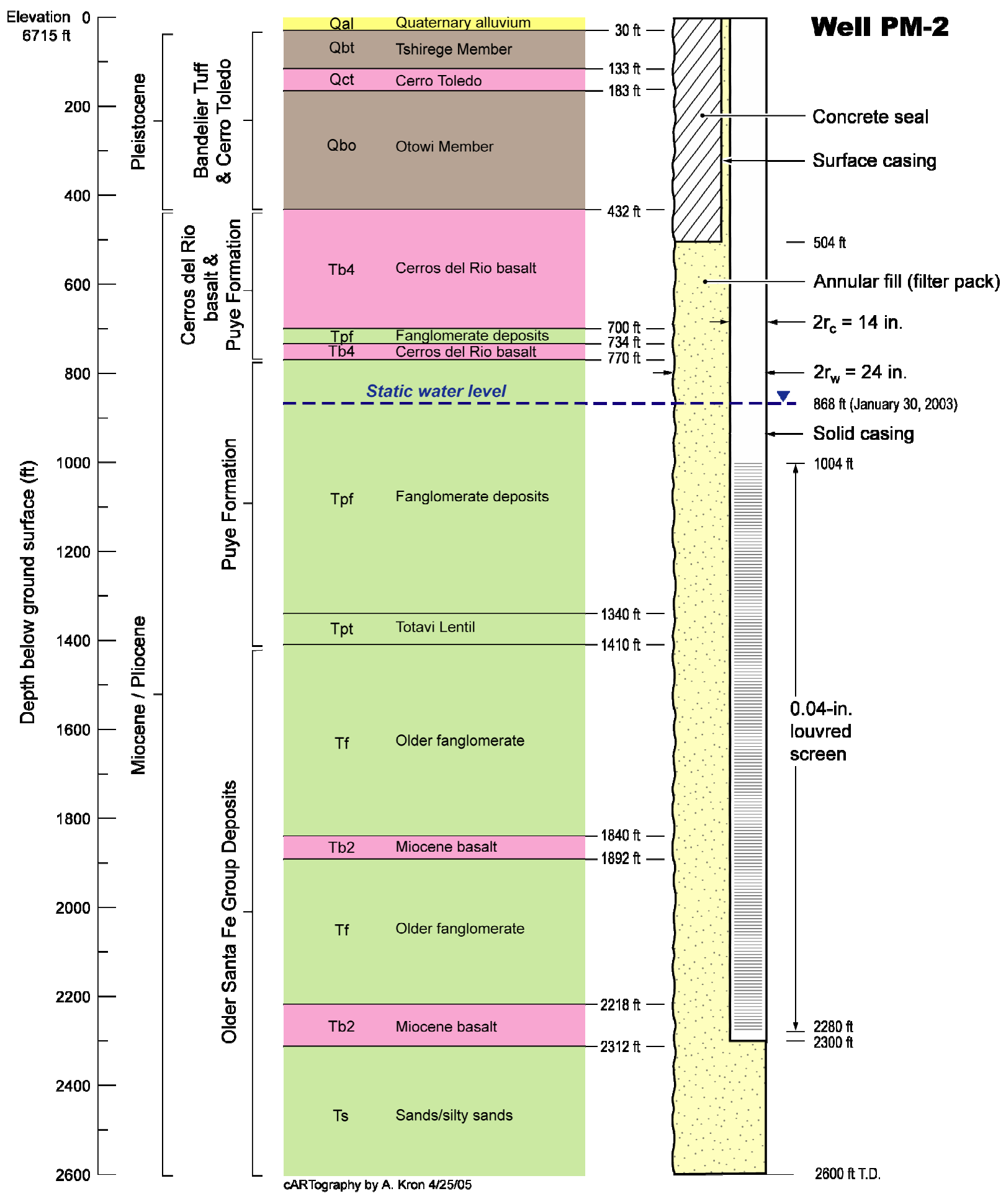

Figure 7. Well completion diagram for PM-2 showing geologic units penetrated. 


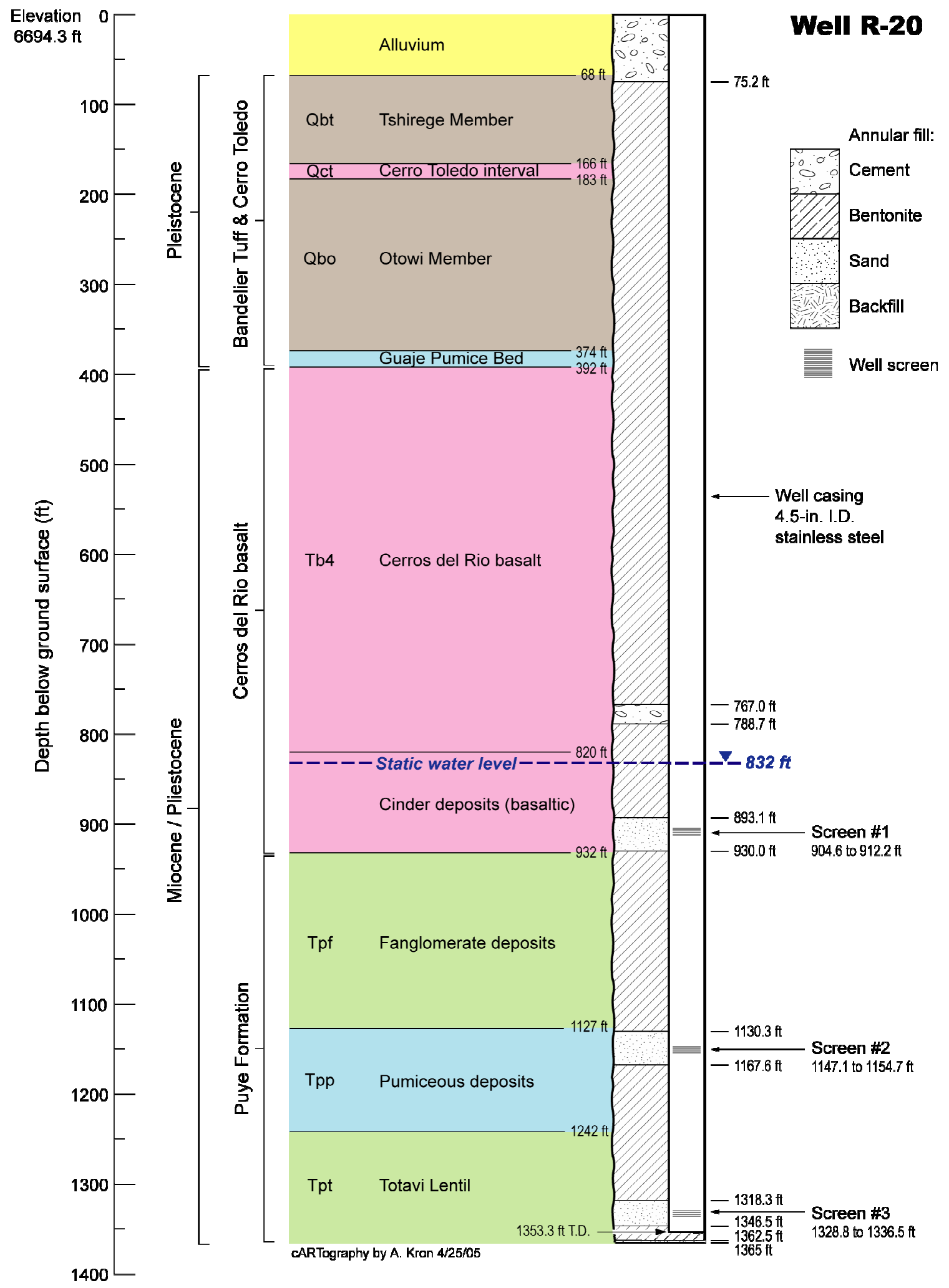

Figure 8. Well completion diagram for R-20 showing geologic units penetrated. 


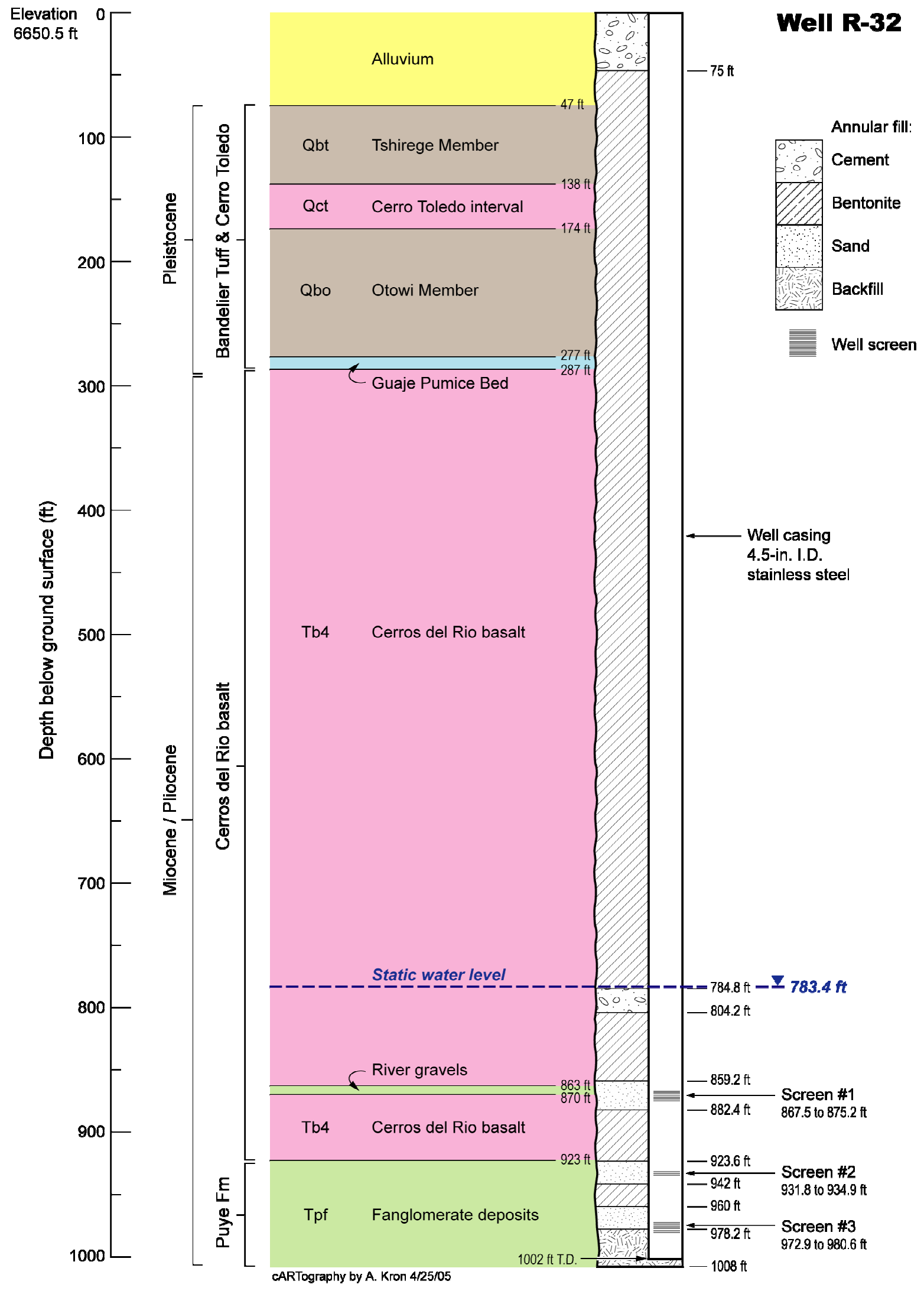

Figure 9. Well completion diagram for R-32 showing geologic units penetrated. 


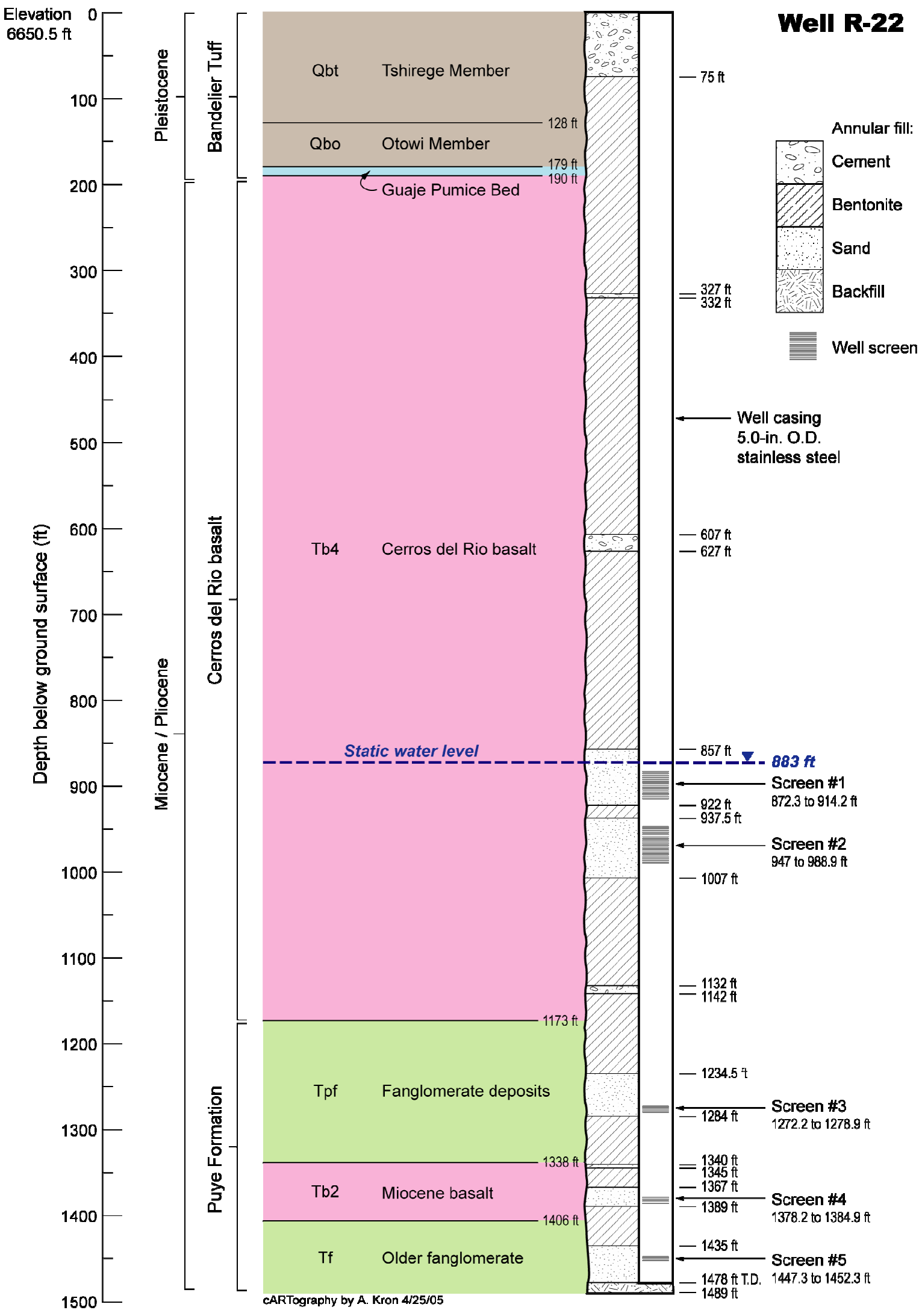

Figure 10. Well completion diagram for R-22 showing geologic units penetrated. 
screens in R-22. According to Figure 2, the high-yielding fanglomerate units that easily produce significant quantities of water at well PM-2 laterally grade into lower-permeability basalts and silty sands somewhere between wells R-21 and R-22.

Finally, Table 1 lists the hydrostatic water levels that were recorded in the primary observation wells that were used during this aquifer test. These water levels were recorded on January 30, 2003, shortly before test pumping started in PM-2 on February 3, 2003. All adjacent water supply wells (i.e., PM-2, PM-4, and PM-5) were shut off on November 5, 2002, to allow hydrostatic conditions to reestablish before the test actually started. In addition, wells PM-4 and PM-5 remained off during the entire testing interval between November 5, 2002, and March 26, 2003.

\section{Aquifer Test Procedure}

A traditional aquifer test procedure was followed at well PM-2. This procedure consisted of turning off all surrounding water supply wells and allowing hydrostatic conditions in the aquifer to become reestablished before the start of actual test pumping. This initial nonpumping, or recovery period (i.e., November 5, 2002, to February 3, 2003), was intentionally set at approximately three times the length of the planned pumping interval to ensure near-complete recovery. Then well PM-2 was turned on for 25 days (i.e., February 3-28, 2003), and drawdown was recorded in surrounding wells. Finally, PM-2 was turned off, and this pumping period was followed by a second recovery period that was about as long as the pumping period (i.e., February 28 to March 26, 2003). Data from the second recovery period were used to verify

Table 1. Water-Level Measurements and Elevations in Wells Used during the PM-2 Aquifer Test

\begin{tabular}{|c|c|c|c|}
\hline Date & Well & Hydrostatic Water Level & Remarks \\
\hline 5 November 2002 & All & See below & PM-2, PM-4, \& PM-5 shut off \\
\hline 30 January 2003 & PM-2 & $5846.0 \mathrm{ft}$ (or $869.0 \mathrm{ft} \mathrm{bgs)}$ & Static in 1965 was 823 ft bgs \\
\hline 30 January 2003 & PM-4 & $5844.7 \mathrm{ft}$ (or 1075.3 ft bgs) & Static in 1981 was 1060 ft bgs \\
\hline 30 January 2003 & PM-5 & $5853.7 \mathrm{ft}$ (or 1241.3 ft bgs) & Static in 1982 was 1208 ft bgs \\
\hline 30 January 2003 & R20-1 & $5869.0 \mathrm{ft}$ (or 825.3 ft bgs) & Near-static in R-20 screen 1 \\
\hline 30 January 2003 & R20-2 & $5864.8 \mathrm{ft}$ (or 829.5 ft bgs) & Near-static in R-20 screen 2 \\
\hline 30 January 2003 & R20-3 & $5844.6 \mathrm{ft}$ (or 849.7 ft bgs) & Near-static in R-20 screen 3 \\
\hline 30 January 2003 & R32-1 & $5858.9 \mathrm{ft}$ (or 778.7 ft bgs) & Near-static in R-32 screen 1 \\
\hline 30 January 2003 & R32-2 & $5852.0 \mathrm{ft}$ (or 785.6 ft bgs) & Near-static in R-32 screen 2 \\
\hline 30 January 2003 & R32-3 & $5849.9 \mathrm{ft}$ (or 787.7 ft bgs) & Near-static in R-32 screen 3 \\
\hline 3-28 February 2003 & PM-2 & See test analysis & Pumping at PM-2 \\
\hline 1-26 March 2003 & PM-2 & See test analysis & Recovery at PM-2 \\
\hline 27 March 2003 & All & Resume normal production & Aquifer test completed \\
\hline
\end{tabular}


drawdown behavior recorded during the pumping phase of the aquifer test and to verify a return to hydrostatic conditions after pumping stopped. Nearly 45 million gallons of water were produced during the 25-day aquifer test at PM-2. These waters were directed into the Los Alamos County water distribution system for normal consumptive use, an arrangement facilitated by Los Alamos County personnel with the Department of Public Utilities. This procedure represents nearly ideal conditions for a conventional aquifer test. Typically, pumpingtest waters are discharged directly into the environment because distribution systems are usually unavailable.

To reiterate, water supply wells PM-2, PM-4, and PM-5 were initially shut down on November 5,2002 , so that the regional aquifer could return to static conditions. Hydrostatic levels were thus established in each well before the start of the aquifer test, although they are considerably lower than when the water supply wells were first drilled (Table 1). These long-term water-level declines are widespread and will not significantly affect our test results because the present regional piezometric surface is approximately parallel to, but lower than, the ancestral piezometric surface of 60 years ago (i.e., before any groundwater development). This piezometric surface is defined as a contour map of equal water levels recorded at the same time and where an individual water level from a given well equals the wellhead elevation minus the depth to water. Except for the pumping interval at well PM-2 of February 3-28, 2003, these water supply wells remained off until March 26, 2003. Usable drawdown data were recorded at 30-minute intervals in wells PM-2, PM-4, PM-5, R-20, and R-32. All of the data files are contained on the CD-ROM included with this report (see the Appendix first); these files are in ASC-II text format.

Figure 11 is a graphical display of drawdown and recovery at well PM-2 in response to an average pumping rate of $1,249 \mathrm{gpm}$. Table 2 summarizes all instantaneous flow rate measurements that were recorded during pumping operations at PM-2. The data demonstrate that the average pumping rate fluctuated less than $0.7 \%$ throughout the test period. This near-constant average pumping rate reflects a near-constant pressure drop between the pump intake and discharge line because the drawdown in the aquifer was relatively small and stabilized after about 4 days of continuous pumping. Normally, an in-line pressure regulator is required to achieve the near-constant pumping rates that are reported here. Figure 12 shows the corresponding drawdown data that were recorded in numerous surrounding wells, including PM2, PM-4, PM-5, and screen 3 of R-20.

Piezometric levels relative to mean sea level for all screens at wells R-20 and R-32 are shown in Figure 13. This figure is important because it shows water-level fluctuations in individual screens that are completed to different vertical depths in the regional aquifer. These different screens are located in different geologic units that were shown in Figures 8 and 9. Figure 13(a) clearly shows that a vertically downward hydraulic gradient existed near well R-20 before the start of the PM-2 aquifer test. This hydraulic gradient is defined as the change in water level between screens divided by the vertical distance between screens. It is also significant that each of the screens in R-20 responded differently to pumping at well PM-2. This behavior is typical of stratified aquifers with different horizontal and vertical hydraulic conductivity $(K)$ values. For this particular situation, the deeper the screen is located, the larger the response. We conclude from these data that screen 3 is located in a zone that yields water to pumping at PM-2 (i.e., water flows horizontally from screen 3 toward PM-2), whereas screens 1 and 2 are located in an 


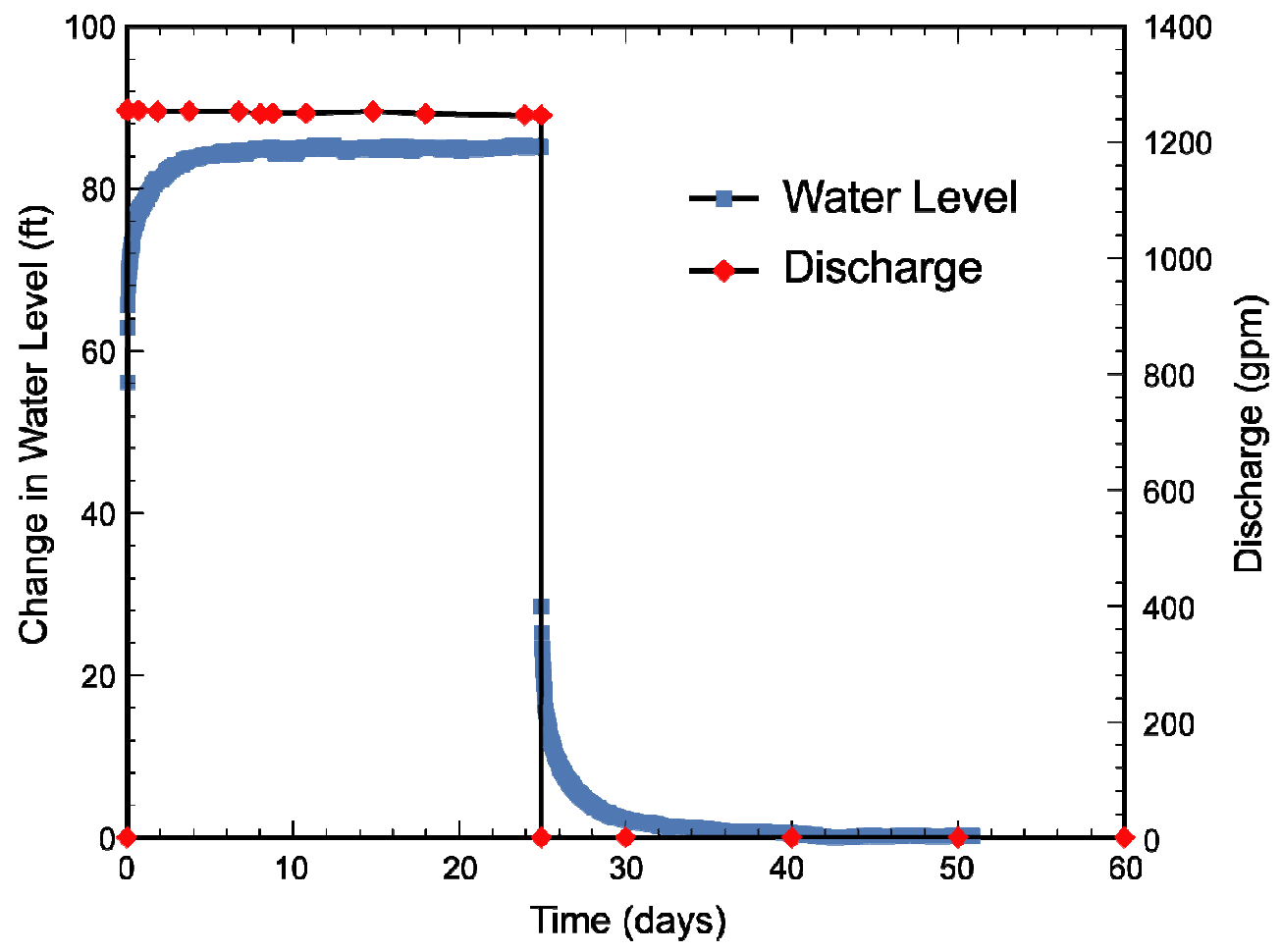

Figure 11. Discharge and water-level response at well PM-2 during the aquifer test.

Table 2. Instantaneous and Average Discharge Rates Measured at Well PM-2

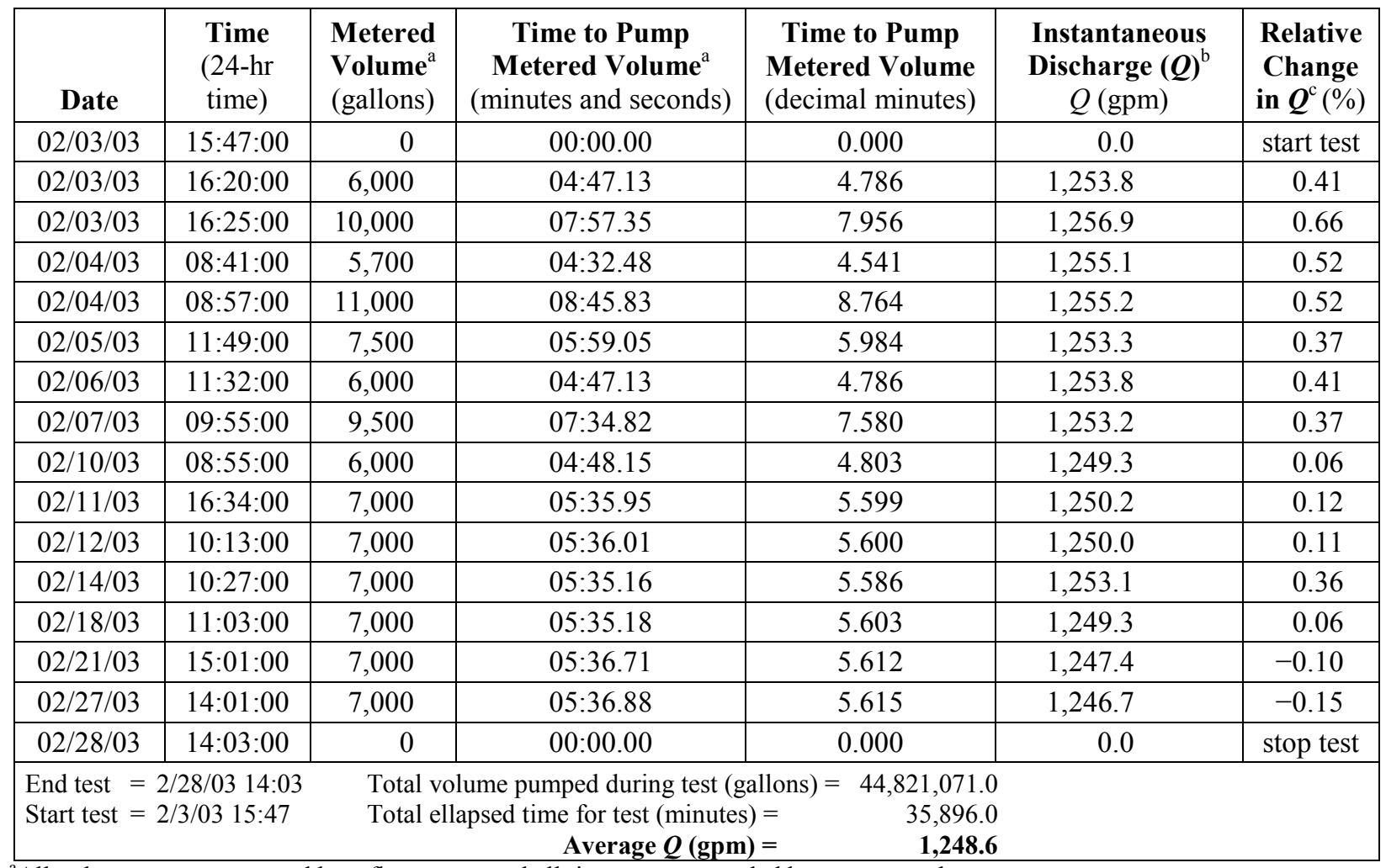

${ }^{\mathrm{a} A l l}$ volumes were measured by a flow meter and all times were recorded by a stop watch.

${ }^{\mathrm{b}}$ Instantaneous discharge $(Q)=$ Metered Volume (gal.)/Time to Pump (min).

${ }^{\mathrm{c}}$ Relative change $=($ Instantaneous $Q-$ Average $Q) \times 100 /$ Average $Q$. 


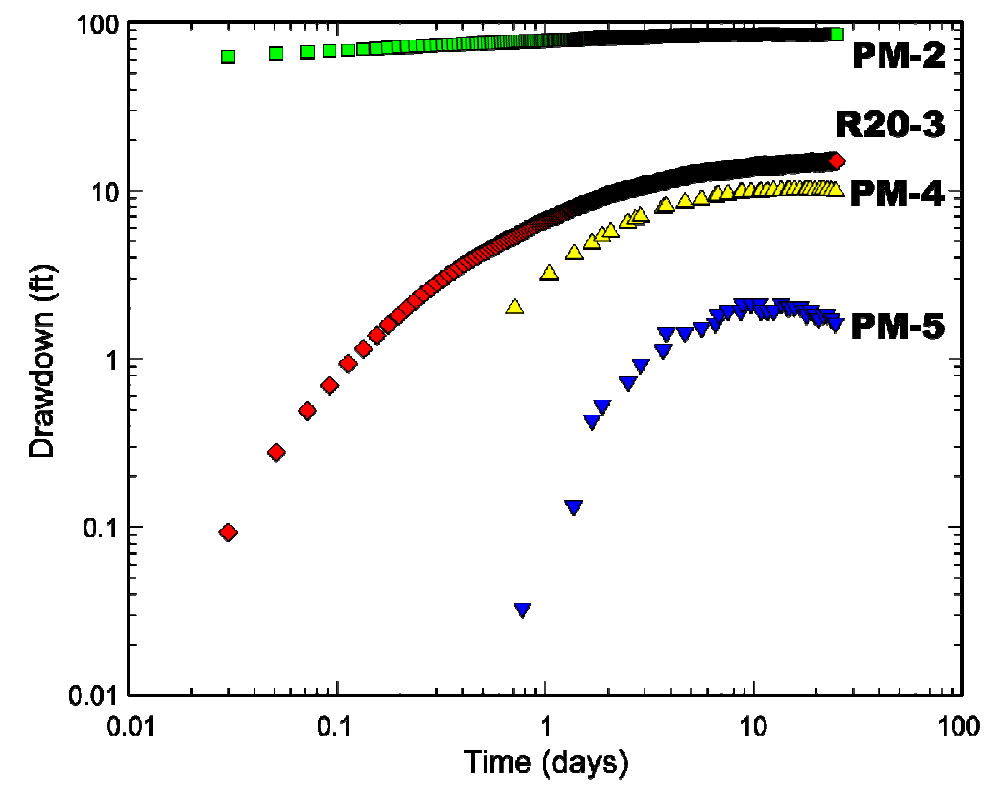

Figure 12. Drawdown in several wells in response to pumping at well PM-2.

(a)

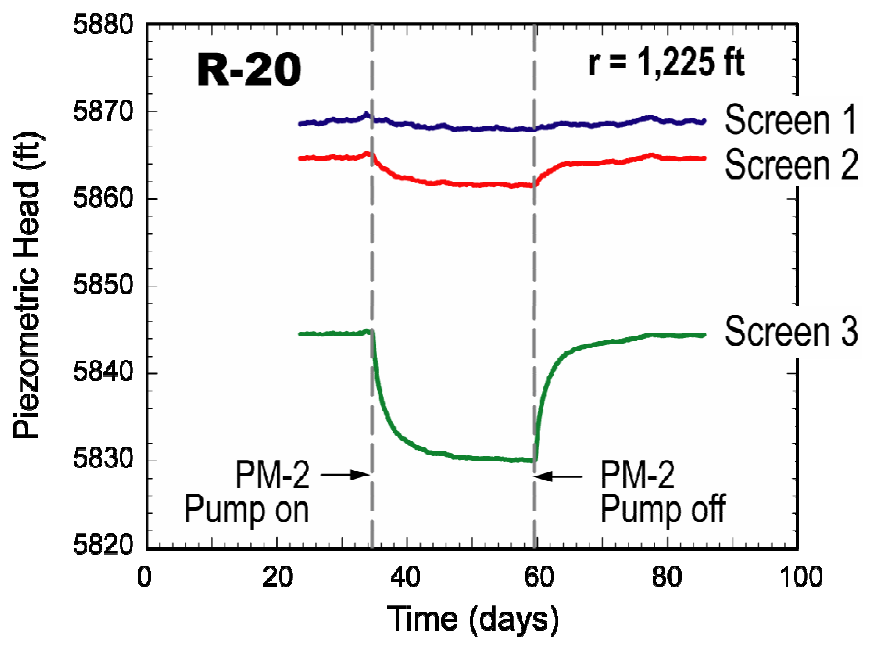

(b)

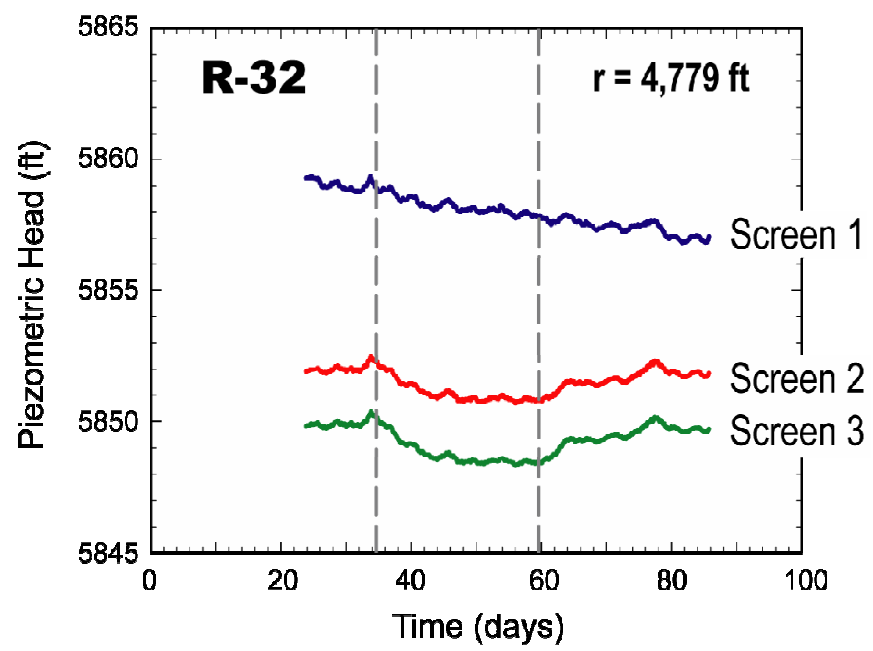

Figure 13. Drawdown at wells R-20 (a) and R-32 (b) in response to pumping at well PM-2. 
overlying leaky zone (i.e., water flows vertically downward from screen 1 toward screen 3). Stated differently, these results clearly imply a vertical anisotropy in $K$ values. Additional quantitative evidence for this statement will be presented further on. Here, it is sufficient to state that the horizontal-to-vertical ratio in directional hydraulic conductivity $\left(K_{h} / K_{v}\right)$ at R-20 increases with depth. These results are consistent with earlier hydraulic testing at this well that demonstrated $K_{h}$ values also increase with depth (McLin 2005a).

A vertically downward hydraulic gradient also exists near well R-32, as seen in Figure 13(b). In addition, hydrologic conditions near R-32 are similar to those at well R-20 but are more subdued because this well is located farther away from well PM-2. Individual patterns of water-level responses at R-32 are similar to those at R-20, but with important differences. For example, water levels in screens 2 and 3 are clearly responding to pumping at PM-2, whereas those in screen 1 seem to be continuously declining throughout all phases of the test. Water levels in screen 1 may not be hydraulically connected to the same water-bearing units that are yielding water at PM-2. In fact, Figure 9 shows that screen 1 is completed into thin river gravels that are sandwiched between two Cerros del Rio basalt flows. These basalt units probably do not yield significant quantities of water to PM-2 (McLin and Stone 2004a). We conclude that the $K_{h} / K_{v}$ ratio also changes with depth near R-32. Like the results for R-20, these results are also consistent with earlier hydraulic testing at this well that demonstrated $K_{h}$ values varied with depth (McLin and Stone 2004b). Nevertheless, we should be cautious about carrying this similarity too far. Certainly the regional aquifer behaves like a leaky-confined aquifer at both locations, but the source-bed at the top of the regional aquifer is more hydraulically isolated from the underlying high-conducting layer near R-32 than near R-20 because of the Cerros del Rio basalts near screen 1 .

A close inspection of the PM-2, R-20, and R-32 well completion diagrams (see Figures 7-9) immediately tells us that the regional aquifer is vertically stratified. This condition is also implied by the interpretative cross-section of Broxton and Vaniman (2005) in Figure 2. In addition, screen 1 in well R-20 and screens 1 and 2 in well R-32 are located above the horizontal elevation of the top of the PM-2 screen (i.e., above 5,711 ft above mean sea level). However, screens 2 and 3 in R-20 and screen 3 in R-32 are all located below this same level. This observation raises an important question: Do the water bearing units at well PM-2 laterally pinch out as we move from PM-2 toward screen 3 in R-32, or are these high-yielding units located below screen 3 as suggested? Recall that significant drawdown was recorded at both well PM-4 and well PM-5 (as seen in Figure 12). Both of these latter wells are located farther away from PM-2 than is R-32; however, both PM-4 and PM-5 penetrate deeper into the regional aquifer than does R-32. This question is important for us to clarify. Alternately, we might ask which stratigraphic zones are actually yielding water to PM-2, how thick are they, and where do they laterally extend? These questions are addressed in the next section.

\section{Idealized Aquifer Configuration}

One of the best ways to determine exactly which zones within the screened interval yield water to a pumping well is with a dynamic spinner log. This log is really a downhole flow meter, an elongated tool with an axial propeller that turns as the tool is raised or lowered past the screened portion of a well while the well is pumped. Each revolution of the propeller generates a pulse that is electronically recorded. More pulses are generated as the tool passes those portions of the 
screen where more water is entering the well bore. In other words, spinner rotation speed is related to fluid entrance velocity. Figure 14 shows a dynamic spinner log that was recently run in well PM-4 (Koch et al. 1999). Table 3 summarizes the production characteristics from this $\log$. These results clearly indicate that the Santa Fe Group sediments immediately below the Totavi Lental produce about $63 \%$ of the total flow at well PM-4 (i.e., zones D, E, and F), wherease the Totavi Lental (i.e., zone $\mathrm{G}$ ) produces $18 \%$, and the alluvial fan deposits (i.e., zones $\mathrm{H}$ and I) yield another $12 \%$. We conclude that the saturated units located below the Cerros del Rio basalts and above the uppermost Miocene basalt layer shown in Figure 6 yield about $93 \%$ of the total production at PM-4. According to the well completion diagram in Figure 6, this interval is between 1,100 ft bgs (i.e., at 5,820 ft above mean sea level) and 1,950 ft bgs (i.e., at 4,970 ft above mean sea level). Hence, the effective saturated thickness of the regional aquifer at PM-4 is about $850 \mathrm{ft}$ in thickness (i.e., 1950 minus 1100). From these data, we can draw an idealized version of the regional aquifer shown in Figure 15. In this figure, the idealized screen depths for wells PM-2, PM-4, and PM-5 terminate at the effective lower boundary of the idealized leakyconfined aquifer because very little water actually comes from these lower depths. This idealized aquifer configuration was used in the drawdown and recovery analyses that follow. In addition, important aquifer dimensions from Figure 15 are summarized in Table 4.

Table 3. Summary of PM-4 Production Zone Characteristics from the Dynamic Spinner Log in Figure 14

\begin{tabular}{|c|c|c|c|c|c|c|c|c|}
\cline { 2 - 9 } \multicolumn{1}{c|}{} & \multicolumn{3}{c|}{ Producing Zones } & \multicolumn{3}{c|}{ Spinner Log Results } & \multicolumn{2}{c|}{ Summary } \\
\hline Zone & $\begin{array}{c}\text { Top } \\
\text { Depth } \\
\text { (ft bgs) }\end{array}$ & $\begin{array}{c}\text { Bottom } \\
\text { Depth } \\
\text { (ft bgs) }\end{array}$ & $\begin{array}{c}\text { Unit } \\
\text { Thickness } \\
\text { (ft) }\end{array}$ & $\begin{array}{c}\text { Bottom } \\
\text { (cps) }\end{array}$ & $\begin{array}{c}\text { Top } \\
(\mathbf{c p s})\end{array}$ & $\begin{array}{c}\text { Difference } \\
\text { (cps) }\end{array}$ & $\begin{array}{c}\text { Production } \\
\text { Amount } \\
(\%)\end{array}$ & $\begin{array}{c}\text { Geologic } \\
\text { Unit }\end{array}$ \\
\hline A & 2500 & 2550 & 50 & 28.5 & 29.4 & 0.9 & 2 & Ts \\
\hline B & 2120 & 2180 & 60 & 29.4 & 30.0 & 0.6 & 2 & Ts \\
\hline C & 1970 & 2000 & 30 & 30.0 & 31.0 & 1.0 & 3 & Ts \\
\hline D & 1800 & 1890 & 90 & 31.0 & 32.1 & 1.1 & 3 & Ts \\
\hline E & 1560 & 1800 & 240 & 32.1 & 50.0 & 17.9 & 50 & Ts \\
\hline F & 1450 & 1560 & 110 & 50.0 & 53.5 & 3.5 & 10 & Ts \\
\hline G & 1400 & 1450 & 50 & 53.5 & 60.0 & 6.5 & 18 & Tpt \\
\hline H & 1340 & 1380 & 40 & 60.0 & 63.4 & 3.4 & 9 & Tpf \\
\hline I & 1260 & 1340 & 80 & 63.4 & 64.6 & 1.2 & 3 & Tpf \\
\hline
\end{tabular}

Note: The table is modified after Koch et al. (1999).

Table 4. Aquifer Configuration Dimensions in Pumping and Observation Wells

\begin{tabular}{|c|c|c|c|}
\hline Well & $\boldsymbol{r}(\mathbf{f t})$ & $\boldsymbol{d}(\mathbf{f t})$ & $\boldsymbol{l}(\mathbf{f t})$ \\
\hline PM-2 & 1 & 109 & 850 \\
\hline R20-1 & 1225 & 30.3 & 37.9 \\
\hline R20-2 & 1225 & 272.8 & 280.4 \\
\hline R20-3 & 1225 & 454.5 & 462.2 \\
\hline PM-4 & 4478 & 160 & 850 \\
\hline R32-1 & 4779 & 37.0 & 44.7 \\
\hline R32-2 & 4779 & 101.3 & 104.4 \\
\hline R32-3 & 4779 & 142.4 & 150.1 \\
\hline PM-5 & 8808 & 165 & 850 \\
\hline
\end{tabular}

Note: See Figure 15 for definitions. 
(a)

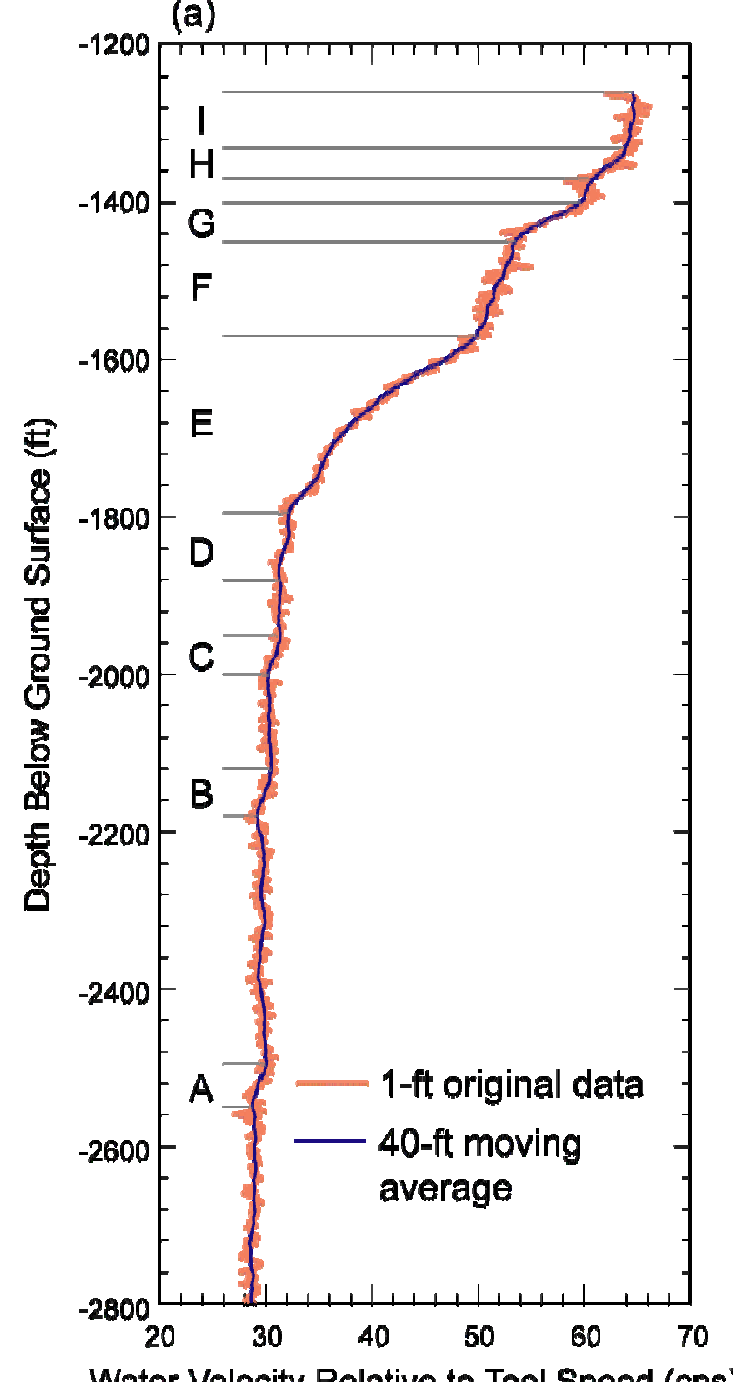

(b)

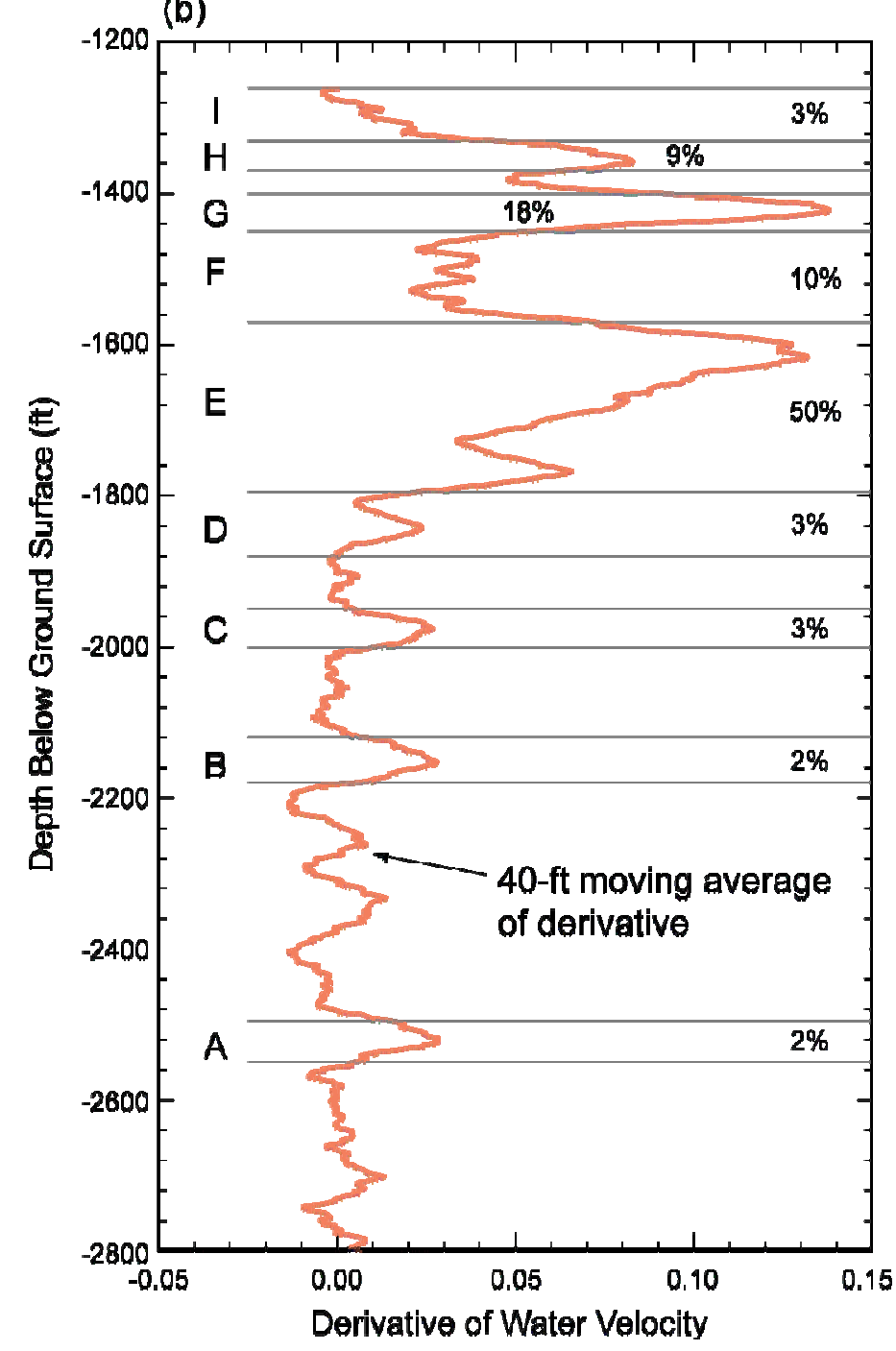

(c)

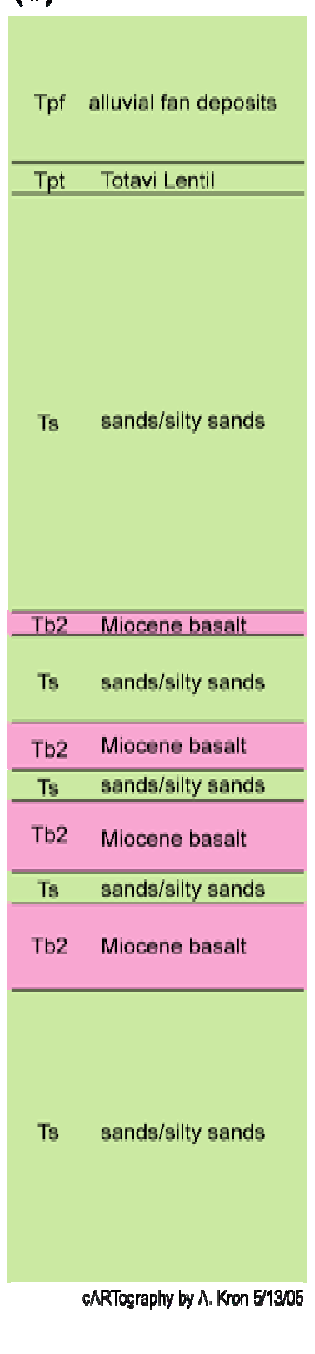

Figure 14. Graphical results of (a) the dynamic spinner log at well PM-4; (b) interpretative results showing the derivative of water velocity with respect to borehole depth; and (c) the geologic log opposite the PM-4 well screen (from Figure 6). Panels (a) and (b) are modified after Koch et al. (1999). Panel (b) shows the percentage of total water production from individual layers listed in Table 3. 


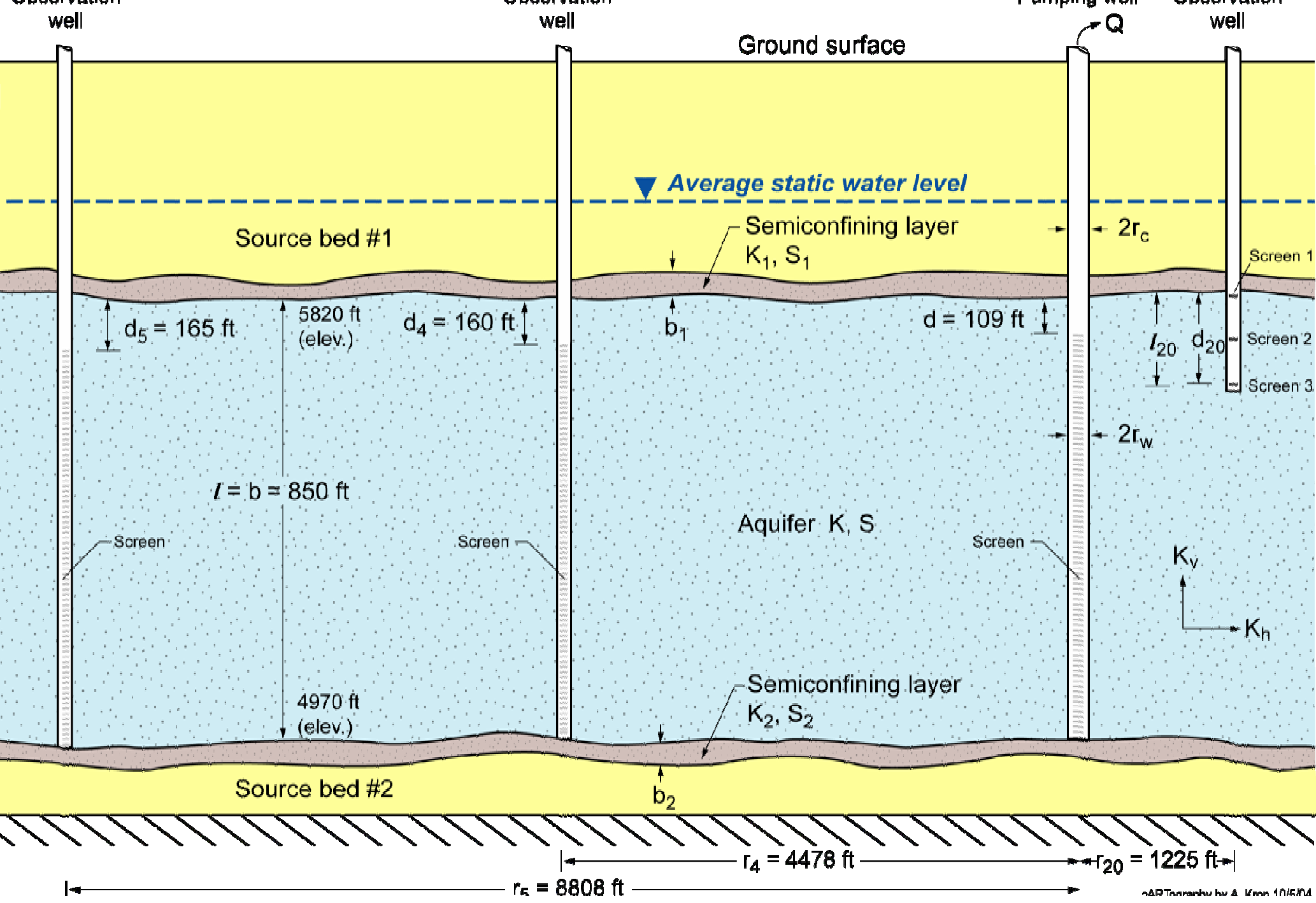

Figure 15. Idealized representation of the regional aquifer along the geologic cross-section B-B' shown in Figures 3 and 4. The top of the high conductive layer corresponds to the bottom of the Cerros del Rio basalts, and the bottom corresponds to the top of the first Miocene basalt shown in Figure 6. 


\section{DATA ANALYSES}

\section{Background}

For most of the analyses that follow, commercially available aquifer-testing software was used for a variety of reasons. These include public availability, program documentation, repeatability of analyses, and convenience. Except for the distance-drawdown and specific-capacity methods presented below, all test data were fitted to appropriate, theoretical type-curve models using Aqtesolv $^{\mathrm{TM}}$ for Windows (version 3.5, professional). This software allows the anisotropy ratio $\left(K_{h} / K_{v}\right)$ to vary for some methods of analysis but keeps it fixed at a value of one for other methods. For consistency throughout all analyses, the $K_{h} / K_{v}$ ratio was set at one in those methods where it could be adjusted. This procedure was followed so that the results could be easily compared with those techniques where this ratio could not be adjusted. However, if anisotropy effects were important in a particular application and if a particular methodology allows this ratio to vary, then a simple parameter sensitivity analysis was also performed. These extra analyses provide insight to the variability in aquifer transmissivity $(T)$ and hydraulic conductivity $(K)$ when $K_{h} / K_{v}$ approaches some realistic value other than one.

The reader should be cautioned that none of these methods of analyses will provide a unique solution for both transmissivity and the anisotropy ratio at the same time. In other words, $K_{h} / K_{v}$ must be fixed in order to find a unique value for $T$. This is a mathematical limitation of the method and not a shortcoming of the software. Hence, the traditional practice of fixing $K_{h} / K_{v}$ at a value of one before solving for $T$ is followed here. If a parameter sensitivity analysis was performed, then we sequentially fix $K_{h} / K_{v}$ at a value of 1 to 1,000 and repetitively solve for the corresponding $T$ value. Aqtesolv also yields a storativity $(S)$ value for any analysis by pumpingtest methods as part of a solution. However, such a determination is only valid for multiple-well tests where both pumping and observation wells are used in the analysis. Therefore, results for this parameter are listed only in summary tables when this well combination is available.

At this point, several important points should be clarified. First, we should ask ourselves when are anisotropy effects significant and when can they be safely neglected? Otherwise, the reader may get the impression that those analytical methods that allow the $K_{h} / K_{v}$ ratio to vary are always preferable to methods that do not have this feature. Second, nearly all analytical solutions used for aquifer test analyses assume radially horizontal flow toward the pumping well because the well screen is assumed to fully penetrate the saturated thickness of the aquifer. In these situations, anisotropy effects will not influence our test even though the $K_{h} / K_{v}$ ratio is not one. Thus, flow toward the pumping well is horizontal and drawdown is only affected by $K_{h}, S$, and $b$, where $b$ represents the saturated thickness of the aquifer. It is common, however, for wells to partially penetrate an aquifer. When this occurs, drawdown and converging flows within the aquifer may result in pronounced vertical flow effects near the pumping well. These vertical flow effects may significantly affect the observed drawdown in both the pumping wells and the observation wells out to a radial distance of about $(3 b / 2)\left(K_{h} / K_{v}\right)^{1 / 2}$. In other words, flow toward the pumping well is now affected by the $K_{h} / K_{v}$ ratio, $b$, and $S$. In these situations we probably should use a technique that allows the $K_{h} / K_{v}$ ratio to vary.

The cautious reader may conclude that an ideal aquifer test will have a partially penetrating well screen in the pumping well and an observation well located less than $(3 b / 2)\left(K_{h} / K_{v}\right)^{1 / 2}$ away. With 
this configuration, we should be able to determine aquifer characteristic values for $T$, $S$, and the $K_{h} / K_{v}$ ratio from a single test. However, to restate, none of the analytical methods of analyses will provide a unique solution for both transmissivity and the anisotropy ratio at the same time. Again, this is not a limitation of the software. In addition, one rarely encounters an ideal test configuration because we generally do not know what it should be a priori.

Response to Pumping. Initially, static water levels are allowed to recover in all wells so that individual responses to pumping can be later determined. This recovery period was set at about 90 days for the tests reported here. Once pumping starts at time $t=0$, a cone of depression propagates radially outward from the production well and intersects different observations wells at different times. Closer observation wells see drawdown first, and these drawdown values are generally larger than observation wells located farther away. Drawdown at a well is computed as the difference between the recorded water level at some time $t>0$ and the initial static water level at $t \leq 0$. When pumping stops, these water-level declines start to rebound toward initial static conditions. Hence, both drawdown and recovery data are collected over time for analyses by classical pumping techniques.

Simple Recovery. A procedure described by Driscoll (1986, pages 252-260) was employed to process recovery data collected after pumping ceased. In this method, a trend line was extended through the data collected from the latter portions of the pumping phase and into the recovery period, as illustrated in Figure 9.37 of Driscoll. Recovery was then computed as the difference between values on this trend line and the observed water levels for the same time. Results of this process are referred to simply as recovery data, and the analysis is identical to that for pumping data. The advantage of using this type of recovery data is that the effects of partial penetration and anisotropy can be taken into consideration when using certain methods in Aqtesolv.

Residual Recovery. Recovery was also determined by subtracting observed water levels after pumping ceased from the static equilibrium value established before pumping. Results of this operation are referred to as residual-recovery data. The advantage of this type of recovery data is that it is not potentially biased by a trend line fitted to the observed data as in the simple recovery method mentioned above. However, the disadvantage is that the effects of partial penetration and anisotropy are not taken into consideration when certain methods in Aqtesolv are used.

Data that were collected from individual observation wells during the long pumping and recovery intervals at well PM-2 were analyzed by various standard pumping-test methods. These observation wells included PM-2, PM-4, PM-5, and screen 3 at R-20 (R20-3). Data were also collected at wells R20-1, R20-2, R32-1, R32-2, and R32-3. However, the latter data were affected by pronounced vertically downward flow (i.e., vertical leakage) and cannot be reliably analyzed by traditional pumping techniques that assume only horizontal flow. Test data collected at individual wells were analyzed by as many as seven different methods for comparison, including Theis pumping, Theis recovery, Theis residual recovery, specific-capacity, HantushJacob leaky-aquifer, Moench leaky-aquifer, and Neumann-Witherspoon leaky-aquifer techniques. In addition, drawdown data from multiple observation wells were also analyzed according to the distance-drawdown and multiple-well leaky-aquifer techniques. To avoid repetition in the text, reference citations for the various methods are given here only.

Theis Method. The aquifer test was initially analyzed by the Theis method (Theis 1935). Analyses include both pumping and simple-recovery data (as defined above). In this classical 
method, a log-log plot of drawdown or recovery data versus time is fitted to a Theis type-curve. The method assumes that the well is fully penetrating, the hydraulic condition of the aquifer is confined, and application or relaxation of stress is by prolonged withdrawal or recovery of water. The method has been extended to include partial penetration effects in confined aquifers and allows the anisotropy ratio $\left(K_{h} / K_{v}\right)$ to vary. Theoretically, both pumping and recovery techniques should replicate one another in both the pumping wells and the observation wells. However, when they do not, one might infer that well bore clogging, turbulence, or other phenomena were present in the pumping well during some phase of the test or that static conditions were not completely reestablished during the recovery phase. Except for static conditions being reestablished, most of these effects are generally present only in the pumping well and not in the observation wells.

Theis Residual Recovery Method. The test data were also analyzed by the Theis residual recovery method (Theis 1935). This traditional method differs from the Theis analysis of recovery data described above in that it uses residual-recovery data. In practice, it is generally most applicable to recovery data from the pumping well where well bore turbulence or clogging may be a problem. In this method, a straight line is drawn through a semilogarithmic plot of residual recovery data versus the dimensionless ratio of $t / t$ '. Residual recovery is the difference between the original static water level and the depth of water at a given instant during recovery. In addition, $t$ is the time since pumping started and $t^{\prime}$ is the time since pumping stopped. This method is probably more widely used than the simple Theis recovery method mentioned above; however, corrections for partial penetration cannot be made with this technique. In addition, $K_{h} / K_{v}$ is fixed at a value of one.

Some readers may wonder why two different recovery methods were employed here. The answer is simple: when using the pumping well as the observation well, many hydrologists consider recovery data to be more reliable than pumping data because well bore turbulence is minimized. As previously mentioned, all three approaches (i.e., Theis pumping, Theis simple recovery, and Theis residual recovery) should replicate one another exactly when $K_{h} / K_{v}$ is one. When they do not, hydrologists simply have additional information to make inferences about dominant effects during certain phases of the test procedure. These differences can influence alternative interpretations by lending support to the method that is most reliable. However, when we have drawdown and recovery data available from an observation well, the advantages of this method are probably overshadowed by other techniques presented here.

Specific-Capacity Method. As an additional method of comparison, test data from the pumping well were also analyzed by the specific-capacity method to determine $T$ (McLin 2005b). This traditional technique was modified by McLin (2005b) from a procedure originally developed by Bradbury and Rothschild (1985). Specific capacity is defined here as discharge (Q) divided by drawdown or injection (s), and has units of gallons per minute per foot of drawdown. Strictly speaking, this method is valid only for confined aquifers and is typically used to estimate a minimum value for $T$. However, it is often used for unconfined aquifers as a basis of comparing alternative techniques. This method uses an iterative approach to solve for $T$ using the CooperJacob approximation for the Theis well-function. It also corrects specific-capacity data for partial penetration and well losses in arriving at an estimate for $T$. In addition, $K_{h} / K_{v}$ is also fixed at a value of one. As before, $K$ is then obtained from the relationship $K=T / b$, where $b$ is saturated thickness. Numerous authors (e.g., Walton 1970) have demonstrated that $T$ values from the 
specific-capacity technique are rather insensitive to changes in storage coefficient $(S)$. McLin (2005b) has also suggested that well efficiency and partial penetration effects can dramatically influence these $T$ values. Hence, the original program of Bradbury and Rothschild (1985) was modified by McLin (2005b) so that it uses a single $S$ value while allowing well efficiency and partial penetration to vary over an expected range of values. The original Basic program was adapted to the Matlab language and is used to compute and plot a range of $T$ values. This range in $T$ values demonstrates that the specific-capacity method is relatively sensitive to variations in these parameters. Results from these analyses therefore might be viewed as representing a lower limit for possible $T$ values.

Hantush-Jacob Method. In many situations, the assumption of an idealized confined aquifer used in the Theis solution is not met because the overlying and/or underlying units leak water into the production interval that yields water to the pumped well. In this situation, the aquifer is considered leaky. Hantush and Jacob (1955) derived an analytical solution for predicting drawdown in an observation well in response to pumping a fully penetrating production well in a leaky-confined aquifer, assuming no storage in the leaky-confining layer and a constant head in the overlying unpumped aquifer material. This solution extended the earlier Theis methodology because it accounted for leakage from adjacent units by assuming it was proportional to the hydraulic head difference between the aquifer and constant-head source bed. However, some hydrologists consider this method to be of limited usefulness because it implies that the unpumped aquifer can supply an infinite amount of water to the pumped well via leakage through the confining unit and because storage in the leaky unit is ignored. Hantush $(1960,1964)$ later corrected his earlier omission of storage in the leaky unit. In addition, this technique was also extended to include the effects of partial penetration and anisotropy. The refined HantushJacob solution provides estimates for $T, S, r / B$, and the $K_{h} / K_{v}$ ratio. Here, $r / B$ is a dimensionless leakage factor defined as

$$
r / B=r \sqrt{K_{a} / T b_{a}}
$$

where $r$ is the radial distance between the pumping and observation wells, $B$ is a leakage factor with dimensions of length and defined by the terms under the square root symbol on the righthand side of Equation (1), $K_{a}$ is the hydraulic conductivity of the aquitard with saturated thickness $b_{a}$, and $T$ is aquifer transmissivity. If $T, S$, and $r / B$ are known from an aquifer test, we can still determine only the $K_{a} / b_{a}$ ratio. However, if we know $b_{a}$ from a driller's log, then we can uniquely determine $K_{a}$. Many hydrologists find this refined solution to be very practical because it limits the number of unknown aquifer parameters.

Neuman-Witherspoon Method. Neuman and Witherspoon (1969, 1971) developed a more general theory for leaky aquifers that included storage effects in the leaky unit (or aquitard) and drawdown in the unpumped aquifer lying above the pumped aquifer configuration in the Hantush-Jacob method. The disadvantage of this technique, however, is that we now have up to four terms like Equation (1) that represent different combinations of pumped, unpumped, and aquitard parameters included in the solution. It is extremely difficult to obtain a unique solution for all parameters without making numerous assumptions about many of them. As a result, this technique is not as widely used as the Hantush-Jacob method presented above even though it is more mathematically appealing. In addition, we can not evaluate the importance of anisotropy 
with this technique. A unique advantage of this method, however, is that we can obtain an estimate for the storage coefficient of the unpumped (i.e., overlying) aquifer.

Moench Method. Moench (1985) derived a modern alternative analytical solution for predicting drawdown in an observation well in response to pumping a fully penetrating production well in a leaky-confined aquifer. This method assumes storage in the aquitard (or leaky-confining unit) and a well bore skin effect. The solution also assumes that the aquitard is overlain or underlain by either a constant head boundary (case 1) or a no-flow boundary (case 2). Like the previous leaky-aquifer solution, the Moench technique also provides estimates for $T, S, r / B$, and $\beta$. Here $\beta$ is defined as

$$
\beta=\frac{B}{4} \sqrt{S_{a} / S}
$$

where $S_{a}$ is the storage coefficient of the aquitard and the other parameters are as defined earlier. The Moench solution is an improvement over the Neuman-Witherspoon method in that the number of parameters has been reduced. It is also an improvement of the Hantush-Jacob solution because we can now get an estimate for the storage coefficient of the aquitard. However, we cannot estimate the relative importance of anisotropy.

\section{Distance-Drawdown Analysis}

Since simultaneous observations of drawdown were made in five separate wells, a distancedrawdown analysis was initially made so that results from all methods could be compared with the results from this important technique. Here drawdown recorded at a given time is plotted against radial distance from the pumping well. Details are discussed by Bouwer (1978, pages 9293) and Fetter (1994, pages 227-229). The distance-drawdown formula is obtained from the Thiem steady-state solution, which says that

$$
T=\frac{Q \operatorname{Ln}\left(r_{2} / r_{1}\right)}{2 \pi\left(s_{1}-s_{2}\right)}=\frac{2.303 Q}{2 \pi \Delta s}
$$

where $Q$ is the discharge rate in the pumping well, $L n$ is the natural logarithmic function, $r_{1}$ and $r_{2}$ are the radial distances from the pumping well to observation wells 1 and 2, respectively, and where drawdown values $s_{1}$ and $s_{2}$ were recorded in observation wells 1 and 2 at the same time. If the data are plotted on semilogarithmic graph paper (base 10), then a linear fit through the data yields the second (or right-hand) relationship shown in Equation (3) above, where $\Delta s$ is measured over one $\log$ cycle. These analyses are shown in Figure 16 with $Q=1,249 \mathrm{gpm}$ and $\Delta s=20.8 \mathrm{ft}$. Using Equation (3), we see that $T=4,235 \mathrm{ft}^{2} /$ day. Data used to construct Figure 16 are summarized in Table 5.

When the best fitting straight line for $t=3.68$ days in Figure 16 is extended to zero drawdown, we find that $r_{0}=10,060 \mathrm{ft}$. Here, $r_{0}$ defines the average radius of influence of well PM-2. It is noteworthy that this value exceeds $10,000 \mathrm{ft}$. When we estimate $S$ from the relationship,

$$
S=2.25 \mathrm{Tt} / \mathrm{r}_{0}^{2}
$$




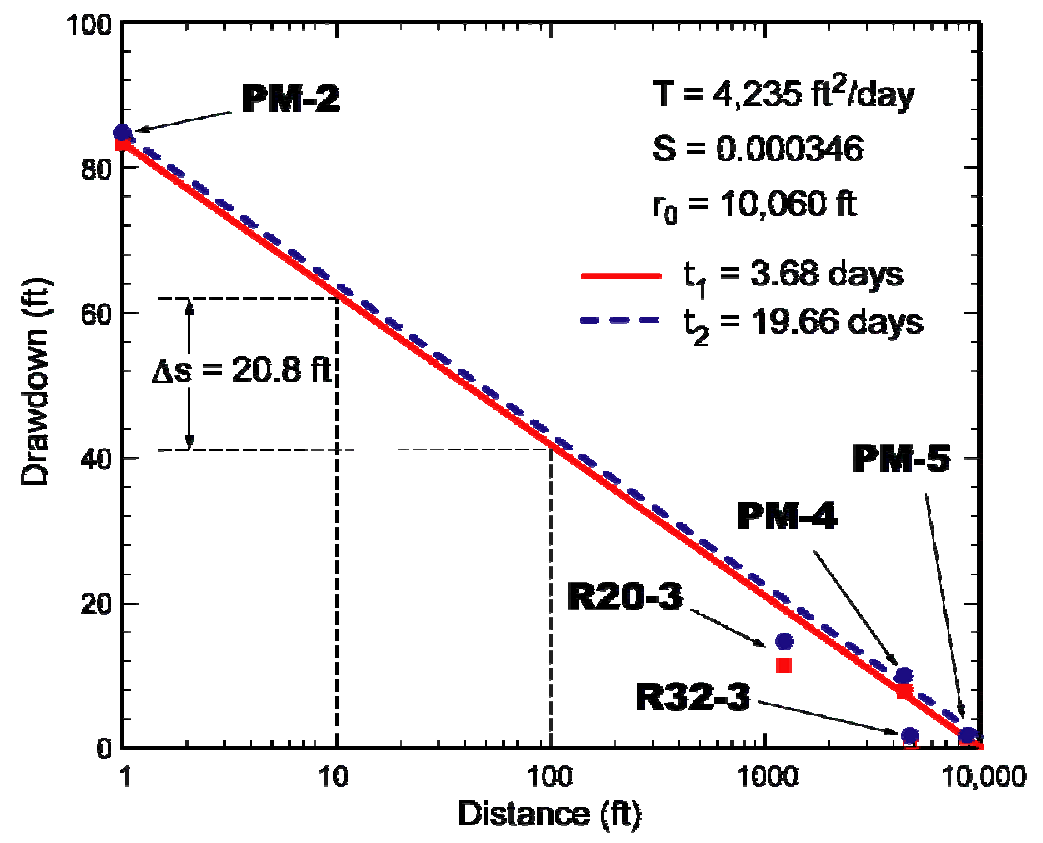

Figure 16. Distance-drawdown analysis from the PM-2 aquifer test using the data listed in Table 5.

we find that $S=0.00035$ when $T=4,235 \mathrm{ft}^{2} /$ day, $t_{1}=3.68$ days, and $r_{0}=10,060 \mathrm{ft}$. The data summarized in Table 5 include drawdown at $t_{1}=3.68$ and $t_{2}=19.66$ days. This second set of drawdown data were not used in the preceding analysis because leaky-aquifer behavior was apparent after about 4 days as described below. These data are still reported in Table 5 and in Figure 16 because they confirm that near-steady state drawdown was achieved during the aquifer test. This means that $\Delta s$ does not significantly change over one log cycle between the two times as seen in Figure 16 (i.e., compare the two linear fits at $t_{1}$ and $t_{2}$ ). Hence, the implied limitations of the Theim steady-state equation given by Equation (3) are adequately met in the foregoing analysis.

Equation (4) is valid only when $u \leq 0.05$, where $u=r^{2} S / 4 T t$. These $u$ values are listed in Table 5 with the $t_{1}$ value for time. We conclude that the Thiem parameters for $T$ and $S$ are only approximate but can still serve as a basis of comparison with other techniques presented below.

In Figure 16, the best-fitting straight line was obtained by using only drawdown from the wells that nearly fully penetrate the highly productive water zone (i.e., wells PM-2, PM-4, and PM-5).

Table 5. Data Used in Distance-Drawdown Analysis Shown in Figure 16

\begin{tabular}{|c|c|c|c|c|}
\hline Well & $\boldsymbol{r}(\mathbf{f t})$ & $\boldsymbol{s}_{\mathbf{1}} \mathbf{( f t}^{\mathrm{a}}$ & $\mathbf{u}_{\mathbf{1}}{ }^{\mathrm{b}}$ & $\boldsymbol{s}_{\mathbf{2}} \mathbf{( f t}^{\mathbf{c}}$ \\
\hline PM-2 & 1 & 83.69 & $<0.0001$ & 85.11 \\
\hline $\mathrm{R} 20-3$ & 1225 & 11.81 & 0.0083 & 14.68 \\
\hline PM-4 & 4478 & 7.90 & 0.1113 & 10.00 \\
\hline R32-3 & 4779 & 0.98 & 0.1268 & 1.64 \\
\hline PM-5 & 8808 & 1.43 & 0.4306 & 1.73 \\
\hline
\end{tabular}

${ }^{\mathrm{a}}$ Drawdown $s_{1}$ measured at $t_{1}=3.68$ days.

${ }^{\mathrm{b}} u=r^{2} S / 4 T t$, where $T=4,235 \mathrm{ft}^{2} /$ day and $S=0.000346$.

${ }^{\mathrm{c}}$ Drawdown $s_{2}$ measured at $t_{2}=19.66$ days. 
The drawdown values from screen 3 at well R-20 (i.e., R20-3) and screen 3 at well R-32 (i.e., R32-3) plot below this best-fitting line in Figure 16 because a vertical flow component influences these readings. However, in the Thiem derivation, it is assumed that flow is moving only horizontally toward the pumping well. Additional discussion on this important point is presented below in the analyses of data from wells R-20 and R-32.

\section{Flow Net and Specific-Capacity Analyses}

A simple 2-D flow net analysis is probably the oldest model used by hydrologists to understand groundwater movement. On Pajarito Plateau, this type of analysis begins with a piezometric contour map of the regional aquifer. This map was originally produced by contouring lines of equal piezometric head obtained from numerous observation wells (Purtymun and Johansen 1974). Here, we use the conventional definition that says piezometric head equals pressure head plus elevation head relative to mean sea level (Freeze and Cherry 1979). The original piezometric map has been updated in this work using more recent water-level measurements; however, the basic shape of the map has not significantly changed over the years if drawdown effects from municipal water supply wells have been carefully minimized. This revised and updated piezometric map for the regional aquifer below Pajarito Plateau is shown in Figure 17. Flow lines have been added by drawing them perpendicular to contour lines of equal piezometric head. Details of this procedure can be found in any introductory text on groundwater hydrology (e.g., Freeze and Cherry 1979; Todd 1980). This piezometric map implies that the regional groundwater moves east-southeast under the plateau and toward the Rio Grande. The intersection of piezometric contour lines and flow lines generates small curvilinear rectangles that are called cells in the discussion below. In addition, the area between two adjacent flow lines defines a flow tube. This 2-D concept is important because once groundwater enters a given flow tube, we assume that it will not cross a bounding flow line and enter an adjacent flow tube. This continuity concept is further quantified below.

Figure 17 is important for several reasons. First, if the real 3-D flow field is adequately represented by our 2-D approximation of piezometric head, then it will reflect horizontal groundwater flow directions. Second, any piezometric contour distortions should be related to the subsurface spatial distribution of $K$ and $w$ (or flow cell width) values near well PM-2 once pumping influences have been minimized.

If different wells are used to construct the piezometric map, then a map different from that shown in Figure 17 will be obtained. For example, Kelley (2005) recently used water level measurements from the shallow R-wells in the central plateau area to construct a water table contour map for the regional aquifer. In addition, he included water-level measurements from the deeper Guaje wells as control points for the northern plateau area. Hence, that map was not used here because we are interested in understanding deeper subsurface changes in $K$ and $w$ values obtained from aquifer tests.

With the above limitations in mind, we can draw some immediate conclusions from Figure 17. First, as previously mentioned, the implied groundwater flow direction is to the east-southeast. This flow direction has not significantly changed over the years. Second, we notice that while many of the cells are similarly shaped, they are of different sizes. These differences tell us that important subsurface changes in aquifer thickness or hydraulic conductivity are controlling the 


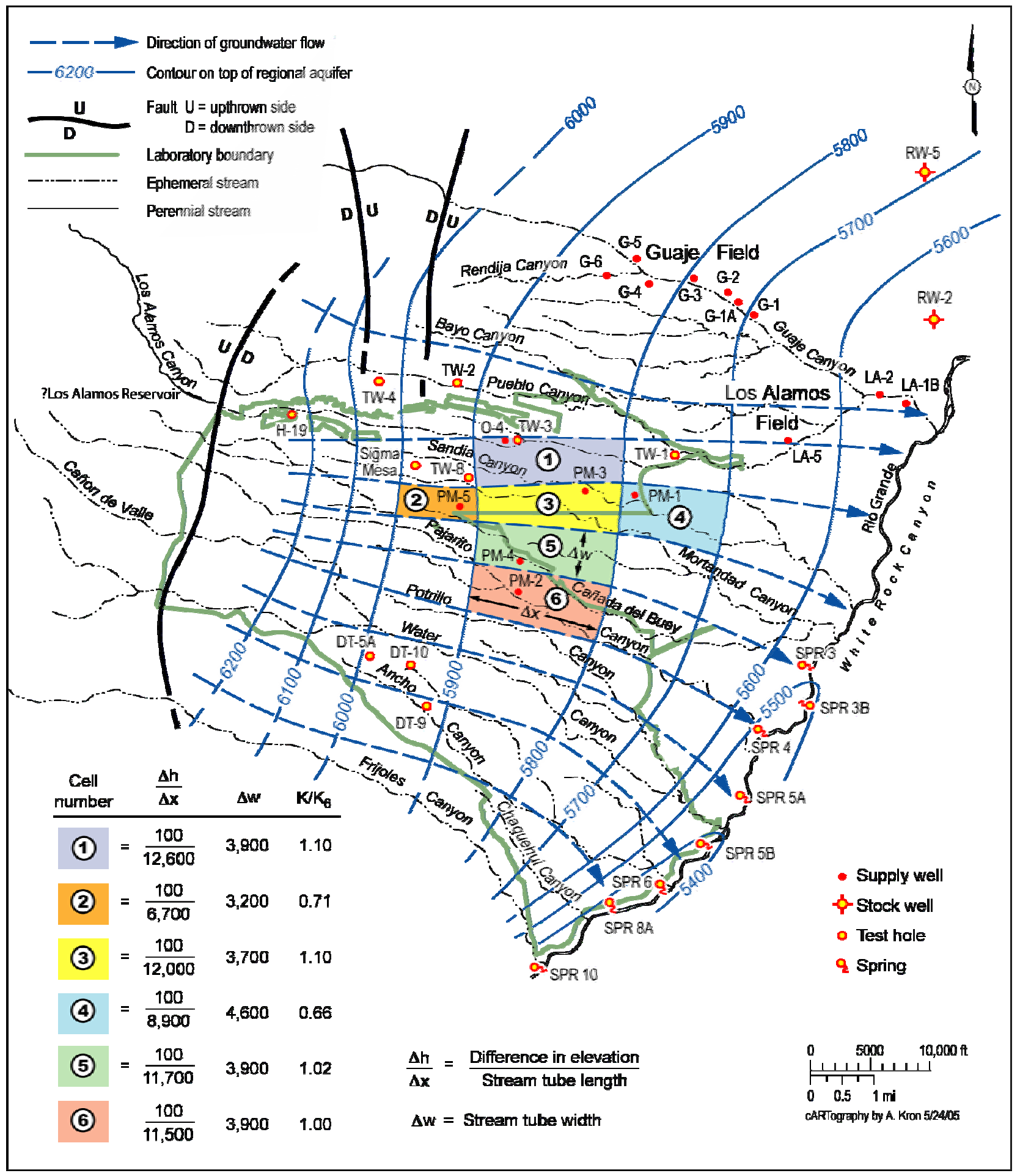

Figure 17. Regional aquifer flow net analysis for central Pajarito Plateau using all available well data (modified after Purtymun and Johansen 1974). 
shapes and sizes of individual cells. For example, the flow tube containing cells identified as 2 , 3 , and 4 are similarly shaped but have different lengths and widths. We assume that the groundwater flow rate entering any flow tube is identical to the flow rate leaving the same tube. In other words, we assume that 2-D continuity is preserved. We can therefore write $Q_{2}=Q_{3}=$ $Q_{4}$, where $Q$ is defined as the specific discharge and has units of volume per unit time. The subscript refers to the individual flow cell. From Darcy's law, we can immediately express this continuity relationship as

$$
K_{2} b_{2} w_{2}\left[\frac{\Delta h}{\Delta x}\right]_{2}=K_{3} b_{3} w_{3}\left[\frac{\Delta h}{\Delta x}\right]_{3}=K_{4} b_{4} w_{4}\left[\frac{\Delta h}{\Delta x}\right]_{4},
$$

where $w$ is the flow cell width, $\Delta h / \Delta x$ is the horizontal hydraulic gradient, and the other terms are as before. Again, the subscripts refer to individual cells within a single flow tube. For the first two cells, Equation (5) can be rewritten as

$$
K_{2}=K_{3}\left(\frac{w_{3}}{w_{2}}\right)\left(\frac{\Delta x_{2}}{\Delta x_{3}}\right)=K_{3}\left(\frac{3,700}{3,200}\right)\left(\frac{6,700}{12,000}\right)=0.65 K_{3},
$$

since $\Delta h_{2}=\Delta h_{3}$ (i.e., a constant contour interval) and $b_{2}=b_{3}$ (i.e., the aquifer thickness is assumed constant). We conclude that $K$ must increase between cells 2 and 3 (i.e., $K_{2}$ near well PM-5 is about 0.65 times $K_{3}$ near well PM-3). This implies that $K$ increases in the downstream direction for the flow tube containing cells 2 and 3 . We can write a similar expression for cells 3 and 4 . Hence,

$$
K_{3}=K_{4}\left(\frac{w_{4}}{w_{3}}\right)\left(\frac{\Delta x_{3}}{\Delta x_{4}}\right)=K_{4}\left(\frac{4,600}{3,700}\right)\left(\frac{12,000}{8,900}\right)=1.68 K_{4} .
$$

We conclude that $K$ must decrease between cells 3 and 4 (i.e., $K_{3}$ near well PM-3 is about 1.68 times $K_{4}$ near well PM-1). This implies that $K$ decreases in the downstream direction for the flow tube containing cells 3 and 4 . Likewise, if we assume that each flow tube carries an equal specific discharge, we can write $Q_{1}=Q_{6}$ for cells 1 and 6 and obtain expressions like Equations (5) and (6). Hence,

$$
K_{1}=K_{6}\left(\frac{w_{6}}{w_{1}}\right)\left(\frac{\Delta x_{1}}{\Delta x_{6}}\right)=K_{6}\left(\frac{3,900}{3,900}\right)\left(\frac{12,600}{11,500}\right)=1.10 K_{6} .
$$

In other words, $K$ values near wells $\mathrm{O}-4$ and PM-2 are approximately related by Equation (8) according to our flow net analysis (i.e., $K_{1}$ at O-4 is about 1.10 times $K_{6}$ at PM-2). Finally, if we again assume that each flow tube carries an equal specific discharge, we can write an expression like Equation (8) for each cell shown in Figure 17. These relationships are summarized in Table 6.

We can compare the ratios obtained from the flow net analysis with similar ratios obtained from a specific-capacity analysis of historical drawdown data. These analyses are summarized in Table 7 using the estimation procedure of McLin (2005b). We are immediately struck by the fact that the specific capacity analyses yield hydraulic conductivity ratios that are consistently 
Table 6. Hydraulic Conductivity Ratios Derived from the Flow Net Shown in Figure 17

\begin{tabular}{|c|}
\hline$K_{1}(O-4)=1.10 K_{6}(P M-2)$ \\
\hline$K_{2}(P M-5)=0.71 K_{6}(P M-2)$ \\
\hline$K_{3}(P M-3)=1.10 K_{6}(P M-2)$ \\
\hline$K_{4}(P M-1)=0.66 K_{6}(P M-2)$ \\
\hline$K_{5}(P M-4)=1.02 K_{6}(P M-2)$ \\
\hline$K_{2}(P M-5)=0.70 K_{5}(P M-4)$ \\
\hline
\end{tabular}

Note: Subscripts refer to individual cell numbers in Figure 17, where production wells are located. Compare ratios to those shown in Tables 7 and 9.

Table 7. Transmissivity ${ }^{\mathrm{a}}$ Estimated from Specific Capacity Data

\begin{tabular}{|c|c|c|c|c|c|c|c|}
\hline Parameter $^{b}$ & $\mathbf{P M} \mathbf{1}^{\mathrm{c}}$ & PM-2 ${ }^{\mathrm{c}}$ & PM-3 ${ }^{\mathrm{c}}$ & PM-4 ${ }^{\mathrm{c}}$ & PM-5 ${ }^{\mathrm{c}}$ & $0-4^{\mathrm{c}}$ & PM-2 $^{\text {d }}$ \\
\hline Year & 1998 & 1998 & 1998 & 1996 & 1998 & 1994 & 2003 \\
\hline$Q(\mathrm{gpm})$ & 574 & 1243 & 1395 & 1270 & 1161 & 1396 & 1249 \\
\hline$s(\mathrm{ft})$ & 27 & 73 & 27 & 48 & 84 & 21 & 84 \\
\hline$t$ (minutes) & 480 & 480 & 480 & 480 & 480 & 480 & 5300 \\
\hline$L(\mathrm{ft})$ & 598 & 850 & 1026 & 850 & 490 & 1423 & 850 \\
\hline$d_{\mathrm{w}}$ (in.) & 22 & 24 & 24 & 26 & 26 & 26 & 24 \\
\hline$S(\operatorname{dim})$ & 0.000346 & 0.000346 & 0.000346 & 0.000346 & 0.000346 & 0.000346 & 0.000346 \\
\hline $\mathrm{D}(\mathrm{ft})$ & 598 & 850 & 1026 & 850 & 490 & 1423 & 850 \\
\hline$E(\%)$ & 100 & 100 & 100 & 100 & 100 & 100 & 100 \\
\hline$T$ (ft $/$ day $)$ & 5355 & 4179 & 13614 & 6614 & 3309 & 17616 & 4214 \\
\hline$K$ (ft/day) & 9.0 & 4.9 & 13.3 & 7.8 & 6.8 & 12.4 & 5.0 \\
\hline$K / K_{P M-2}$ & 1.81 & 0.99 & 2.68 & 1.57 & 1.36 & 2.50 & 1.00 \\
\hline$K / K_{\text {Fig-17 }}$ & 0.66 & 1.00 & 1.10 & 1.02 & 0.71 & 1.10 & 1.00 \\
\hline$K / K_{2}$ & - & - & - & 1.00 & 2.56 & - & 1.00 \\
\hline
\end{tabular}

${ }^{\mathrm{a}}$ Transmissivity from specific capacity; see McLin (2005b) for details.

${ }^{\mathrm{b}}$ Parameter definitions are as follows:

Year $=$ year that data were reported.

$Q=$ average well discharge (gpm).

$s=$ quasi-steady-state drawdown (ft).

$t=$ estimated time of drawdown ( $\mathrm{min})$.

$L=$ effective screen length (ft) from PM-4 spinner log or estimated value.

$d_{\mathrm{w}}=$ effective screen diameter (in.).

$S=$ storage coefficient from distance-drawdown analysis (see Figure 16).

$\mathrm{D}=$ effective aquifer thickness ( $\mathrm{ft}$ ) from spinner log or estimated value.

$E=$ assumed well efficiency $(\%)$.

$T=$ aquifer transmissivity estimated from specific capacity.

$K=\mathrm{T} / \mathrm{D}$; the last $K$ value is used in the denominator for the $K$ ratios below.

$K / K_{P M-2}=$ ratio of $K$ compared to last $K$ from specific capacity analysis.

$K / K_{\mathrm{Fig}-17}=K$ ratios based on cell sizes from flow net analysis (see Figure 17).

$K / K_{2}=K$ ratios based on aquifer test analyses from this report (see Table 9).

${ }^{c}$ Data summarized from Koch and Rogers (2003) and Purtymun (1995).

${ }^{\mathrm{d}}$ Data from this aquifer test. 
different from those obtained from the flow net analyses. These ratios are different because the 2-D flow net analysis does not consider changes in aquifer thickness. However, the specific capacity analysis does consider these changes. We also may conclude that the flow net shown in Figure 17 may not be representative of the true 3-D flow field below Pajarito Plateau. The relationships summarized in Table 7 are helpful in the comparison of aquifer test results below.

\section{ANALYSIS OF PM-2 DATA}

Since drawdown and recovery were automatically recorded in well PM-2, we can analyze the data for aquifer transmitting properties. Figure 11 shows a plot of discharge and water-level responses to continuous pumping for almost 25 days, followed by responses to no pumping for the next 25 days. Figure 12 shows several observation well responses to pumping, whereas Figure 13 shows both pumping and recovery responses at the multiple-screened wells. Analyses of the PM-2 data shown in Figure 18 use the idealized aquifer configuration shown in Figure 15 and aquifer dimensions shown in Table 4. Hence, the Theis analysis of drawdown is shown in Figure 18(a), while the Theis analysis of recovery is shown in Figure 18(b). Figure 18(c) shows an analysis using the Theis residual recovery method. If we assume that the distance-drawdown analysis presented in Figure 16 represents the actual value for $T$ and the Theis analyses shown in Figure 18 represent predicted values, then the relative error in each of these analyses is $+6.4 \%$, $-3.9 \%$, and $-9.5 \%$, respectively, for panels (a), (b), and (c) in Figure 18. We define relative error as predicted $T$ minus actual $T$, divided by actual $T$, noting that the results are expressed as a percentage. This margin of error would probably be considered minor by most hydrologists. In each of these analyses, the Theis type-curve is fitted through the early-time data (i.e., before about 4 days). It is obvious that after this time, observed drawdown effects are falling below that predicted by the Theis model. In other words, the water-level responses in well PM-2 are starting to sense the presence of a recharge boundary. More will be said about these boundary effects later. In Figure 18(c), this departure occurs at a dimensionless time of about $t / t^{\prime}=7$ and corresponds to about $t=4$ days.

Figure 19 presents a plot of anisotropy ratio $\left(K_{h} / K_{v}\right)$ versus $T$, and demonstrates that the effects of anisotropy increase $T$ by about $7 \%$ as $K_{h} / K_{v}$ increases from 1 to 1000 . We define this variational increase as high $T$ value minus low $T$ value, divided by low $T$ value, and express the resultant as a percentage. Hence, the variation in $T$ caused by increasing the $K_{h} / K_{v}$ ratio is relatively small. These $T$ values were computed using drawdown data presented in Figure 18(a) while systematically varying $K_{h} / K_{v}$. These data show that $T$ values vary nonlinearly from 4,507 to $4,820 \mathrm{ft}^{2} /$ day, respectively, as $K_{h} / K_{v}$ varies from 1 to 1000 . Using the technique described by McLin (2005b) and the data listed in Table 5, a specific-capacity analysis yields a $T$ value of $4,214 \mathrm{ft}^{2} /$ day by comparison (see Table 7 ) and corresponds to a relative error of $-0.5 \%$. The specific-capacity technique does not consider the effects of changes in the anisotropy ratio. The results shown in Figure 18 suggest that there is little difference between the Theis methods of analyses and the distance-drawdown technique shown in Figure 16. However, our $T$ estimates near well PM-2 still vary from about 3,800 to about 4,500 $\mathrm{ft}^{2} /$ day. Furthermore, the results shown in Figure 19 suggest that the effects of anisotropy are also relatively minor. Here, our $T$ estimates vary from about 4,500 to about $4,800 \mathrm{ft}^{2} /$ day for the method shown in Figure 18(a). Although the anisotropy analyses were not completed for the techniques shown in Figure 
18(b,c), we would expect that they would show comparable variability. In other words, we might reasonably conclude that parameter uncertainty could result in a $T$ estimate that varies somewhere between 3,800 and 4,800 $\mathrm{ft}^{2} /$ day. More is included about this further on.
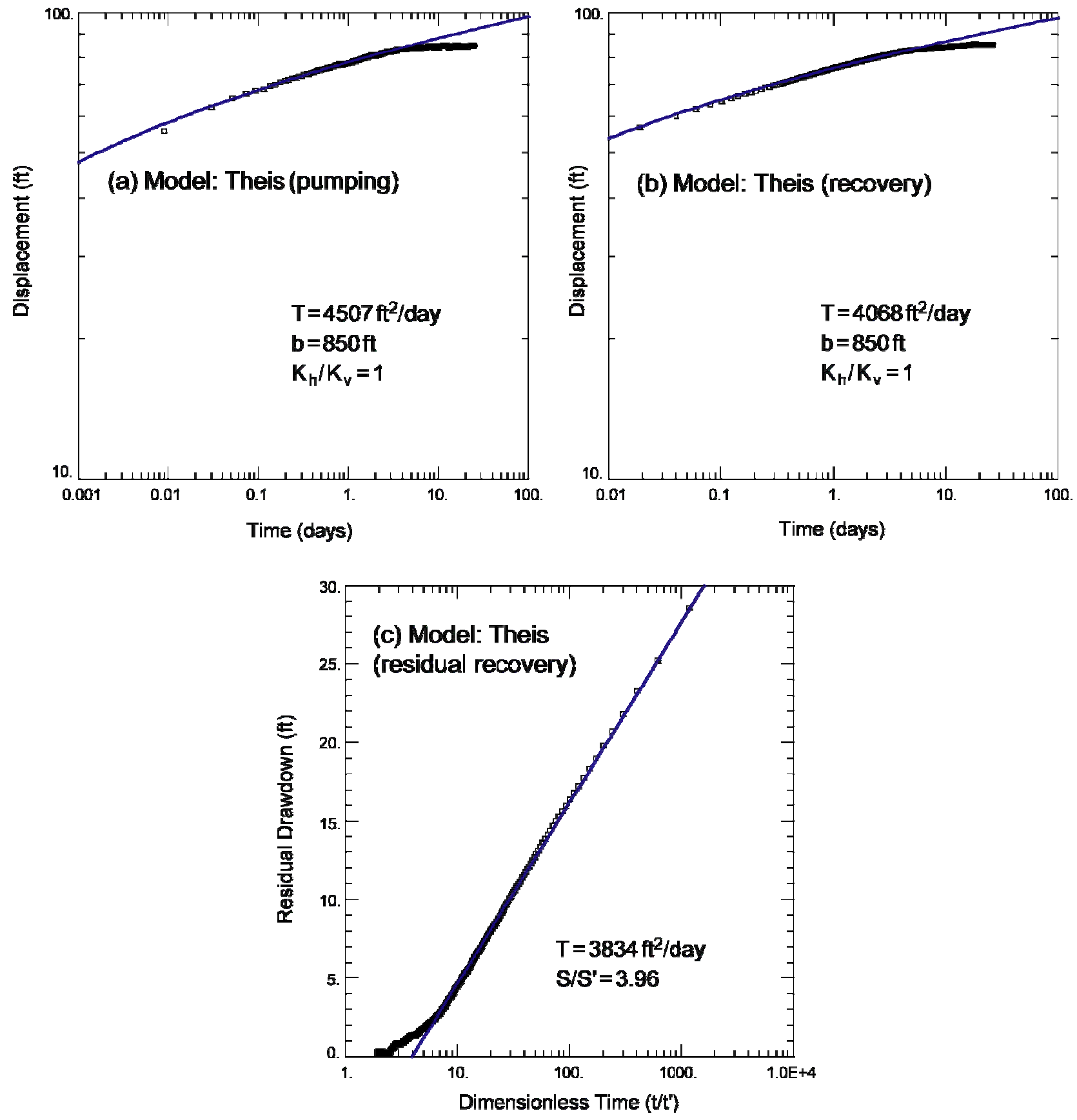

Figure 18. Theis confined-aquifer analysis using PM-2 data from (a) drawdown, (b) recovery, and (c) residual recovery. In (a) and (b) the anisotropy ratio is 1. 


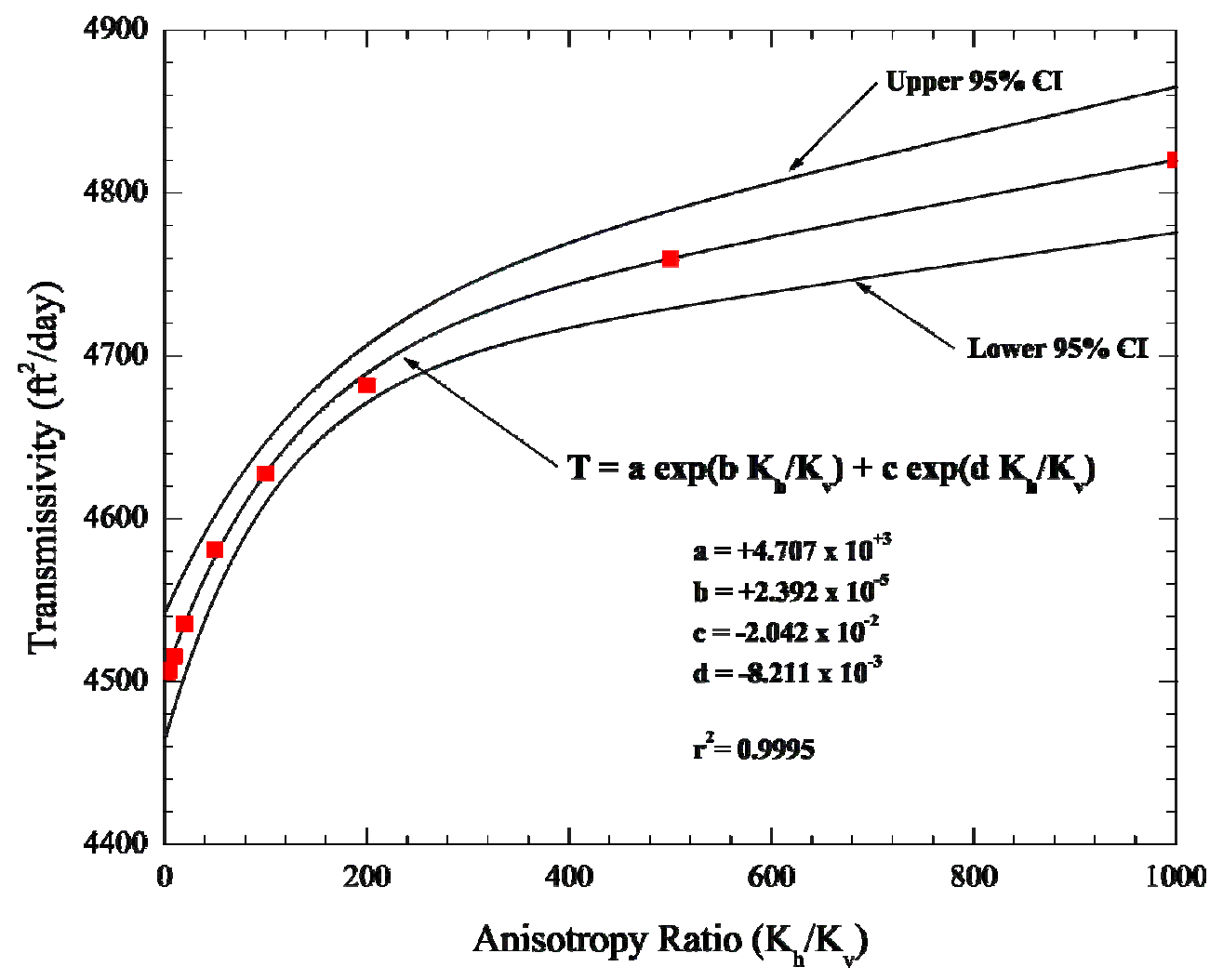

Figure 19. Anisotropy ratio as a function of transmissivity from the Theis analysis for PM-2 drawdown data.

All of the Theis analyses shown in Figure 18 imply that leaky-aquifer behavior started after about 4 days of continuous pumping. Hence, this behavior was evaluated using the HantushJacob, Neuman-Witherspoon, and Moench techniques. Results are shown in Figure 20 and summarized in Table 8. All three of the leaky-aquifer methods show good to excellent curve matches and yield similar aquifer parameters. The primary advantage of these leaky-aquifer models is that they provide us with dimensionless leakage estimates $(r / B)$. However, parameters like $S$ and $r / B$ are not considered valid when they are estimated from pumping-well data because $r \rightarrow 0$. In other words, these leakage estimates require an observation well with $r>0$. Hence, these $S$ and $r / B$ values are not reported in Figure 20; however, these parameters are listed in Table 8 for completeness. It may at first seem that the Neuman-Witherspoon technique is best because it also provides reasonable estimates for $T^{\prime}$ and $S^{\prime}$ that represent the leaky source aquifer. However, these parameters are not well constrained and actually may vary by several orders of magnitude. The problem with all curve-matching solutions is that many different possible matches result in different possible solutions. For example, the Hantush-Jacob curve match yields possible $T$ and $S$ values that vary between about 3,820 and $4,565 \mathrm{ft}^{2} /$ day and between about 0.000260 and 0.004200 , respectively, whereas leakage $(B)$ varies between 2,200 and $11,100 \mathrm{ft}$. But how do we narrow this range down to a single best estimate for each parameter? The procedure used here was to fix $T=4,235 \mathrm{ft}^{2} /$ day (i.e., the value from the distance-drawdown procedure shown in Figure 16) and then solve for $S$ and $r / B$. This process yielded more consistent results between the various methods as seen in Table 8 . 

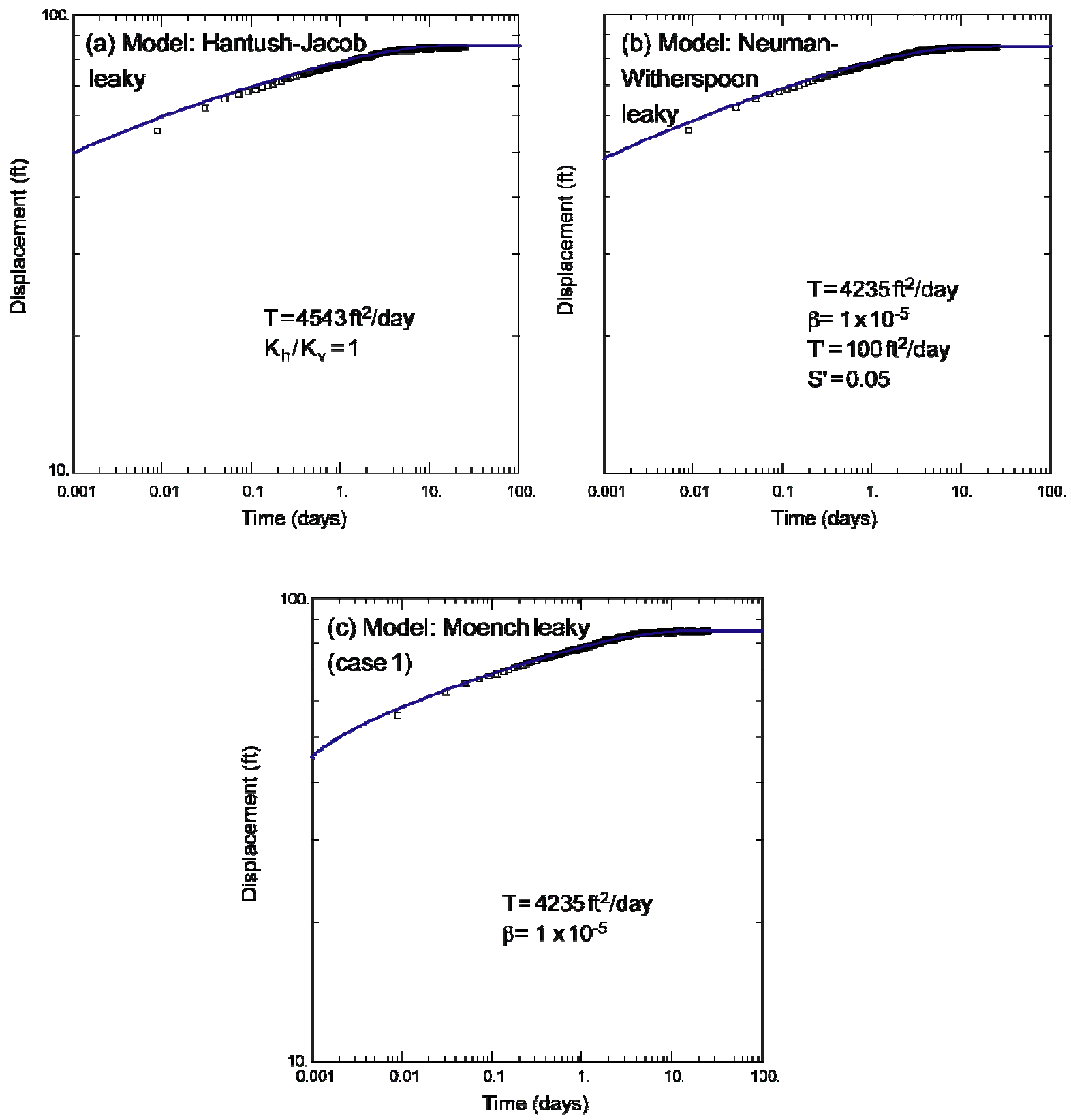

Figure 20. Leaky-aquifer analysis using PM-2 drawdown data for the (a) Hantush-Jacob, (b) the Neuman-Witherspoon, and (c) the Moench models.

One final point needs to be mentioned. The Hantush-Jacob method is the only leaky-aquifer technique that allows the $K_{h} / K_{v}$ ratio to vary. Unfortunately, we can not obtain a unique value for both $T$ and $K_{h} / K_{v}$ simultaneously. We therefore assume a value for $K_{h} / K_{v}$, and solve for $T$. The curve-matching solution also adds additional uncertainty, as mentioned earlier. In order to overcome these limitations, the following methodology was used with the Hantush-Jacob method. First, leakage $(B)$ was fixed at $B=11,094 \mathrm{ft}$ (i.e., about the same value as $B$ from the Neuman-Witherspoon and Moench techniques). Then the $K_{h} / K_{v}$ ratio was systematically varied between 1 and 1,000, and the corresponding $T$ and $S$ values were determined. These results are shown in Figure 21(a,b). These results say that for constant $B=11,094 \mathrm{ft}, T$ and $S$ values 
Table 8. Summary of Aquifer Parameters from PM-2 Aquifer Test

\begin{tabular}{|c|c|c|c|c|c|c|c|c|c|c|}
\hline Well & Method & Figure & $r(\mathbf{f t})$ & $T$ (ft ${ }^{2} /$ day) & $b(\mathbf{f t})$ & $S$ & $r / B$ & $\boldsymbol{B}$ & $\boldsymbol{\beta}$ & $S_{\mathrm{a}}$ \\
\hline \multirow[t]{7}{*}{ PM-2 } & Theis pumping & $18-\mathrm{a}$ & 1 & 4507 & 850 & $4.37 \mathrm{E}-04$ & & & & \\
\hline & Theis recovery & $18-\mathrm{b}$ & 1 & 4068 & 850 & $3.76 \mathrm{E}-04$ & & & & \\
\hline & Theis residual recovery & $18-\mathrm{c}$ & 1 & 3834 & 850 & & & & & \\
\hline & Specific capacity & - & 1 & 4214 & 850 & $3.46 \mathrm{E}-04$ & & & & \\
\hline & Hantush-Jacob & $20 \mathrm{a}$ & 1 & 4543 & 850 & $2.60 \mathrm{E}-04$ & $9.01 \mathrm{E}-05$ & 11094 & & \\
\hline & Neuman-Witherspoon & $20 \mathrm{~b}$ & 1 & 4235 & 850 & $2.00 \mathrm{E}-04$ & $9.03 \mathrm{E}-05$ & 11078 & $1.00 \mathrm{E}-05$ & $2.61 \mathrm{E}-21$ \\
\hline & Moench (case 1) & $20 \mathrm{c}$ & 1 & 4235 & 850 & $2.15 \mathrm{E}-04$ & $9.00 \mathrm{E}-05$ & 11109 & $1.00 \mathrm{E}-05$ & $2.78 \mathrm{E}-21$ \\
\hline \multirow[t]{6}{*}{ PM-4 } & Theis pumping & $22-a$ & 4478 & 3999 & 850 & $3.49 \mathrm{E}-04$ & & & & \\
\hline & Theis recovery & $22-b$ & 4478 & 4390 & 850 & $3.82 \mathrm{E}-04$ & & & & \\
\hline & Theis residual recovery & $22-c$ & 4478 & 4965 & 850 & & & & & \\
\hline & Hantush-Jacob & $23-a$ & 4478 & 4235 & 850 & $2.74 \mathrm{E}-04$ & 0.384 & 11671 & & \\
\hline & Neuman-Witherspoon & $23-b$ & 4478 & 4235 & 850 & $2.74 \mathrm{E}-04$ & 0.385 & 11637 & $4.98 \mathrm{E}-03$ & $8.02 \mathrm{E}-16$ \\
\hline & Moench (case 1) & $23-c$ & 4478 & 4235 & 850 & $2.74 \mathrm{E}-04$ & 0.384 & 11677 & 4.77E-03 & $7.30 \mathrm{E}-16$ \\
\hline \multirow[t]{7}{*}{ PM-5 } & Theis pumping & $24-a$ & 8808 & 12980 & 850 & $7.83 \mathrm{E}-04$ & & & & \\
\hline & Theis recovery & $24-b$ & 8808 & 14740 & 850 & 4.69E-04 & & & & \\
\hline & Theis residual recovery & 24-c & 8808 & 16340 & 850 & & & & & \\
\hline & Hantush wedge-shaped & $24-d$ & 8808 & 6246 & 490 & $6.88 \mathrm{E}-04$ & & & & \\
\hline & Hantush-Jacob & $26-\mathrm{a}$ & 8808 & 4235 & 850 & 4.15E-04 & 1.442 & 6108 & & \\
\hline & Neuman-Witherspoon & $26-b$ & 8808 & 4235 & 850 & $4.06 \mathrm{E}-04$ & 1.453 & 6062 & 7.07E-02 & $8.84 \mathrm{E}-13$ \\
\hline & Moench (case 1) & $26-c$ & 8808 & 4235 & 850 & $4.08 \mathrm{E}-04$ & 1.441 & 6112 & $8.32 \mathrm{E}-02$ & $1.21 \mathrm{E}-12$ \\
\hline \multirow[t]{6}{*}{ R20-3 } & Theis pumping & $27-a$ & 1225 & 4312 & 850 & $1.82 \mathrm{E}-03$ & & & & \\
\hline & Theis recovery & $27-b$ & 1225 & 4334 & 850 & $1.80 \mathrm{E}-03$ & & & & \\
\hline & Theis residual recovery & $27-c$ & 1225 & 4645 & 850 & & & & & \\
\hline & Hantush-Jacob & $28-a$ & 1225 & 4235 & 850 & $1.52 \mathrm{E}-03$ & 0.220 & 5566 & & \\
\hline & Neuman-Witherspoon & $28-b$ & 1225 & 4235 & 850 & $1.50 \mathrm{E}-03$ & 0.224 & 5476 & $1.47 \mathrm{E}-03$ & $1.73 \mathrm{E}-15$ \\
\hline & Moench (case 1) & $28-c$ & 1225 & 4235 & 850 & $1.52 \mathrm{E}-03$ & 0.220 & 5571 & 4.79E-04 & $1.80 \mathrm{E}-16$ \\
\hline \multirow[t]{5}{*}{ Multiple } & Theis pumping & $29-a$ & 1 & 4235 & 850 & $3.70 \mathrm{E}-04$ & & & & \\
\hline & Hantush-Jacob & $29-b$ & 1 & 4235 & 850 & $3.50 \mathrm{E}-04$ & $9.05 \mathrm{E}-05$ & 11051 & & \\
\hline & Neuman-Witherspoon & $29-d$ & 1 & 4235 & 850 & $3.24 \mathrm{E}-04$ & $9.05 \mathrm{E}-05$ & 11046 & $1.00 \mathrm{E}-05$ & $4.25 \mathrm{E}-21$ \\
\hline & Moench (case 1) & $29-c$ & 1 & 4235 & 850 & $3.49 \mathrm{E}-04$ & $9.10 \mathrm{E}-05$ & 10990 & $1.00 \mathrm{E}-05$ & 4.63E-21 \\
\hline & Distance-Drawdown & 16 & - & 4235 & 850 & $3.46 \mathrm{E}-04$ & & & & \\
\hline
\end{tabular}


increase as $K_{h} / K_{v}$ increases from 1 to 1,000 . Figure 21(b) shows that $S$ values actually vary nonlinearly but remain in a relatively narrow range of values near about 0.000280 . However, Figure 21(a) shows that $T$ values vary linearly between 4,543 and $4,764 \mathrm{ft}^{2} /$ day. Then $T$ was fixed at $4,235 \mathrm{ft}^{2} /$ day, and the $K_{h} / K_{v}$ ratio was again varied between 1 and 1,000 . The corresponding $B$ and $S$ values are shown in Figure 21(c,d). These results say that for constant $T=$ $4,235 \mathrm{ft}^{2} /$ day, $B$ and $S$ values vary nonlinearly as the $K_{h} / K_{v}$ ratio increases from 1 to 1,000 . Hence, $B$ drops from 5,583 $\mathrm{ft}$ to $3,528 \mathrm{ft}$ as seen in Figure 21(c). Likewise, $S$ increases from 0.00085 to 0.00186 as seen in Figure 21(d).

It is important to recall that variations in the $K_{h} / K_{v}$ ratio are only revealed when vertical flow effects are near the well screen in a pumping well. If flow is moving toward a fully penetrating screen in a pumping well, the flow is essentially horizontal regardless of the $K_{h} / K_{v}$ ratio. In other words, we need a partially penetrating well screen in a pumping well that results in sufficient vertical flow before we can estimate the $K_{h} / K_{v}$ ratio. According to Hantush (1964), these vertical flow effects theoretically extend radially outward from the pumping well for a distance of $(3 b / 2)\left(K_{h} / K_{v}\right)^{1 / 2}$. If an observation well is within this radial distance, then the effects of partial penetration may cause sufficient vertical flow effects in the observation well. If $1 \leq K_{h} / K_{v} \leq 100$ and $b=850 \mathrm{ft}$, then this distance is somewhere between $1,275 \mathrm{ft}$ and $12,750 \mathrm{ft}$. In this report, all observation wells are within this range, where vertical flow effects might be important. These partial penetration effects are automatically considered in the Aqtesolv program. The problem, however, is that we still do not have a way to uniquely fix the $K_{h} / K_{v}$ ratio.

Discussion. The static water level obtained in well PM-2 before the start of the aquifer test was reestablished after the recovery period (see Figure 11). In addition, wells PM-2, PM-4, and PM-5 are considered to be nearly fully penetrating according to the geologic and spinner $\log$ information presented earlier. The dilemma encountered in testing wells on Pajarito Plateau is that many of these wells encounter a massively thick aquifer that is lithologically variable. This is nothing new, but we cannot overemphasize the difficulty in establishing the idealized leakyaquifer configuration depicted in Figure 15. Although this figure is based on geologic information from all wells reported here, it also heavily emphasizes spinner log information from well PM-4. Hence, the idealized aquifer and semi-confining layers shown in Figure 15 are intentionally drawn as continuous horizontal units because that is the implied assumption inherent in all analytical aquifer test methods. All analytical methods of analyses represent the real 3-D world as 2-D. In reality, we must recognize that the thickness of a high-yielding waterbearing unit may vary greatly between wells as seen in Figure 4. We should anticipate therefore that our test results represent only estimates that are also subject to natural variability. Hence, it is often not possible to know what aquifer thickness to use when calculating hydraulic conductivity $(K)$, using the relationship $K=T / b$. In Figure 15 , this $b$ value is fixed at $850 \mathrm{ft}$. In reality, $T$ may change as the cone of depression expands because $b$ is changing in an unknown fashion. This condition makes test analyses extremely difficult because no analytical methods specifically apply to these complex test conditions. Furthermore, this test variability cannot be completely eliminated. All analytical models assume horizontal flow toward the pumping well. Departures from this assumption may result because both $b$ and $K_{h} / K_{v}$ change in unpredictable ways. We have attempted to characterize some of this variability by using multiple techniques to analyze drawdown and recovery data in the pumping well. We have also attempted to estimate uncertainty in $T$ associated with varying the anisotropy ratio. These analyses suggest that $T$ increases only about $7 \%$ as the $K_{h} / K_{v}$ ratio increases from 1 to 1,000 in the Theis analysis, and 

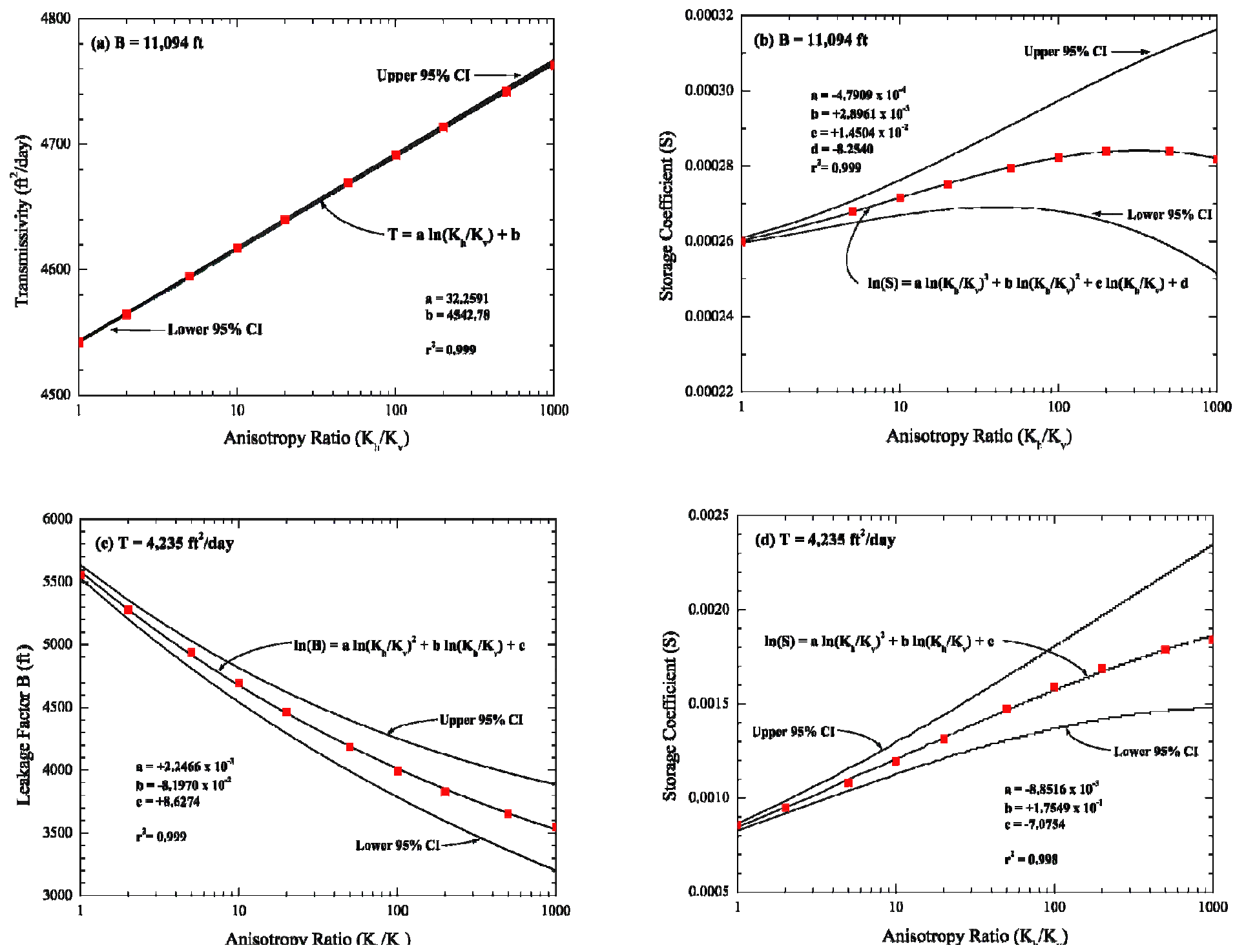

Figure 21. Anisotropy ratio as a function of transmissivity from the Hantush-Jacob method of leaky-aquifer analysis for PM-2 drawdown data. 
about $10 \%$ in the Hantush-Jacob method. Ultimately, we must accept that these analyses are only approximate because we have no way to accurately fix the $K_{h} / K_{v}$ ratio. In addition, there is added uncertainty in the curve-matching procedure. Some of this uncertainty is probably associated with using the pumping well as an observation well. The good news is that aquifer parameters could be estimated, and these results are significant. As shown later, the results from PM-2 agree with results from PM-4. It is likely that the Hantush-Jacob leaky-aquifer analysis yielded the most reliable results because there are fewer aquifer parameters than with either the NeumanWitherspoon or the Moench techniques. Hence, $T$ varied between 3,820 and 4,542 $\mathrm{ft}^{2} /$ day, $S$ varied between 0.000260 and 0.004200 , and $B$ varied between 2,200 and 11,100 ft. According to Equation (1), this means that $K_{a}$ varies between 0.16 and $0.0074 \mathrm{ft} /$ day when $b_{a}=200 \mathrm{ft}$.

In Figure 11, which shows drawdown and recovery data versus time for well PM-2, the effect of casing storage is not apparent. The theoretical duration of casing storage can be calculated from the following equation (Schafer 1979):

$$
t_{c}=\frac{0.6\left(D^{2}-d^{2}\right)}{Q / s},
$$

where $t_{c}$ is the duration of casing storage (minutes), $D$ is the inside diameter of the well casing (14.0 inches here), $d$ is the outside diameter of column pipe (10.0 inches for the PM-2 production tubing and pump bowls), $Q$ is the discharge rate (gpm), and $s$ is drawdown at time $t_{c}$. The data from the PM-2 aquifer test and Equation (9) produced a theoretical casing storage duration of less than 3 minutes. Hence, the pumping and recovery data should each describe a steep curve for about 3 minutes. The curve should gradually transition to the correct theoretical slope after these effects have dissipated. This formula usually produces a conservative $t_{c}$ estimate. In many tests, the observed effects of casing storage can be as little as half the theoretical value because the asymptotic approach of the data to the theoretical drawdown curve has been largely achieved by then. Inspection of the time-drawdown graphs on Figure 18 shows that the observed duration of casing storage effects were not observed because the sampling interval was 30 minutes. We conclude that the effects of casing storage are not present in the PM-2 data collected during the aquifer test.

Which analytical method gives the most representative hydraulic properties for the formation opposite the screen in PM-2? First of all, the distance-drawdown analysis presented earlier accurately reflects an average $T$ and $S$ value for the productive zone yielding water to well PM-2 probably better than any of the techniques presented above simply because it provides a single answer. We must look to the Theis and Hantush-Jacob methods, however, to understand how the anisotropy ratio affects parameters like $T, S$, or $r / B$. In addition, the spinner log at well PM-4 was used to estimate the best representation for aquifer thickness, $b$. A close examination of Figure 18 shows that the Theis analyses of this confined-aquifer method essentially reproduces the distance-drawdown method quite well. In addition, the specific-capacity technique appears to be the least accurate of all techniques presented because it uses only one value for drawdown at one time during the entire test. This is in stark contrast to a conventional aquifer test in which numerous $s$ and $t$ values are matched to an appropriate theoretical type-curve. However, according to Walton (1970, pages 314-321), the specific-capacity method gives minimum values for $T$ because the effects of partial penetration, well losses, and hydrogeologic boundaries are taken into consideration. Finally, the leaky-aquifer methods all yield comparable aquifer parameters, including important estimates for leakage. These results and recommended values for aquifer parameters are summarized in Table 8 . 


\section{ANALYSIS OF PM-4 DATA}

Drawdown and recovery data were manually recorded in well PM-4 during the aquifer test. Because municipal supply well PM-4 was not producing water before, during, or after the 25-day pumping interval at well PM-2, PM-4 was used strictly as an observation well. Hence, we can also analyze this data for aquifer transmitting properties. This well is located approximately 4,478 ft from PM-2 (see Figure 3). Analyses similar to that presented earlier for PM-2 were conducted. However, unlike before, we can now estimate valid parameters for $T, S$, and $r / B$. Much of the discussion presented for PM-2 is also applicable here but is not repeated. Analyses of the PM-4 data are shown in Figure 22 using the idealized aquifer configuration previously
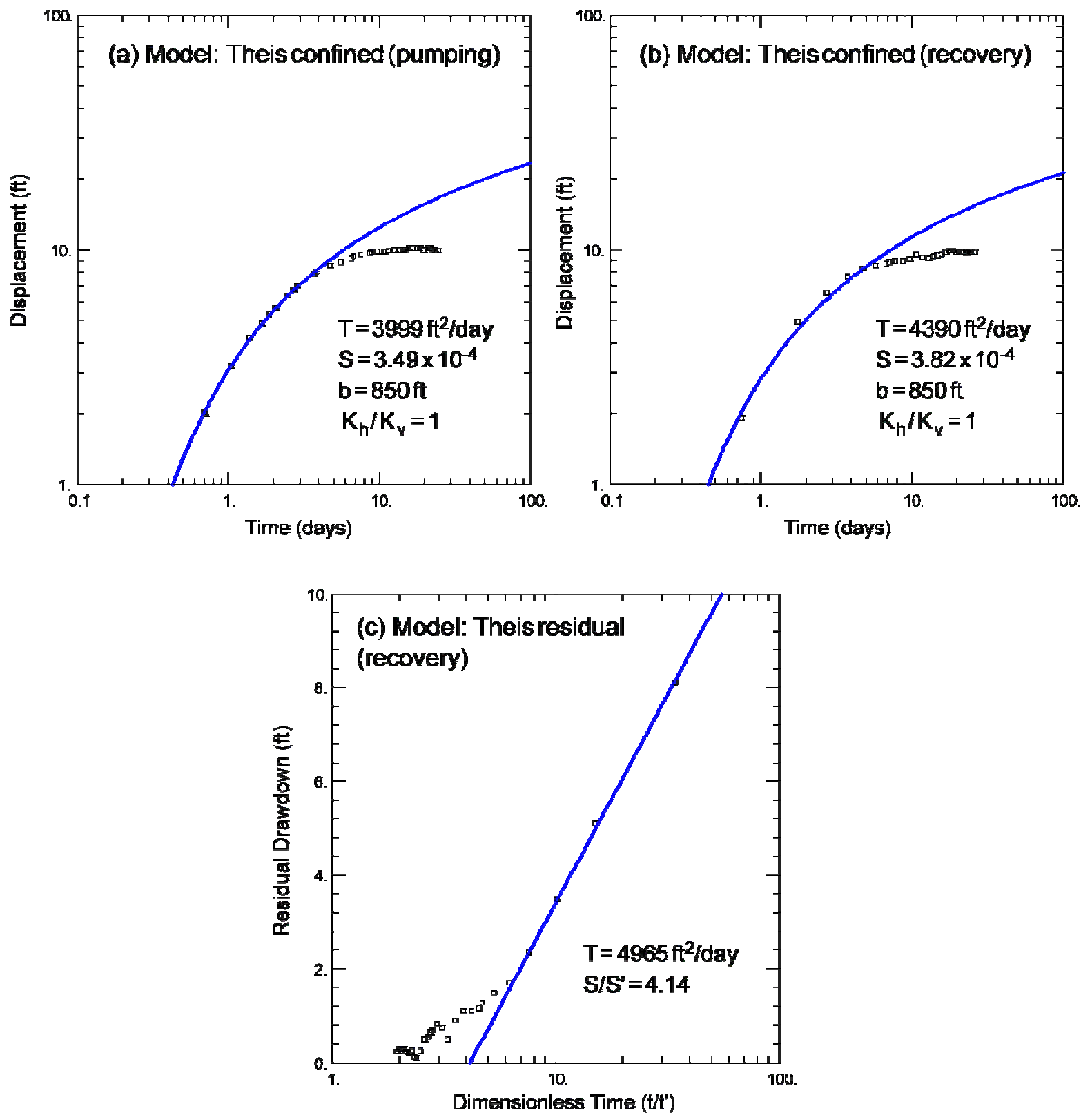

Figure 22. Theis confined-aquifer analysis using PM-4 data from (a) drawdown, (b) recovery, and (c) residual recovery. 
shown in Figure 15 and aquifer dimensions shown in Table 4. Hence, Theis analyses of drawdown data are shown in Figure 22(a), while recovery data are shown in Figure 22(b). Figure 22(c) shows an analysis using the Theis residual recovery method. Again, if we assume that the distance-drawdown analysis presented in Figure 16 represents the actual values for $T$ and $S$, then the relative error in each of these $T$ analyses are $-5.6 \%,+3.7 \%$, and $+17.2 \%$, respectively, compared with the distance-drawdown $T$ value shown in Figure 16. Similarly, the relative errors in the parameter $S$ are $+0.9 \%$ and $+10.4 \%$, respectively, for the Theis pumping and Theis simple recovery analyses. These margins of error would probably be considered very good by most hydrologists. The Theis residual recovery method does not yield an $S$ value directly. Instead, we obtain an $S / S^{\prime}$ ratio, where $S$ is the storage coefficient during pumping, and $S^{\prime}$ is the storage coefficient during recovery. Again, in each of these analyses, the Theis type-curve is fitted through the early-time data (i.e., before about 4 days). It is obvious that after this time, observed drawdown effects are falling below that predicted by the Theis model. As in well PM-2, the water-level responses in well PM-4 also sense the presence of a recharge boundary. This observation is also confirmed in Figure 22(c) because $S / S^{\prime}>1$. More will be said about these boundary effects later. This departure occurs in Figure 22(c) at a dimensionless time of about $t / t^{\prime}$ $=7$ and corresponds to about $t=4$ days. These times are remarkably close to those previously reported at PM-2 and are significant. These similarities in time reveal when boundary effects first start to appear. They are significant because they confirm our interpretation that recharge effects result from leaky-aquifer behavior.

One final point is worth mentioning about the Theis residual recovery method shown in Figure 22(c). This technique assumes that $u \leq 0.05$, where $u=r^{2} S / 4 T t$. Using the values of $T$ and $S$ from the distance-drawdown analysis, along with $r=4,478 \mathrm{ft}$ and $t=4$ days, we find that $u=$ 0.010. In other words, this technique is not as accurate as the Theis pumping or Theis recovery methods presented in Figure 22(a,b). In addition, this method yields the highest relative error in $T$, as reported above.

Finally, Figure 23 shows a leaky-aquifer analysis using drawdown data and the Hantush-Jacob, Neuman-Witherspoon, and Moench methods. Again, as with the PM-2 data, the curve-matching process also revealed the possibility of multiple matches and similar variability in final parameter values to that previously seen. Hence, a process similar to that already described was used again. Thus, when $T$ was set at $4,235 \mathrm{ft}^{2} /$ day, all three of the leaky-aquifer analyses produced excellent curve matches and yielded similar aquifer parameters. These results are shown in Figure 23 and Table 8.

As mentioned before, the real advantage of these leaky-aquifer models is that they provide us with dimensionless leakage estimates that were previously defined by Equations (1) and (2). Hence, we obtain $r / B$ values of $0.384,0.382$, and 0.384 , respectively, for the various methods. All of these techniques report similar dimensionless leakage estimates for these parameters. On first thought, it may seem that the Neuman-Witherspoon technique is best because it also provides reasonable estimates for $T^{\prime}$ and $S^{\prime}$ that represent the leaky source aquifer. However, as before, these parameters are not well constrained and actually may vary by several orders of magnitude while still obtaining reasonable looking curve matches. Both the NeumanWitherspoon and Moench techniques also yield estimates for the parameter $\beta$, whereas the Hantush-Jacob method does not. Both the Hantush-Jacob and Moench methods of leaky-aquifer analysis are more appealing than the Neuman-Witherspoon technique because they are much 

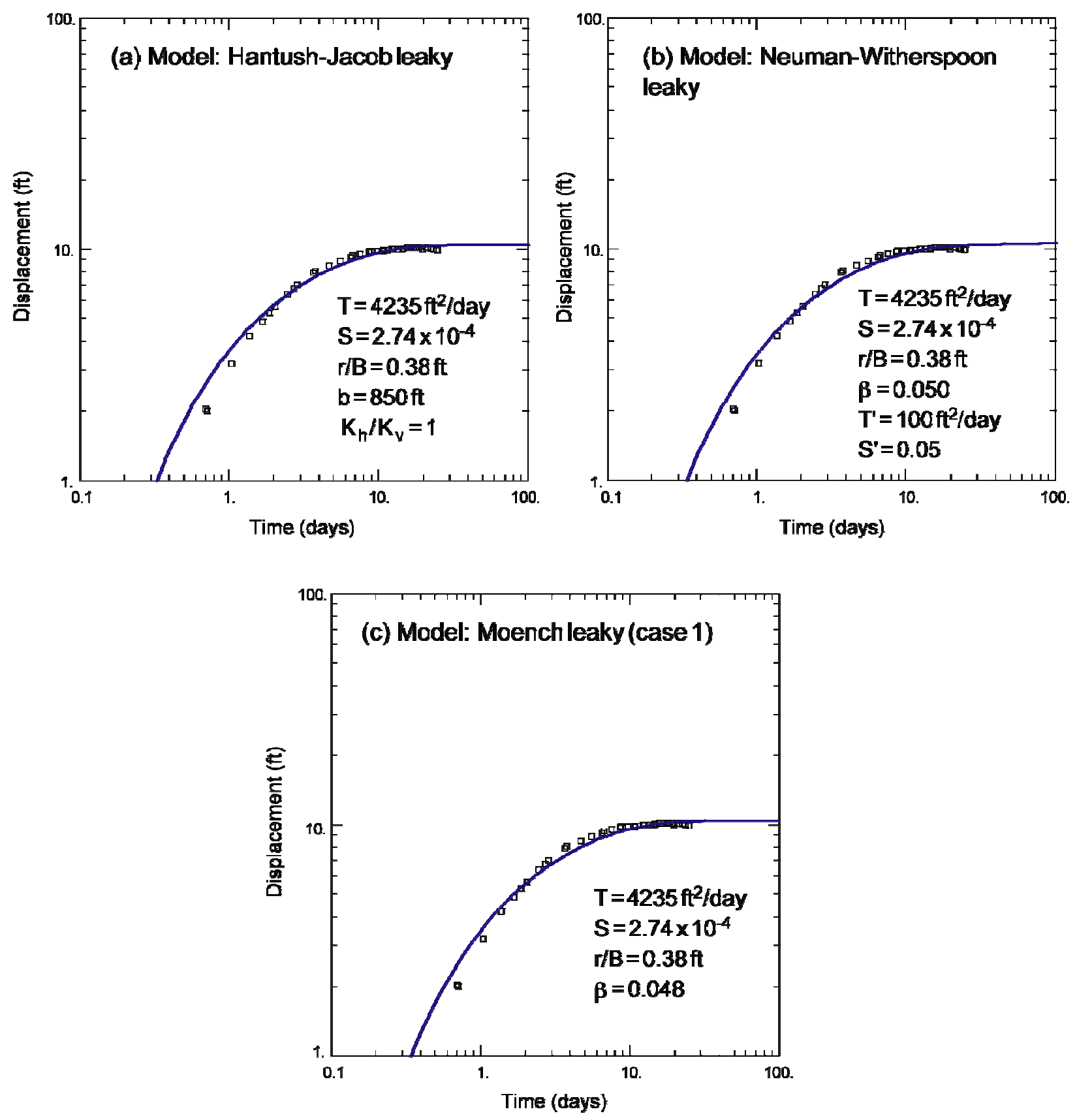

Figure 23. Leaky-aquifer analysis using PM-4 drawdown data for the (a) Hantush-Jacob, (b) the Neuman-Witherspoon, and (c) the Moench models.

simpler to use. This observation has been noted before by numerous authors despite the insistence by some that more complex methods of analyses are preferable. In reality, these methods are simpler to use because they are more restrictive than the Neuman-Witherspoon solution.

Discussion. Most of the discussion points presented earlier for well PM-2 also apply here but are not repeated. Furthermore, since well PM-4 was used as an observation well, no casing storage effects were computed because these effects are equal to, or less than, similar effects in the 
pumping well. In addition, the effects of partial penetration are also taken into consideration because this well is probably within a radial distance of $(3 b / 2)\left(K_{\mathrm{h}} / K_{\mathrm{V}}\right)^{1 / 2}$ from the pumping well. In other words, if $1 \leq K_{\mathrm{h}} / K_{\mathrm{v}} \leq 100$ and $b=850 \mathrm{ft}$, then vertical flow effects may be present in observation wells located anywhere between about 1,275 ft and 12,750 ft from PM-2. Recall that PM-4 is about 4,478 ft from PM-2.

Which analytical method gives the most representative hydraulic properties for the formation opposite the screen in well PM-4? Again, the distance-drawdown analysis presented earlier accurately reflects an average $T$ and $S$ value for the productive zone yielding water to well PM-2 probably better than any of the techniques presented above. In addition, the spinner log at PM-4 was used to estimate the best representation for aquifer thickness, $b$. Normally, these spinner logs are unavailable and estimates for $b$ are made from lithology or geophysical logs. The estimates for $b$ represented by the spinner log shown in Figure 14 are likely better than any previous estimates for this parameter because it is based on observed water yield. A close examination of Figure 22 shows that the Theis confined aquifer method essentially reproduces the distancedrawdown method reasonably well. However, the variability in $T$ is more pronounced at PM-4 than at PM-2, whereas $S$ values are relatively constant at both wells. Finally, the leaky aquifer analyses provide important estimates for $T, S, r / B, \beta, T^{\prime}$, and $S^{\prime}$. These results and the recommended values for PM-4 aquifer parameters are summarized in Table 8.

Finally, according to the flow net relationships developed in Figure 17 and Table 6 , the $K$ value near well PM-4 should be about 1.02 times larger than the $K$ value near well PM-2. However, according to the specific-capacity analysis shown in Table 7, the $K$ value near PM-4 should be about 1.57 times larger than the $K$ value near PM-2. According to the analytical methods used to obtain $K$ values from Figures 18 and 22, this ratio varies between 0.91 and 1.17 for the different Theis methods, and averages about 1.05. All of the other ratios from the remaining analytical methods are summarized in Table 9 for comparison. Compare these ratios with values in Table 7 . We conclude that the analytical methods used to obtain $K$ from the aquifer test results from wells PM-2 and PM-4 are consistent with those obtained from the flow net and specific-capacity analyses shown in Figure 17, Table 6, and Table 7. This is a significant observation because it confirms the validity of the piezometric contours near wells PM-2 and PM-4 that are shown in Figure 17.

\section{ANALYSIS OF PM-5 DATA}

Drawdown and recovery data were also manually recorded in well PM-5 during the aquifer test. Because municipal supply well PM-5 was not producing water immediately before, during, or after the 25-day pumping interval at well PM-2, like well PM-4, PM-5 was used strictly as an observation well during the aquifer test. We can also analyze these data for aquifer transmitting properties. Well PM-5 is approximately 8,808 ft from PM-2 (see Figure 3), and maximum drawdown values were relatively small. Analyses similar to that presented earlier for PM-2 and PM-4 were still conducted. Hence, much of the discussion presented there is also applicable here but is not repeated. As seen in Figure 12 for late time, it appears that PM-5 drawdown values may have been affected by barometric pressure oscillations. We can anticipate therefore that the results from PM-5 will contain more uncertainty than the results from either PM-4 or PM-2. Although long-term records of both static water levels at PM-5 and barometric pressure are not 


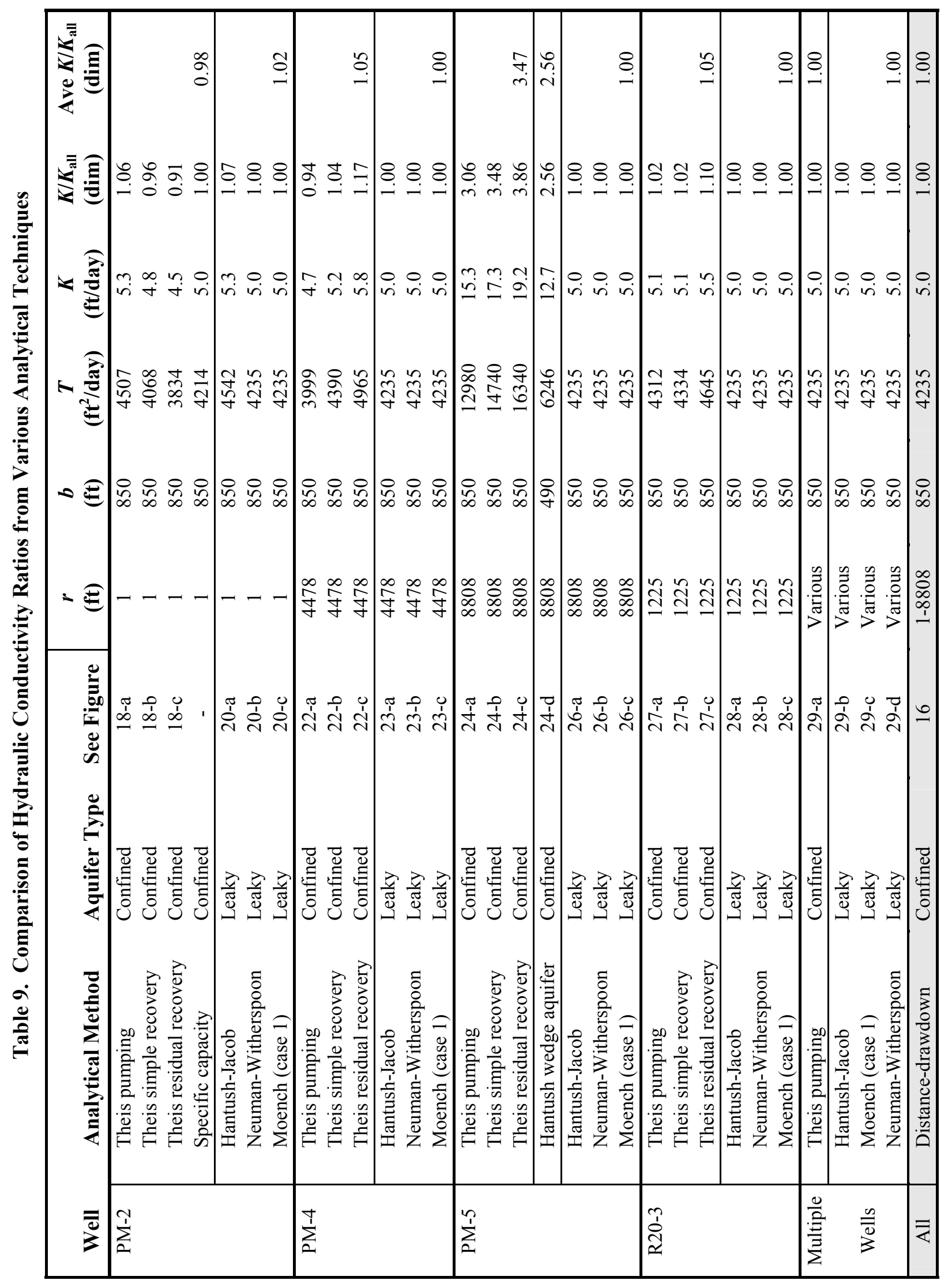


available, we conclude that water-level fluctuations at PM-5 that result from barometric pressure changes will be small (i.e., $<0.3 \mathrm{ft}$ ) even if barometric efficiency is $100 \%$. Hence, corrections for these effects were not made to the PM-5 data. In addition, there is also uncertainty in aquifer thickness variations between PM-4 and PM-5. Finally, we note that the overall aquifer behavior at PM-5 could be characterized as confined, leaky-confined, or possibly even phreatic. These combined effects will greatly overshadow any barometric influence on $T$ and $S$ values as illustrated below. We simply assume than these combined effects are not present because we have no way to accurately remove them from the recorded data.

Preliminary Theis curve matches for well PM-5 are shown in Figure 24 using the idealized aquifer configuration previously shown in Figure 15 and aquifer dimensions shown in Table 4. Theis analyses of drawdown data are shown in Figure 24(a), while recovery data are shown in Figure 24(b). Figure 24(c) shows an analysis using the Theis residual recovery method. Last of all, Figure 24(d) shows a Theis analysis of drawdown data for a wedge-shaped aquifer using the technique developed by Hantush (1962). The latter analysis used the aquifer dimensions shown in Figure 25 rather than the configuration shown in Figure 15. Figure 25 represents an alternative interpretation of the wedge-shaped aquifer that would exist if the tops of the highest Miocene basalts in wells PM-2, PM-4, and PM-5 are connected together. In other words, these basalts are considered as the bottom of the regional aquifer between PM-4 and PM-5 (see Figure 4) because the regional aquifer apparently thins toward the northwest. In Figure 25, the top of the regional aquifer has not changed from that shown in Figure 15. Hence, we are still depicting a hypothetical, idealized, leaky source bed in the regional aquifer that is above the high-yielding zone. More will be said about this wedge-shaped aquifer configuration later.

In Figure 24, we are immediately struck by the relatively large values that were obtained for $T$ from the first three analyses, whereas the corresponding $S$ values are generally comparable to previous results. Again, assuming that the $T$ and $S$ values from the distance-drawdown analysis represent the true aquifer parameters, then the relative errors in each of the $T$ values is $+207 \%$, $+248 \%$, and $+286 \%$, respectively, for each of the first three methods. Likewise, the relative errors for $S$ are $+126 \%$ and $+36 \%$, respectively, for the Theis pumping and the Theis recovery methods. The last method in Figure 24(d) yields $T$ and $S$ values that are more consistent with previous results; hence, the relative errors are $+48 \%$ for $T$, and $+99 \%$ for $S$.

Finally, it is worth mentioning that the Theis residual recovery method is not as accurate as the other Theis analyses in Figure 24. Recall that this technique assumes that $u \leq 0.05$, where $u=r^{2} S / 4 T t$. Using the values of $T$ and $S$ from the distance-drawdown analysis, along with $r=$ $8,808 \mathrm{ft}$ and $t=4$ days, we find that $u=0.40$. If we use values of $T$ and $S$ from Figure 24(d) in this calculation, then $u=0.53$. In other words, this technique is not as accurate as either the Theis pumping method or the Theis recovery methods presented in Figure 24(a,b), or the Theis analysis for a wedge-shaped aquifer shown in Figure 24(d). In fact, because $u$ is so large, we consider this particular analysis to be unreliable.

Some might argue that each of the first three matches shown in Figure 24 could be improved; however, when this is done, unreasonably high $T$ values still persist. Part of the problem with these curve matches is that there is a combination of manual measurement errors and barometric pressure fluctuations that are affecting water levels. These combined effects make the matches more difficult. This situation is readily apparent in Figure 24(b, c). Again, in each of these 

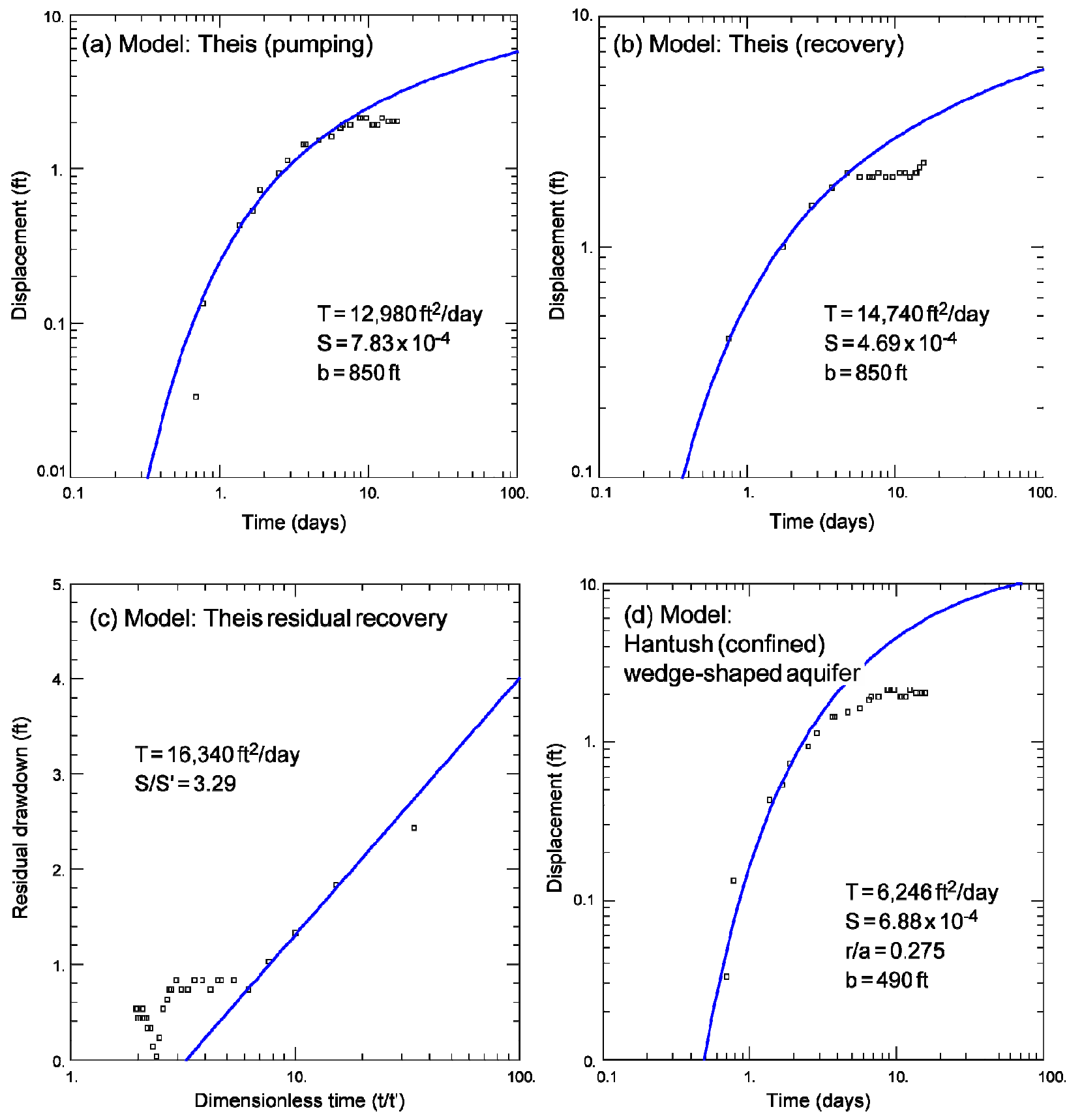

Figure 24. Theis confined-aquifer analysis using PM-5 data from (a) drawdown, (b) recovery, (c) residual recovery, and (d) a wedge-shaped aquifer. 


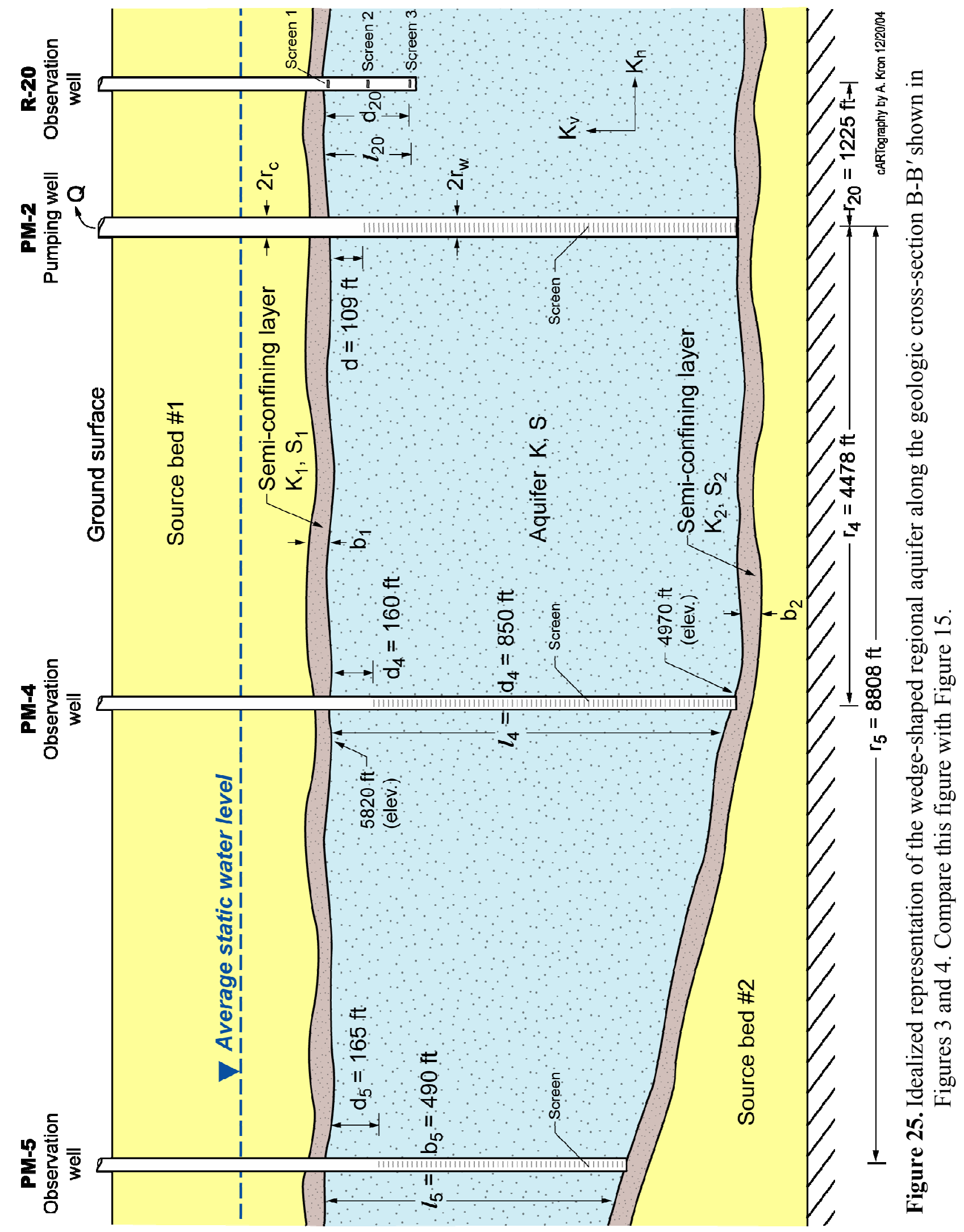


analyses, the Theis type-curve is fitted through the early-time data [i.e., before about 5 days in Figure 24(b) which corresponds to $t / t^{\prime}=6$ in Figure 24(c)]. Before this time, these combined influences appear relatively minor. However, after this time, observed water levels are falling below that predicted by the Theis model or are being affected by these combined effects. This transition from confined- to leaky-confined aquifer behavior occurs after about 8 days according to Figure 24(a), but only after about 4 days according to Figure 24(d). These differences are discussed below. The important point here is that the water-level responses in well PM-5 are simultaneously sensing the presence of a recharge boundary and an increase in barometric pressure after about 4 days.

The thickness of the high-yielding aquifer zone is also obviously changing at well PM-5. This $b$ value varies from about $850 \mathrm{ft}$, according to Figure 15, to as low as $490 \mathrm{ft}$, according to Figure 25 (i.e., where $b$ is represented by the distance between the bottom of the Cerros del Rio basalt in well PM-4 to the top of the first Miocene basalt layer in PM-5). In other words, the aquifer thins dramatically between PM-4 and PM-5. However, since there is no dynamic spinner log for PM5 , we do not know if significant quantities of water are produced below the Miocene basalts shown in Figure 5 (i.e., below about $1,765 \mathrm{ft} \mathrm{bgs}$ ). In this report, it is assumed that all of the basalt and fine sand units in PM-5 that are below 1,765 ft bgs do not produce significant quantities of water. In addition, the aquifer may also transition from a confined to a leakyconfined aquifer near wells PM-2 and PM-4, to a phreatic aquifer near PM-5 (as suggested by the static water level in Figure 5 before the start of the PM-2 aquifer test). These combined effects reflect a complex aquifer configuration that does not lend itself to simple interpretation. This problem of representing aquifer behavior in an appropriate manner is important because vertical drawdown propagation to the phreatic surface may occur near well PM-5 but not near wells PM-4, PM-2, or R-20. In the future, we should verify this behavioral transition by monitoring water level fluctuations in shallow wells completed into the regional aquifer near PM-5 to see if they respond to cyclical pumping at either PM-4 or PM-5.

The effects of anisotropy ratio $\left(K_{h} / K_{v}\right)$ versus $T$ were not evaluated at well PM-5 because this observation well is located 8,808 ft from well PM-2. However, the effects of partial penetration at PM-5 were still taken into consideration. Again, this does not mean that the $K_{h} / K_{v}$ ratio is one or that the effects of partial penetration at PM-5 are not important. Instead, it means only that we cannot use our test results to estimate a value for $K_{h} / K_{v}$ because these influences were not very significant during this particular test.

Finally, Figure 26 shows a leaky-aquifer analysis using drawdown data and the Hantush-Jacob, Neuman-Witherspoon, and Moench methods. These curve matches are much improved over those shown in Figure 24(a,b). Again, as with the PM-2 and PM-4 data, the curve-matching process revealed the possibility of multiple matches and similar variability in final parameter values. Hence, the process already described was used again here. Thus, $T$ was set at $4,235 \mathrm{ft}^{2} /$ day, and all of the leaky aquifer analyses produced excellent curve matches and yielded similar aquifer parameters. These results are shown in Figure 26 and Table 8.

Values for the parameter $S$ varied only slightly from that obtained in the distance-drawdown method as seen in Figure 26. Hence, we obtained a relative error of $17 \%$ to $20 \%$ for the three leaky-aquifer techniques. The real advantage of these leaky-aquifer models, however, is that they provide us with dimensionless leakage estimates. Hence, we obtain $r / B$ values of $1.442,1.453$, and 1.441, respectively, for the various methods. In other words, all of these techniques report 

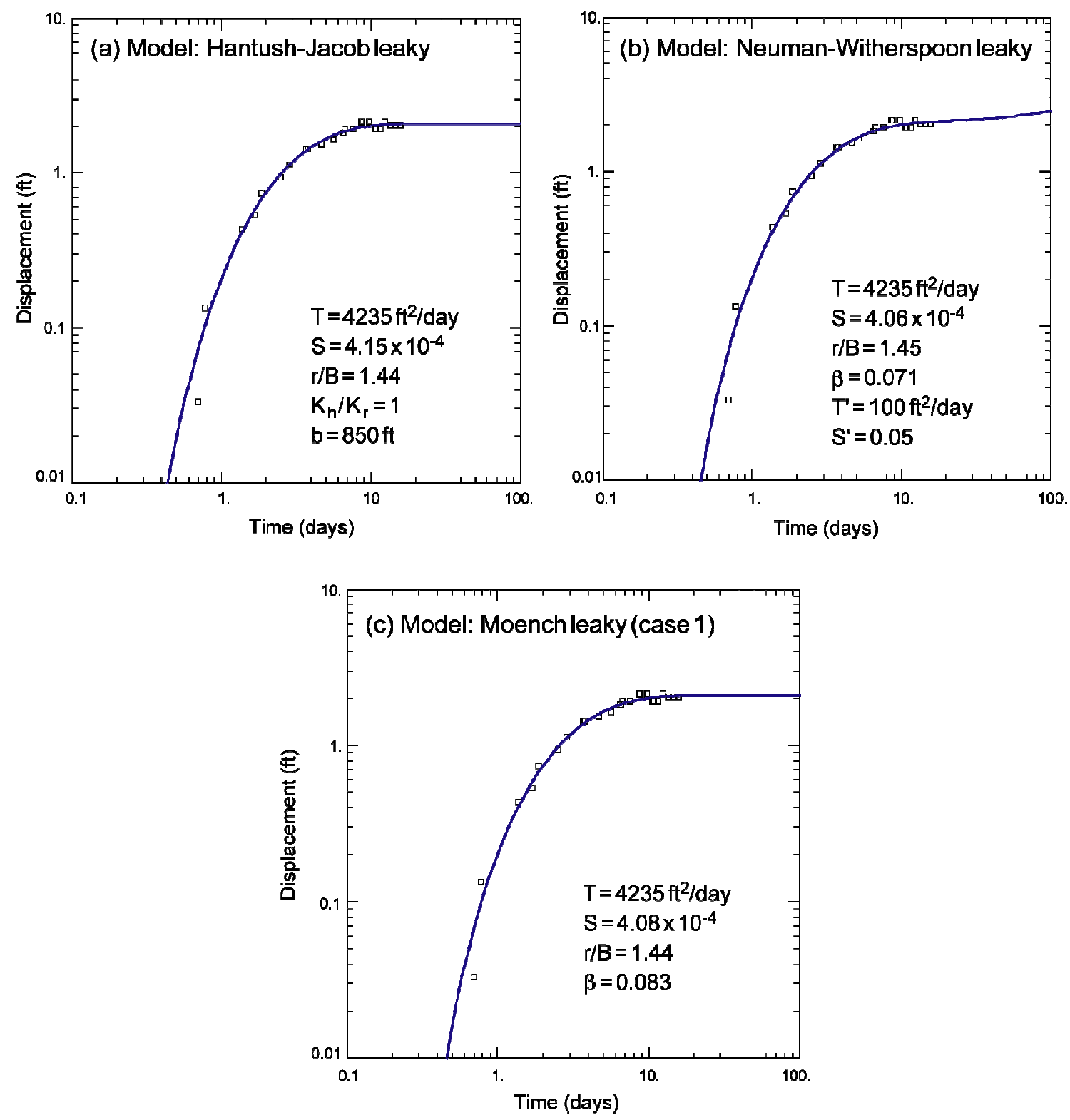

Figure 26. Leaky-aquifer analysis using PM-5 drawdown data for the (a) Hantush-Jacob, (b) the Neuman-Witherspoon, and (c) the Moench models.

similar dimensionless leakage estimates. These $r / B$ estimates are reasonably comparable to those previously obtained at PM-4. On first thought, it may seem that the Neuman-Witherspoon technique is best because it also provides reasonable estimates for $T^{\prime}$ and $S^{\prime}$ that represent the leaky source aquifer. However, as before, these parameters are not well constrained and actually may vary by several orders of magnitude. The Hantush-Jacob method of leaky-aquifer analysis is more appealing than the other two because it is much simpler to use. In addition, this method seems to yield comparable results for all parameters.

Discussion. The static water level obtained in well PM-5 before the start of the aquifer test was reestablished after the recovery period. In addition, well PM-5 is considered to be fully penetrating according to the information presented earlier. However, the dilemma encountered 
previously was also seen here. Hence, variations in the value for $b$ are probably considerable. This condition makes test interpretation extremely difficult because there are no analytical methods that specifically apply to these complex test conditions. In other words, this test variability cannot be completely eliminated. All analytical models assume horizontal flow toward the pumping well. Departures from this assumption may result because both $b$ and $K_{h} / K_{v}$ change in unpredictable ways. However, such characterization was more difficult with PM-5 data as previously noted. In addition, since well PM-5 was used as an observation well, no casing storage effects were computed because these effects primarily affect pumping wells. One final note is worth mentioning. All wells that tap into the regional aquifer below Pajarito Plateau experience water-level fluctuations caused by barometric pressure fluctuations. These effects were not a problem at other observation wells located closer to well PM-2 because drawdown values associated with pumping at PM-2 were more than an order-of-magnitude larger than barometric effects. However, this was not the case at PM-5. Regardless, the hydraulic parameters obtained from PM-5 were not corrected for barometric fluctuations because variations in $b$ and aquifer behavior greatly overshadow any barometric influences.

Obviously, the most important question to answer is this: Which analytical method gives the most representative hydraulic properties for the formation near well PM-5? The Hantush wedgeshaped aquifer analysis shown in Figure 24(d) probably represents the test data at PM-5 best because it accounts for aquifer-thinning effects. Hence, $T=6,246 \mathrm{ft}^{2} /$ day and $S=0.00069$ near PM-5. The corresponding $K$ is about $12.7 \mathrm{ft} /$ day based on a $b$ value of $490 \mathrm{ft}$. Furthermore, the leaky-aquifer analyses provide $T$ and $S$ estimates consistent with those from Theis. In addition, these analyses yield important estimates for $r / B, \beta, T^{\prime}$, and $S^{\prime}$. These results and the recommended values for PM-5 aquifer parameters are summarized in Table 8. It is also likely that the distancedrawdown analysis presented earlier accurately reflects an average $T$ and $S$ value for the productive zone yielding water between PM-4 and PM-2 just as well as any of the techniques presented above. In addition, the spinner log at PM-4 was used to estimate the best representation for aquifer thickness, $b$, near PM-4. However, the best estimate for $b$ near PM-5 was $490 \mathrm{ft}$, and came from a stratigraphic log interpretation.

At this point, we might be wondering why there are such dramatic differences between the analyses shown in Figures 24 and 26. It is obvious that there were similar differences between models of the confined aquifer and the leaky-confined aquifer at both PM-2 and PM-4; however, the magnitude of these earlier differences was much smaller than at PM-5. These larger differences can be attributed to complex changes in saturated aquifer thickness between wells PM-2, PM-4, and PM-5. In addition, the hydraulic conductivity also appears to be simultaneously increasing in the same direction.

According to the flow net relationship developed earlier, the $K$ value near well PM-5 should be about 0.71 times the $K$ value near well PM-2 (Table 6). However, the specific-capacity relationship suggested that the $K$ value near PM-5 should be about 1.36 times this same $K$ value (Table 7). Obviously, these comparisons are inconsistent. But which one? According to the recommended $K$ values obtained from Figure 24(d) above and from the distance-drawdown method seen in Figure 16, this ratio (see Table 9) is about 2.56. These results suggest that both the flow net and specific-capacity analyses are wrong. However, the specific-capacity analysis at least predicts that the $K$ value near PM-5 is larger than the $K$ value near PM-2. The Hantush wedge-shaped analysis is also likely to be more reliable than the specific-capacity analysis 
because it is based on the aquifer test data. Furthermore, the flow net analysis contains more subjectivity associated with contouring piezometric heads. Finally, the $K$ ratios obtained from the various Theis methods shown in Figure 24 vary between 3.06 and 3.86, and average about 3.47. These different ratios are summarized in Table 9 and are larger than the ratios mentioned above. However, these Theis methods also assume an effective aquifer thickness of $850 \mathrm{ft}$, whereas the Hantush wedge-shaped analysis uses an effective aquifer thickness of only $490 \mathrm{ft}$. The flow net analysis simply assumes a constant value for $b$. It was previously concluded that the Theis analytical methods used to obtain $K$ from the aquifer test results from well PM-5, although consistent with one another, are not as good as the $K$ value obtained with the wedge-shaped aquifer analysis. In addition, the flow net near well PM-5 may not be as reliable as that near wells PM-2 and PM-4. Ultimately, these conclusions are based on suspected aquifer thinning between wells PM-4 and PM-5. They may also be related to the suspected transition of leakyconfined aquifer behavior to phreatic aquifer behavior somewhere to the north of PM-5. One final point is worth mentioning. The specific capacity analysis shown in Table 7 suggests that the $K$ value near wells PM-3 and O-4 should be at least 2.5 times larger than the $K$ value near PM-2, and almost 2 times larger than that at PM-5. In other words, the aquifer appears to increase in productivity as we move north because $K$ values increase. This simple, but very practical, observation also calls into question the validity of the piezometric map between PM-5, PM-3, and $\mathrm{O}-4$.

\section{ANALYSIS OF R-20 AND R-32 DATA}

Drawdown and recovery were automatically recorded by the Westbay ${ }^{\mathrm{TM}}$ transducer systems in wells R-20 and R-32. These data were previously shown in Figure 13. Well R-20 is located approximately 1,225 ft east-southeast of well PM-2 along Pajarito Road, while R-32 is also located along Pajarito Road about 4,779 ft east-southeast of PM-2 (see Figure 3). A close examination of Figure 13 reveals important information that can help us understand various responses to PM-2 pumping at different horizontal and vertical positions within the regional aquifer.

First, it is clear that hydrostatic conditions within the regional aquifer in all R-20 screens [Figure 13(a)] and the lower two screens at well R-32 [Figure 13(b)] were established before the start of pumping at well PM-2. These static water levels were previously listed in Table 1. However, hydrostatic conditions were not established in screen 1 at R-32 before the PM-2 test started. Here, hydrostatic conditions are defined to mean that water levels within a given well screen are constant (except for minor barometric influences) before the start of pumping. This definition for hydrostatic does not require water levels in individual screens to be identical (i.e., the true definition for hydrostatic). Therefore, we see nearly constant water levels in individual screens and a downward vertical hydraulic gradient between individual screens in the same well. However, this gradient is larger at well R-20 than at R-32 because R-20 is closer to PM-2, and the lower two well screens in R-20 are deeper than all of the screens in R-32. These individual well elevations are listed in Table 10. These data, when combined with Table 1 data. are used to compute hydraulic gradients between well screens. We are assuming that the vertically downward gradients that existed at both R-20 and R-32 before the start of pumping at PM-2 actually developed in response to historical pumping at PM-2. Recall that PM-2 became operational in 1966. 
Table 10. Top of Screen Elevations in Selected Wells

\begin{tabular}{|c|c|c|c|c|c|}
\hline Well & Screen & $\begin{array}{c}\text { Surface } \\
\text { Elevation }\end{array}$ & $\begin{array}{c}\text { See } \\
\text { Figure }\end{array}$ & $\begin{array}{c}\text { Depth of } \\
\text { Screen Top }\end{array}$ & $\begin{array}{l}\text { Elevation of } \\
\text { Screen Top }\end{array}$ \\
\hline PM-2 & 1 & 6715.0 & 6 & 1004.0 & 5711.0 \\
\hline PM-4 & 1 & 6920.0 & 5 & 1260.0 & 5660.0 \\
\hline PM-5 & 1 & 7095.0 & 4 & 1440.0 & 5655.0 \\
\hline $\mathrm{R}-20$ & 1 & 6694.3 & 7 & 904.6 & 5789.7 \\
\hline R-20 & 2 & 6694.3 & 7 & 1147.1 & 5547.2 \\
\hline R-20 & 3 & 6694.3 & 7 & 1328.8 & 5365.5 \\
\hline $\mathrm{R}-32$ & 1 & 6650.5 & 8 & 867.5 & 5783.0 \\
\hline $\mathrm{R}-32$ & 2 & 6650.5 & 8 & 931.8 & 5718.7 \\
\hline $\mathrm{R}-32$ & 3 & 6650.5 & 8 & 972.9 & 5677.6 \\
\hline PM-4 & 1 & 6920.0 & 5 & $1100.0^{c}$ & $5820.0^{c}$ \\
\hline PM-4 & 1 & 6920.0 & 5 & $1950.0^{\mathrm{d}}$ & $4970.0^{\mathrm{d}}$ \\
\hline
\end{tabular}

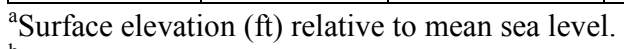

${ }^{\mathrm{b}}$ Depth (ft) below ground surface.

${ }^{\mathrm{c}}$ Bottom of Cerros del Rio basalt; top of high- $K$ zone (ft).

${ }^{\mathrm{d}}$ Top of first Miocene basalt; bottom of high- $K$ zone $(\mathrm{ft})$.

Second, before pumping at well PM-2, the vertical hydraulic gradient at well R-20 between screens 2 and 3 was +0.111 [i.e., using the data in Tables 1 and 10, we obtain (5844.6$5864.8) /(5365.5-5547.2)=+0.111$, where the positive sign indicates that our assumed order of operation of screen 3 minus screen 2 values correctly reflects a downward flow direction], whereas the gradient between screens 1 and 2 was only +0.017 [i.e., $(5864.8-5869.0) /(5547.2-$ $5789.7)=+0.017$, where the positive sign again reflects a downward flow direction]. In other words, vertical hydraulic gradients at well R-20 increase with increasing depth because individual screen elevations are getting deeper below the top elevation of the high-yielding water zone in the regional aquifer (i.e., below the $5820.0 \mathrm{ft}$ elevation level in Table 10 and Figure 15). These gradients increase with depth because the horizontal hydraulic conductivity increases with depth (and thus the horizontal flow toward PM-2 increases), while the vertical hydraulic conductivity apparently remains relatively constant between screens (McLin 2005a). These gradients were measured after about 90 days of no pumping at wells PM-2, PM-4, or PM-5. Hence, they reflect hydrostatic conditions. But these gradients are still influenced by historical PM-2 pumping. In contrast, before pumping at PM-2, the vertical hydraulic gradient between screens 2 and 3 at well R-32 was +0.051 [i.e., $(5849.9-5852.0) /(5677.6-5718.7)=+0.051$ and is again downward]. This value at R-32 closely resembles the upper hydraulic gradient at R-20 (i.e., 0.017) because the respective screen depths are similar. It is likely that vertical hydraulic gradients at R-32 also increase with increasing depth, as at R-20, and for similar reasons.

Once pumping did start at well PM-2, the vertical hydraulic gradients between screens at wells R-20 and R-32 changed because water levels in individual screens responded differently to pumping. For example, the vertical hydraulic gradient between screens 2 and 3 at R-20 increased more than between screens 1 and 2 at R-20 because water near screen 3 is moving almost horizontally toward PM-2. Most of the gradient increase between screens 2 and 3 resulted from the bigger water-level drop in screen 3. Hence, some water near screens 1 and 2 is slowly moving vertically downward because the regional aquifer behaves like a leaky-confined aquifer 
here. This happens because screens 1 and 2 at R-20 are located within the leaky unit. However, screen 3 is located in the upper portion of the high-yielding aquifer. It is also important to recognize that the small vertical hydraulic gradient between screens 2 and 3 at R-20 causes a small vertical flow component near screen 3 . Recall that the screen 3 drawdown data plot below the straight line fit between the PM-2, PM-4, and PM-5 data shown in Figure 16. This low plotting position also shows that there is still a small vertical flow component at screen 3 . However, this vertical component is sufficiently small so that horizontal flow dominates. Hence, as seen below, the $T$ value for screen 3 from the Theis analysis is similar to that from the distance-drawdown method.

If we look at the vertical hydraulic gradients at R-32 that are implied in Figure 13, we notice that they were continually declining between screens 1 and 2 because there was a downward trend in water levels at screen 1. This trend was unrelated to pumpage at well PM-2. However, the vertical hydraulic gradient between screens 2 and 3 remained relatively constant throughout the entire aquifer test. Screens 2 and 3 at well R-32 are also located within the leaky unit. We conclude that a small vertically downward flow component was active here and replaces deeper water that was moving toward PM-2. In other words, had a fourth screen been located below screen 3 in R-32, drawdown behavior similar to that in screen 3 at R-20 probably would have resulted. Again, this vertical flow component at screen 3 in R-32 is also reflected by the low plotting position of the screen 3 drawdown data in Figure 16. In addition, the water-level response at screen 1 in R-32 appears to be unaffected by pumping at PM-2. This conclusion is supported by the observation of a clear downward water-level trend in screen 1 at R-32 before, during, and after pumping operations in PM-2. A close inspection of the well completion diagrams for these wells (see Figures 8 and 9) reveals why screen 1 is hydraulically isolated from $\mathrm{PM}-2$. This screen is actually completed in a 7-ft-thick layer of river gravels that is sandwiched between two massive basalt layers. We conclude that these basalt layers are acting as confining units above and below the river gravels and restrict hydraulic communication with units within the regional aquifer that yield significant quantities of water to PM-2. Additional supporting data are presented later that conclusively demonstrate that screen 1 at R-32 is hydraulically connected to another unknown production well on Pajarito Plateau. However, it is also clearly isolated from PM-2 as seen in Figure 13.

The third and final point about Figure 13 is that screen 3 at well R-20 clearly responds to pumping at well PM-2. By comparison, all of the other responses in the remaining screens at wells R-20 and R-32 are greatly subdued. More will be said about this later. For the time being, we will accept the fact that only water-level data from screen 3 at R-20 can be analyzed by conventional pumping test methods. This limitation is imposed because we essentially have horizontal flow at screen 3 and toward PM-2. However, the remaining screens in both R-20 and R-32 have enough vertical flow so that the horizontal flow assumption must be called into question. This conclusion is also supported by the unrealistically high $T$ values that result when we analyze data from these screens. These unrealistically high $T$ values are also contradicted by independent test results (McLin and Stone 2004b; McLin 2005a). Hence, alternative methods must be used with these data to estimate $T$ and $S$ values. This is not to imply that the other data at the remaining screens are not useful. In fact, these data are preserved in the CD-ROM at the end of this report (see Appendix first) in the hope that alternative methods will eventually be applied. The alternative methods might include numerical simulations of the aquifer test using a modified version of the Laboratory's groundwater flow model. 
As mentioned above, well R-20 is approximately 1,225 ft from well PM-2 (see Figure 3). Analyses of the R20-3 (i.e., screen 3 at well R-20) data are shown in Figure 27 using the idealized aquifer configuration previously shown in Figure 15 and aquifer dimensions shown in Table 4. Hence, Theis analyses of drawdown data are shown in Figure 27(a), and recovery data are shown in Figure 27(b). Figure 27(c) shows an analysis using the Theis residual recovery method. Except for the $S$ values, all of these results closely resemble earlier analyses at other wells. Again, if we assume that the distance-drawdown analysis presented in Figure 16 represents the actual values for $T$ and $S$, then the relative errors in each of these $T$ analyses are $1.8 \%, 2.3 \%$, and $9.7 \%$, respectively. The relative errors in the parameter $S$ are $426 \%$ and $420 \%$, respectively, for the Theis pumping and the Theis simple recovery analyses. Again, the Theis residual recovery method does not yield an $S$ value. These margins of error for $T$ would probably be considered minor by most hydrologists; however, the differences in $S$ are significant. In other words, the relative errors in $S$ from the R-20 data are much larger (i.e., 400\%-500\%) than previously seen at wells PM-4 and PM-5. It seems that the data from longer screened observation wells (i.e., PM-4 and PM-5) yield $S$ values that are comparable to the distance-drawdown method, whereas those from R20-3 yield $S$ values that are an order-of-magnitude higher. This does not imply that these higher $S$ values are in error. Instead, they reflect a transition of confined to partially confined behavior that was first observed in the upper regions of the highyielding regional aquifer. We would expect that such a transition would begin in the upper high transmissivity zone where the R20-3 screen is located and then propagate vertically downward and radially outward where the fully penetrating screens of PM-4 and PM-5 are located. In other words, if we had a fourth screen at R-20 located near the base of the high-yielding water zone (i.e., near the 4,970-ft elevation level), then we would have probably seen this same transition in $S$ values but at a later time. Hence, had the pumping duration at PM-2 been longer, we might have eventually seen higher $S$ values at PM-4 and PM-5, too. Our aquifer test appears to have captured the transition from confined to leaky-confined behavior as reflected by the transition in $S$ values from about 0.00032 to about 0.00180 . Similar transitions are typically seen in early-time drawdown behavior in phreatic aquifers but are rarely observed in leaky-confined aquifers at late time.

Again, in each of these analyses, the Theis type-curve is fitted through the early-time data (i.e., before about 4 days). It is obvious that after this time, observed drawdown effects are falling below that predicted by the Theis model. The water-level responses in R20-3 are also starting to sense the presence of the recharge boundary noted earlier. In addition, in Figure $27(\mathrm{c})$ this departure occurs at a dimensionless time of about $t / t^{\prime}=7$, and corresponds to about $t=4$ days. These times are remarkably close to those previously reported at wells PM-2 and PM-4 and are significant. These similarities in time reveal when boundary effects first start to appear. They are significant because they confirm our interpretation that recharge effects result from leaky-aquifer behavior. Hence, all water produced at PM-2 ultimately derives from vertically downward leakage originating in lower permeable units that are located within the regional aquifer and above the high-yielding unit. The ultimate source of water for PM-2 is from the uppermost saturated units within the regional aquifer. Furthermore, this area of capture is approximated by the idealized 8,808- $\mathrm{ft}$ radius shown in Figure 3. We say this radius is idealized because the simple circular area shown in Figure 3 neglects the influence of horizontal and vertical anisotropy known to be present. In addition, this idealized area of capture would be further distorted by routine operation of wells PM-4 and PM-5 for municipal water production. 

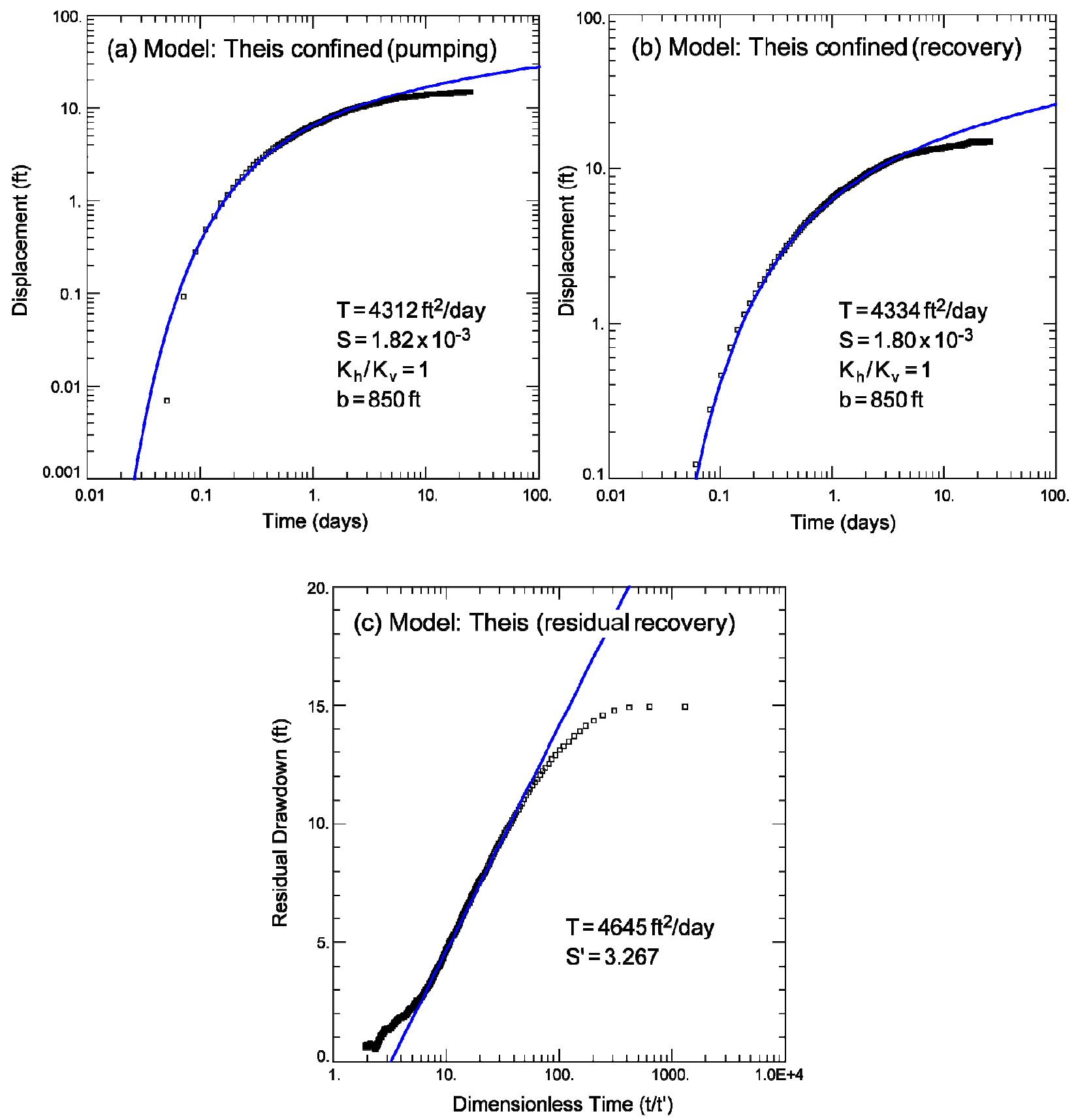

Figure 27. Theis confined-aquifer analysis using R20-3 data from (a) drawdown, (b) recovery, and (c) residual recovery.

Recall that the Theis residual recovery method assumes that $u \leq 0.05$, where $u=r^{2} S / 4 T t$. Using the values of $T$ and $S$ from the distance-drawdown analysis, along with $r=1,225 \mathrm{ft}$ and $t=4$ days, we find that $u=0.008$. In other words, unlike the applications at wells PM-4 and PM-5, this technique is theoretically just as accurate as both the Theis pumping and the Theis recovery methods presented in Figure 27(a,b). In addition, the effects of partial penetration are automatically taken into consideration in the analyses. 
Finally, Figure 28 shows a leaky-aquifer analysis using drawdown data with the Hantush-Jacob, Neuman-Witherspoon, and Moench methods. Again, as with the PM-2, PM-4, and PM-5 data, the curve-matching process revealed the possibility of multiple matches and similar variability in aquifer parameters. The process previously described was therefore used again. Thus, $T$ was set at $4,235 \mathrm{ft}^{2} /$ day, and all of the leaky-aquifer analyses produced excellent curve matches and yielded similar aquifer parameters. These results are shown in Figure 28 and Table 8.
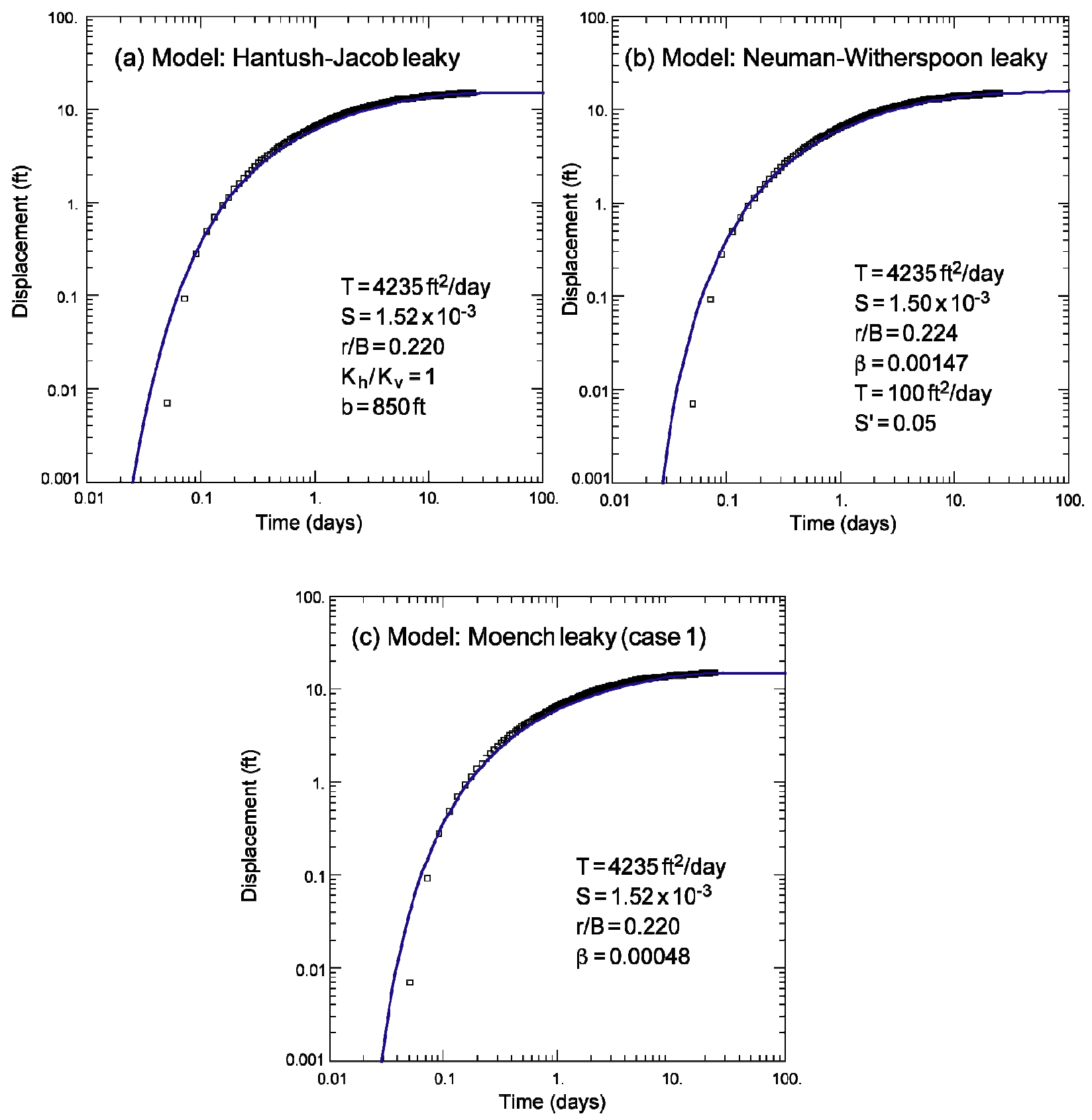

Figure 28. Leaky-aquifer analysis using R20-3 drawdown data for the (a) Hantush-Jacob, (b) Neuman-Witherspoon, and (c) Moench models. 
In addition, larger estimates for $S$ are about the same with the leaky-aquifer analyses as with the Theis analyses presented earlier. Actually, the overall observed shift for $S$ from about 0.00032 to about 0.00180 is exactly what would be expected as the aquifer near R20-3 starts its transition from truly confined to leaky-confined behavior. This transition apparently started after about 4 days. Hence, the different analyses represented by Figures 27 and 28 actually support the hypothesis that the aquifer behaves like a leaky-confined aquifer. The second advantage of these leaky aquifer models is that they also provide us with dimensionless leakage estimates. Hence, we obtain $r / B$ values of $0.220,0.224$, and 0.220 , respectively, for the various methods. Thus, all of these techniques report similar dimensionless leakage estimates. The corresponding estimates for $B$ are remarkably similar once the influence of distance $(r)$ is removed. On first thought, it may seem that the Neuman-Witherspoon technique is best because it also provides reasonable estimates for $T^{\prime}$ and $S^{\prime}$ that represent the leaky source aquifer. However, as before, these parameters are not well constrained and actually may vary by several orders of magnitude. The Hantush-Jacob method of leaky-aquifer analysis probably is better than the other two because it is much simpler to use. In addition, this method seems to yield comparable results for all parameters. This observation has been noted before by numerous authors despite the insistence by some that more complex methods of analyses are preferable.

Again, as at wells PM-4 and PM-5, it is interesting to note that the leaky-aquifer method of analysis significantly affects predicted aquifer parameters (i.e., compare Figures 27 and 28). These changes were computed using the Hantush-Jacob method along with the drawdown data at R20-3. These results and recommended values for R20-3 aquifer parameters are summarized in Table 8.

Discussion. The static water level obtained in well R20-3 before the start of the aquifer test was reestablished during the recovery period. Also, since well R20-3 was used as an observation well, no casing storage effects were computed because these effects primarily affect pumping wells. In addition, well R20-3 is considered to be partially penetrating according to the geologic information presented earlier. Recall that the saturated thickness of the high-yielding water zone was $850 \mathrm{ft}$ according to the dynamic spinner log at PM-4. Again, the thickness of this unit may be highly variable between wells as seen in Figure 4. As a direct consequence of this implied variability, we should anticipate that test results are also subject to significant variability. All analytical models assume horizontal flow toward the pumping well. Departures from this assumption may occur because both $b$ and $K_{h} / K_{v}$ change in unpredictable ways. Using vertical hydraulic gradients between screens in the same well, we have established the likelihood of small but significant vertical flow components to groundwater movement between screens 1 and 2 at well R-20 and between screens 2 and 3 at well R-32. Hence, these data were not analyzed by conventional pumping techniques because of the requirement for essentially horizontal flow was violated. If these data had been analyzed, then much larger values for $T$ would have been obtained than corresponding values from the distance-drawdown analysis. However, previous straddle-packer injection tests at these same screens have already shown that these $T$ values are significantly lower than predicted by the distance-drawdown method (McLin and Stone 2004b; McLin 2005a). Hence, the conclusion of small but significant vertical flow components to groundwater movement at these locations is also supported by additional test data. In other words, these screens are in the leaky-confined unit as previously described. 
This report also characterizes some of the variability in aquifer parameter values according to results from multiple techniques using both drawdown and recovery data. In addition, when $K_{h} / K_{v}$ is allowed to vary in both the Theis and Hantush-Jacob techniques, the effects on aquifer parameters are about the same as at well PM-2. Ultimately, however, we must accept that these analytical models have limitations and recognize that the analyses are only approximate.

Which analytical method gives the most representative hydraulic properties for the formation opposite screen 3 in well R-20? First of all, the distance-drawdown analysis presented earlier accurately reflects an average $T$ and $S$ value for the productive zone yielding water to well PM-2 probably better than any of the techniques presented above. In addition, the spinner log at well PM-4 was used to estimate our best representation for aquifer thickness, $b$. A close examination of Figure 27 shows that the Theis analyses of this confined-aquifer method essentially reproduces the distance-drawdown method reasonably well. However, the variability in $T$ is more pronounced at R20-3 than at wells PM-2, PM-4, or PM-5. The $S$ values are also significantly larger at R20-3 than at any of the other observation wells. Finally, the leaky-aquifer analyses yield important estimates for $T, S, r / B, \beta, T^{\prime}$, and $S^{\prime}$. These results and recommended values for R20-3 aquifer parameters are summarized in Table 8.

\section{MULTIPLE WELL ANALYSES}

Except for the distance-drawdown analysis presented earlier, all of the preceding results are from the analyses of drawdown and/or recovery data from single pumping wells or observation wells. These analyses use a variety of confined-aquifer and leaky-confined aquifer methods. We can also repeat these same procedures using multiple well analyses. Figure 29 shows these analyses using drawdown data from wells PM-2, PM-4, and PM-5 for (a) Theis confined-aquifer; (b) Hantush-Jacob leaky-aquifer; (c) Moench leaky-aquifer; and (d) Neuman-Witherspoon leakyaquifer conditions. In these multiple-well analyses, three different drawdown histories are simultaneously matched. The Theis matches are through the early-time data, whereas the leaky matches use all of the data for their respective matches.

Again, these multiple-well analyses were completed using the idealized aquifer configuration previously shown in Figure 15 and aquifer dimensions shown in Table 4. All of these multiplewell analyses yield remarkably consistent estimates for $T$ and $S$ values. We should also remember that different curve matches would yield some variability in these estimates; however, these differences are no larger than previously suggested for individual well estimates. These results are also summarized in Table 8.

Discussion. Which analytical method gives the most representative hydraulic properties for the formation opposite the screens in the multiple well analyses? Again, the distance-drawdown analysis presented earlier accurately reflects an average $T$ and $S$ value for the productive zone yielding water to well PM-2 probably better than any of the techniques presented above. In addition, the spinner log at well PM-4 was used to estimate the best representation for aquifer thickness, $b$. A close examination of Figure 29 shows that the Theis analyses of this confinedaquifer method essentially reproduces the distance-drawdown method reasonably well. However, the leaky-aquifer analyses yield important estimates for $T, S, r / B, \beta, T^{\prime}$, and $S^{\prime}$. These results and our recommended values for aquifer parameters are summarized in Table 8. 

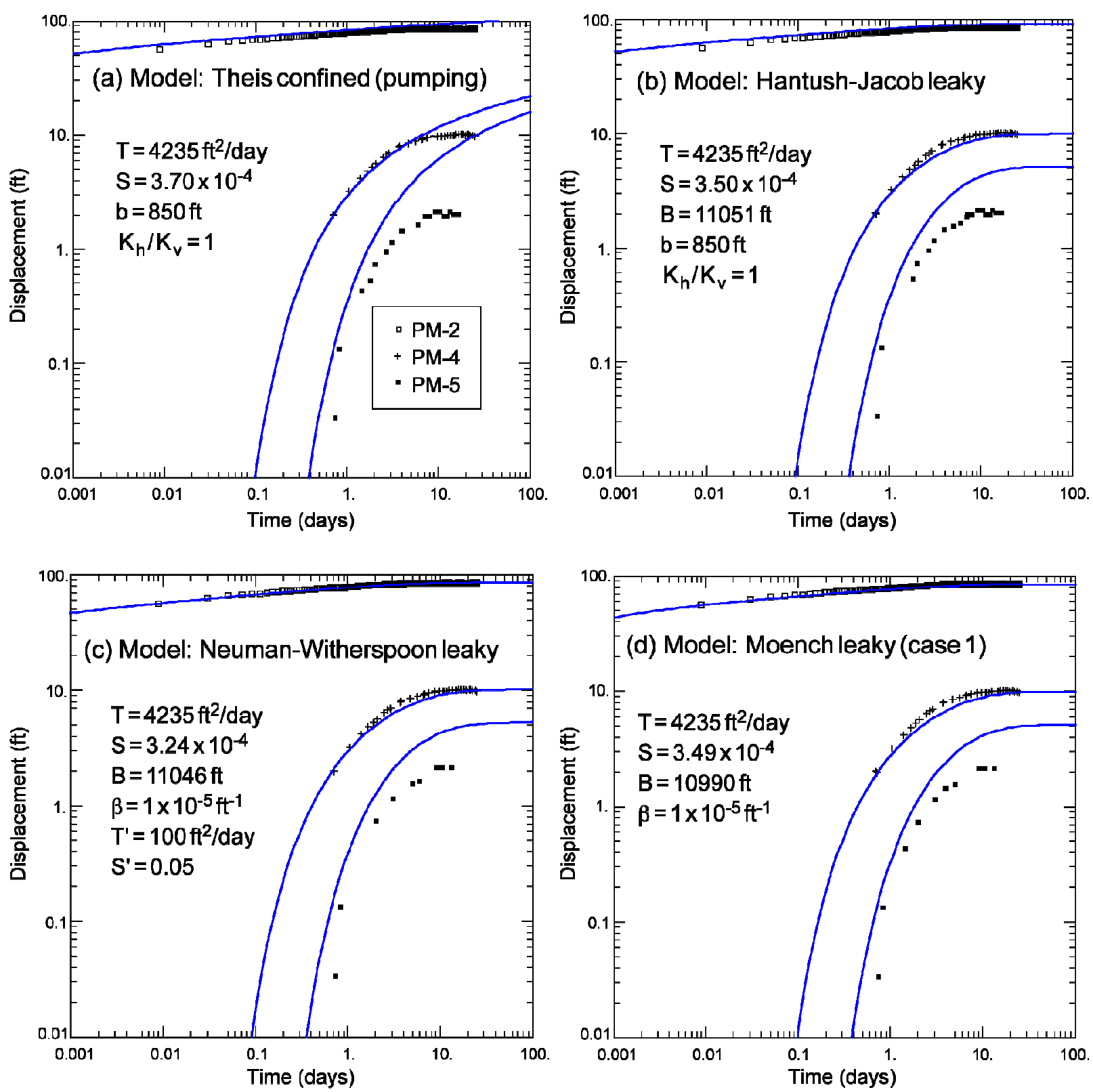

Figure 29. Multiple-well analyses using PM-2, PM-4, and PM-5 drawdown data for (a) Theis confined-aquifer, (b) Hantush-Jacob leaky-aquifer, (c) Neuman-Witherspoon leakyaquifer analyses, and (d) Moench leaky-aquifer (case 1).

\section{SUMMARY AND CONCLUSIONS}

Figure 30(a, b) shows water-level fluctuations in wells R-20 and R-32, respectively, from March 26, 2003, to March 5, 2004 (i.e., in the year following the PM-2 aquifer test). Figure 30(c) shows water levels in well R-22 from November 5, 2002, to November 17, 2003. It is clear from Figure 30 (a) that R-20 water levels are continuing to respond to normal cycles of PM-2 production pumping throughout the year following the PM-2 aquifer test. Not surprisingly, the water levels in screen 3 show a strong, high-frequency oscillation (daily) in response to this cyclical pumping (also daily). This oscillation develops because screen 3 water levels drop in response to PM-2 
pumping and recover when the pump cycles off. The responses at screens 1 and 2 are much less dramatic than at screen 3 because of anisotropy in the hydraulic conductivity ratio $\left(K_{h} / K_{v}\right)$. Hence, the amplitude of these water-level fluctuations is greatly dampened as we move upward from screen 3. Thus, the magnitude of these responses decreases with decreasing depth as previously noted during the PM-2 test analyses. This response pattern, while not unexpected, is quite striking because it has never been observed on Pajarito Plateau before. It is significant because it documents anisotropy in the $K_{h} / K_{v}$ ratio for the first time.

Figure 31 shows the combined monthly water production pattern during 2003 for all wells in Los Alamos County. With some minor variations, this seasonal pattern is fairly typical of the water supply system (e.g., Purtymun and Stoker 1988; McLin et al. 1998; Koch and Rogers 2003). During 2003, average monthly production was lowest during January at about 91 million gallons (or about 2.9 million gallons per day [mgpd]). Monthly production slowly increased to about 223 million gallons by July (or about $7.2 \mathrm{mgpd}$ ) before it slowly tapered down to about 140 million gallons in September (or about $4.7 \mathrm{mgpd}$ ). From mid-September through the end of the year, monthly production steadily declined to about 83 million gallons (or about $2.7 \mathrm{mgpd}$ ). A similar but inverted seasonal pattern is clearly evident in the 2003-04 water level responses from screens 2 and 3 in well R-20, as implied in Figure 30(a) (i.e., when the 30-minute data from screen 3 are smoothed to daily, weekly, or even monthly averages). This pattern is inverted because average water level trends slowly drop in response to slowly increasing average daily pumping volumes during the spring and summer, and slowly rise as these average daily production volumes begin to drop in the fall and winter.

This same inverted pattern is readily apparent in the water levels from screen 2 without any smoothing because the daily cycle of pumping at well PM-2 is dampened out by anisotropy. Hence, the porous media near screen 2 behave like low-pass filters because they smooth out high-frequency water level oscillations. By the time we reach screen 1, this pumping pattern is almost completely obliterated, so a declining water-level trend dominates the monthly pattern. If water-level records had not been available from the two deeper screens, we probably would have concluded that screen 1 is not in direct hydraulic communication with PM-2. But the responses in screens 2 and 3 clearly tell us otherwise. We conclude that the declining trend in screen 1 water levels is directly linked to the patterns in screens 2 and 3, and ultimately to the monthly production pattern at PM-2. In effect, the seasonal pumping pattern at screen 1 has been dampened and time-delayed; hence, the vertical hydraulic communication to the deeper subsurface is thinly veiled. This is a very significant observation that should not be minimized. This simple observation is the primary evidence that points us toward a conventional leakyaquifer response in lieu of a sandwiched, high-low $K$ interpretation that is detailed later.

But the important point to stress is that multiple-level screens are essential if the true hydraulic behavior of the regional aquifer system is to be understood. In fact, we would have likely reached the incorrect conclusion without these data. Finally, it would have been enlightening if more than three screens had been installed in well R-20, especially if they were located even deeper in the regional aquifer. Water-level observations from these vertically arrayed screens, when used in conjunction with dynamic spinner logs and aquifer tests, can help us understand vertical communication between alternating layers of high and low $K$ values better than just about any other technique available. The implications for adequate water-quality monitoring seem obvious. 


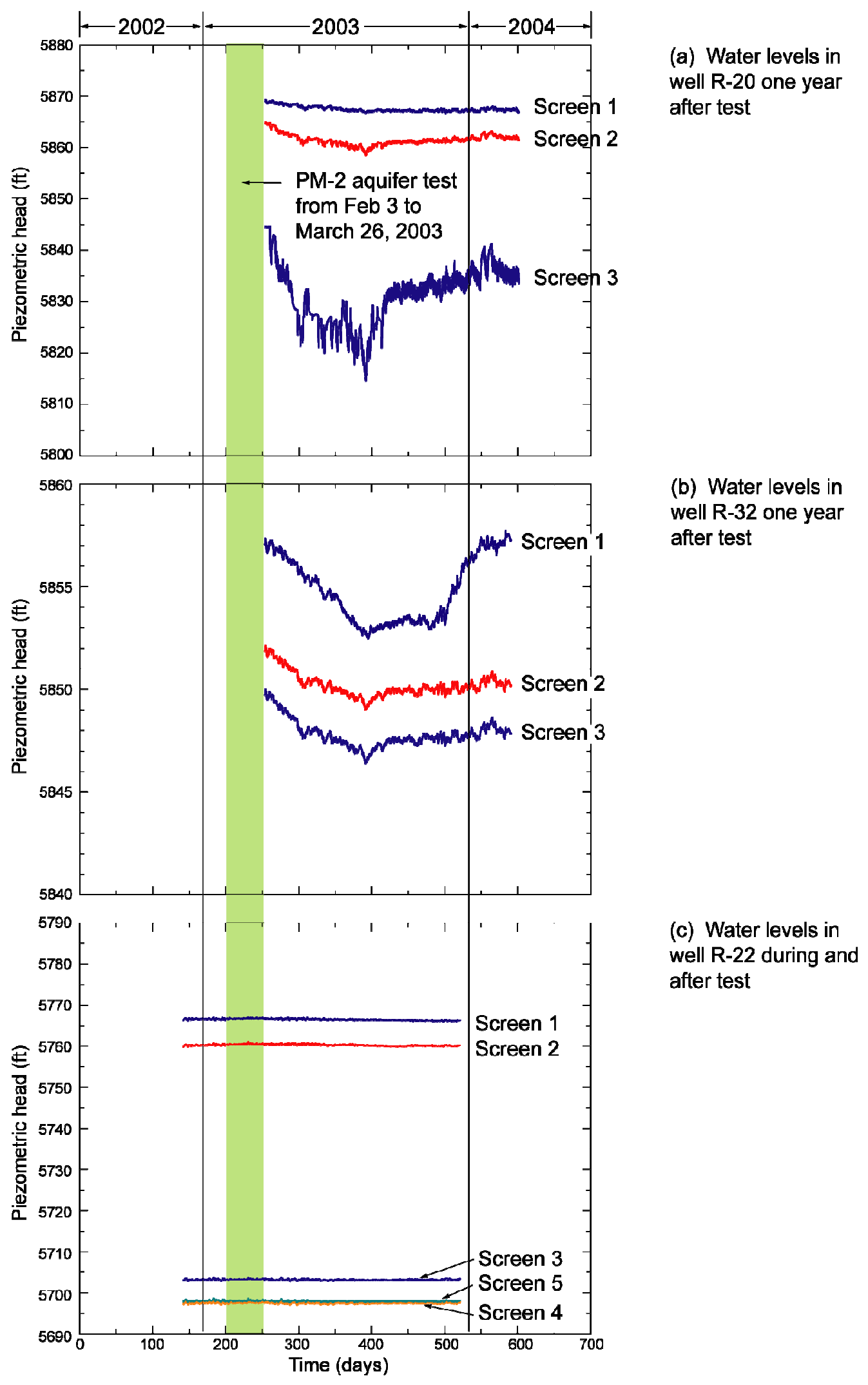

Figure 30. Drawdown at wells (a) R-20, (b) R-32, and (c) R-22 following the aquifer test at well PM-2. 


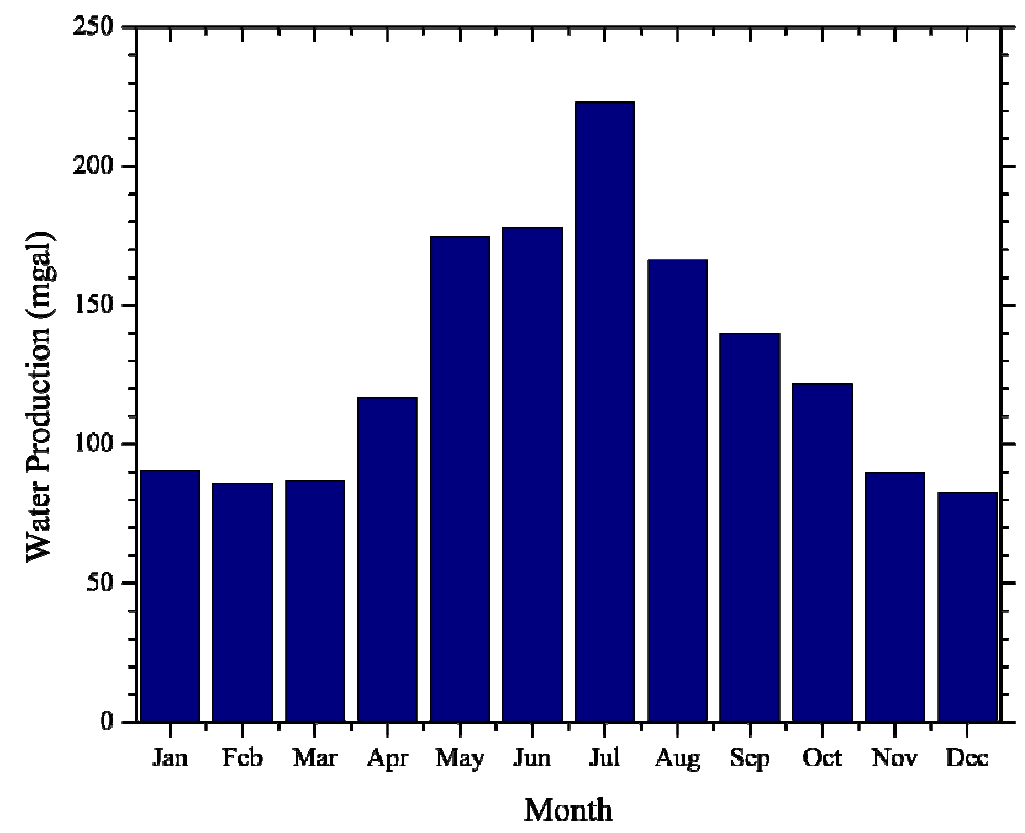

Figure 31. Monthly water production for Los Alamos County during 2003.

As seen in Figure 30(b), water levels in screens 2 and 3 at well R-32 also follow similar patterns to those in well R-20 for the year following the aquifer test. We had previously noted this behavior during the analyses so there are no surprises here. But look closely at the water-level pattern in screen 1 at R-32. It seems to follow a pattern similar to that in screen 2 at R-20. In fact, our attention is drawn to this similarity because the total magnitude of the decline in screen 1 is nearly the same as in screen 2 . The water levels in screen 1 appear to be responding to pumping at well PM-2. But how can this be true? The test analyses clearly demonstrated that these water levels do not respond to PM-2 pumping. In addition, even if the water levels in screen 1 at R-32 did respond to PM-2 pumping, why are the declines nearly the same as in screen 2 at R-20? We expect them to be much smaller because R-32 is so much farther from PM-2 than is R-20. Regardless, the water-level fluctuations in screen 1 at R-32 are clearly following a similar but inverted pattern to the total monthly water production record shown in Figure 31 . We are forced to conclude that water levels in screen 1 must be in hydraulic communication with some other unknown supply well on Pajarito Plateau.

The conclusion above is based on several important observations that are summarized in Table 11. First, the maximum PM-2 induced drawdown in screen 1 at R-32 should be much smaller than in screen 2 at well R-20 because it is located nearly four times farther from well PM- 2 . However, according to data in Table 11, these drawdown values are very similar in magnitude. Second, we also expect to see much less drawdown in screen 1 at R-32 because it is completed in river gravels that are sandwiched between Cerros del Rio basalts (see Figure 9). Hence, we expect that the lower basalt will hydraulically isolate the gravels from the deeper subsurface, whereas the upper basalt will hydraulically isolate the gravels from surface recharge. Third, the observed water-level pattern in screen 1 at R-32 is an inverted pattern of the average monthly water production pattern in all wells, as previously noted. Fourth, the expected pattern of potential canyon-bottom recharge near R-32 does not correlate with the observed water-level pattern in screen 1 at R-32. 
Table 11. Maximum Water-Level Changes in Selected Observation Wells

\begin{tabular}{|l|c|l|c|l|}
\hline Well & $\begin{array}{c}\text { Water-Level Change } \\
\text { during Aquifer Test (ft) }\end{array}$ & \multicolumn{1}{|c|}{ Remarks } & $\begin{array}{c}\text { Water-Level Change } \\
\text { after Aquifer Test (ft) }\end{array}$ & \multicolumn{1}{|c|}{ Remarks } \\
\hline R20-1 & 1.53 & PM-2 connection & 2.61 & PM-2 connection \\
\hline R20-2 & 3.62 & PM-2 connection & 6.39 & PM-2 connection \\
\hline R20-3 & 14.75 & PM-2 connection & 30.01 & PM-2 connection \\
\hline R32-1 & 2.16 & No PM-2 connection & 5.25 & $\begin{array}{l}\text { Clear pumping } \\
\text { influence }\end{array}$ \\
\hline R32-2 & 1.62 & PM-2 connection & 3.12 & PM-2 connection \\
\hline R32-3 & 1.84 & PM-2 connection & 3.60 & PM-2 connection \\
\hline
\end{tabular}

Note: The aquifer test interval was February 3 to March 26, 2003; the observation period following the test was March 26, 2003, to March 5, 2004.

Canyon-bottom infiltration to the deeper subsurface should be highest in March and April (snowmelt runoff) and in July and August (rainfall runoff). However, the observed water-level pattern in screen 1 at well R-32 is exactly the reverse of this expected behavior. Also, for the record, 2003 was a dry precipitation year, and no snowmelt or rainfall runoff actually accumulated in the alluvium near R-32. Hence, canyon-bottom recharge near R-32 may have been temporally halted due to the drought. We conclude that screen 1 observed water-level responses are not associated with surface infiltration that originated in the area surrounding R-32. In addition, screens 2 and 3 at R-32 are in hydraulic communication with well PM-2, whereas screen 1 is hydraulically connected to a different (but unknown) water supply well. Had these data been recorded without the benefit of the aquifer test at PM-2 or if 2003 had been a very wet precipitation year, we would have likely concluded that either the water levels in screen 1 at R32 were in hydraulic communication with PM-2 or there was significant canyon-bottom recharge to the regional aquifer. These incorrect conclusions would also imply that the Cerros del Rio basalts near R-32 screen 1 are vertically fractured and exhibit high vertical hydraulic conductivity when in fact they probably do not (see McLin and Stone 2004a and 2004b). Again, this second example points out the value of combining short-term aquifer tests with long-term water-level monitoring data. It also provides another illustration of how complex the regional aquifer really is.

The above example raises an obvious question. Exactly which production well is affecting water levels in screen 1 at well R-32? If we look at Figure 3, we might speculate that this screen could be communicating with any PM well, including PM-1, PM-3, PM-4, or PM-5. Other candidate supply wells might also include those in the Buckman well field operated for Santa Fe County. In fact, Vesselinov and Keating (2002) have suggested that in the future the Buckman well field will eventually extend its hydraulic influence under the Rio Grande and onto Pajarito Plateau. A logical approach to finding our unknown culprit is to list all candidate wells in order of increasing distance from R-32. These data are summarized in Table 12. We can immediately rule out well PM-2 because of our aquifer test results presented earlier. We conclude that PM-4, PM3, PM-1, and possibly PM-5 might be causing the water-level fluctuations in screen 1 at R-32. Again, these candidate wells are listed in order of increasing distance from R-32. The remaining wells listed in Table 12 are unlikely suspects because they are simply too far from R32 to have much influence on drawdown behavior. 
Table 12. Distance of Various Water Supply Wells from Well R-32

\begin{tabular}{|c|c|c|l|}
\hline Well & Distance (ft) & Distance (miles) & \multicolumn{1}{|c|}{ Remarks } \\
\hline PM-2 & 4779 & 0.91 & No affect on screen 1 \\
\hline PM-4 & 7750 & 1.47 & Limited operation in 2003 \\
\hline PM-3 & 11250 & 2.13 & Operational in 2003 \\
\hline PM-1 & 12000 & 2.27 & Operational in 2003 \\
\hline PM-5 & 13750 & 2.60 & Operational in 2003 \\
\hline Otowi-4 & 15250 & 2.89 & Operational in 2003 \\
\hline Otowi-1 & 16750 & 3.17 & Nonoperational in 2003 \\
\hline Buckman well field & $>26000$ & $>4.92$ & Operational in 2003 \\
\hline
\end{tabular}

Finally, the water-level fluctuations in five different screens at well R-22 were shown in Figure 30(c). These water levels do not respond to any pumping influence from any production well, including the Buckman well field located on the east side of the Rio Grande. This is also a significant observation because it constrains the suspect well list shown in Table 12. Furthermore, it does not imply that future water level observations from R-22 are of no value as some have suggested. In fact, these water-level observations are valuable because they document a lack of pumping or recharge influence in this vicinity (i.e., vertically downward through the Cerros del Rio basalts, within the eastern extent of the Puye fanglomerate, or in the older fanglomerates). It is also instructive to review Figure 2, noting the relative positions of various wells with respect to subsurface geology. This cross-section suggests that the primary wateryielding units at well PM-2 are the older fanglomerates and not the Puye fanglomerates as previously thought. In addition, Figure 2 also suggests that drawdown effects from the Buckman well field have already reached well R-16 but will not propagate past the Miocene basalts near PM-2. In other words, Figure 2 explains why we see vertically downward hydraulic gradients at well R-16 (McLin 2005c) when they should be vertically upward toward the Rio Grande.

The implications of these observations are somewhat overwhelming. First, the test procedure used here is significant because it revealed that a combination of aquifer tests and routine waterlevel observations can greatly assist us in understanding the regional aquifer. This understanding is essential if we are trying to locate an optimal groundwater monitoring system for the plateau. Second, the test procedure revealed that well PM-2 is affecting the water levels in the lower two screens at well R-32, but that a different supply well is affecting the upper screen. These observations were greatly assisted by routine water-level monitoring in multiple-screened observation wells. Finally, this aquifer test has revealed for the first time important and reliable aquifer-transmitting characteristics, including anisotropy effects, in the central plateau area.

\section{Conclusions}

The following general conclusions for the PM-2 aquifer test can be summarized.

1. All of the confined and leaky-confined aquifer techniques yielded consistent estimates for aquifer transmissivity $(T)$ and storage coefficient $(S)$. However, the distancedrawdown method provided the best overall estimates for $T$ and $S$ for the regional aquifer between wells PM-4, PM-2, and R-20, screen 3 (R20-3). Drawdown data used in 
this analysis were presented in Table 5, while the results were presented in Figure 16. This analysis says that $T=4,258 \mathrm{ft}^{2} /$ day and $S=0.00032$. Based on an effective aquifer thickness $(b)$ of $850 \mathrm{ft}$, the corresponding values for hydraulic conductivity $(K)$ and specific storage $\left(S_{S}\right)$ are $5.0 \mathrm{ft} /$ day and $3.76 \times 10^{-7} / \mathrm{ft}$, respectively.

2. The effective aquifer thickness between wells PM-4, PM-2, and R20-3 was obtained from drill logs and a dynamic spinner log at PM-4. This spinner log showed that $93 \%$ of the production capability at PM-4 is obtained from geologic materials located between the bottom of the Cerros del Rio basalt (at about 1,100 ft bgs), and the top of the first Miocene basalt (at about 1,950 ft bgs). As seen in Figure 6, these depths correspond to elevations of $5,820 \mathrm{ft}$ and $4,970 \mathrm{ft}$ above mean sea level, respectively. Hence $b=850 \mathrm{ft}$.

3. The Hantush wedge-shaped aquifer test results for well PM-5 account for effective aquifer thinning between wells PM-4 and PM-5 from about $850 \mathrm{ft}$ to about $490 \mathrm{ft}$. The corresponding $T=6,246 \mathrm{ft}^{2} /$ day and $S=0.00069$ values are more representative of the regional aquifer near PM-5 than those from the distance-drawdown analysis. Based on an effective $b$ of $490 \mathrm{ft}$, the corresponding values for $K$ and $S_{s}$ are $12.7 \mathrm{ft} /$ day and $1.41 \times$ $10^{-6} / \mathrm{ft}$, respectively.

4. The regional aquifer near well PM-2 behaves like a leaky-confined aquifer with a leaky source bed located at the top of the regional aquifer. This conclusion is supported by observed drawdown obtained from wells PM-2, PM-4, PM-5, R-20, and R-32 during the 25-day aquifer test at PM-2. Hence, when field time-drawdown plots are compared against a theoretical Theis type-curve, we see observed drawdown falling below the Theis curve after about 4 days in all wells. These plots are shown in Figures 18 (PM-2), 22 (PM-4), 24 (PM-5), and 27 (R20-3). This conceptual model for the regional aquifer says that a leaky source bed is located above the high-yielding unit but says nothing about recharge to this leaky source bed. Presumably, this recharge comes from two likely sources. These include (a) direct infiltration from alluvial systems in canyon bottoms in the western and central plateau area and (b) recharge to the regional aquifer system in the Sierra de los Valles area west of the Laboratory.

5. Vertically downward hydraulic gradients were documented at wells R-20 and R-32 even when nearby water supply wells had been off for three months. These data, when combined with the distance-drawdown analyses shown in Figure 16, document vertically downward flow from the regional water table toward a leaky-confined aquifer system that yields water to well PM-2. This observation reveals a complex aquifer response that must be considered when designing a regional monitoring network.

6. The effects of horizontal and vertical anisotropy in hydraulic conductivity values were apparent during the aquifer test. Horizontal anisotropy is revealed by an elliptically shaped cone of depression recorded at multiple observation wells. Figure 3 showed an idealized radius of influence extending 8,800 ft between wells PM-2 and PM-5. However, the distance-drawdown analysis in Figure 16 suggested that this radius of influence exceeded 10,000 ft. In all probability, these differences reflect an elliptically shaped cone of depression oriented approximately northwest between these wells. In addition, responses in different screens at well R-20 reveal increasing drawdown with increasing depth as seen in Figure 13. These data clearly show vertical anisotropy and a 
leaky-aquifer behavior. Similar, but more subdued, drawdown data were also obtained from well R-32. These observations confirm previous hydraulic test results from R-20 and R-32 (McLin 2005a; McLin and Stone 2004b) that show changes in horizontal hydraulic conductivity with screen depth.

7. A transition from confined to leaky-confined aquifer behavior was apparent during the test. Hence, we reported a typical, early-time, confined $S$ value of about 0.00032 for the distance-drawdown method, and a typical early-time, leaky-confined $S$ value of 0.00180 from R20-3. These values were also replicated by numerous analyses from different observation wells. This transition occurred after about 4 days in the fully penetrating observation wells. However, it appears to have occurred much earlier in the multiplescreened well at R-20. In addition, this transition time seemed to be affected by aquifer thinning between wells PM-4 and PM-5. This transitional behavior appears to have started in the upper portions of the regional aquifer near well R20-3, and propagated radially outward and vertically downward as time progressed. Hence, it seems to have been spatially and temporally sequential, much like the propagating cone of depression that caused it.

8. The flow net analysis presented in Figure 17, although only approximate, appears to be a valid 2-D representation between wells PM-2 and PM-4 because the predicted hydraulic conductivity ratios are comparable to those obtained from specific capacity analyses of historical data and to those actually obtained from the independent aquifer test analyses. However, the flow net between wells PM-4, PM-5, PM-3, and O-4 is more suspect because the specific-capacity analyses yielded ratios different than predicted by flow net analysis. All of the $K$ ratios obtained from the various methods of analyses were summarized in Tables 7 and 9.

9. The dynamic spinner log at well PM-4 suggests that an alternative conceptual leakyaquifer model may be possible. In this alternative visualization, the leaky units are actually sandwiched between the highly productive zones within the $850 \mathrm{ft}$ interval described earlier. This alternative model does not have a leaky source bed located above the high-yielding unit. Instead, this visualization requires the low-production zones to recharge the adjacent high-production zones during pumping intervals. Then during nonpumping intervals, this recharge process apparently reverses and the high-production zones recharge the low-production zones. Ultimately, recharge to this sandwiched interval probably originates from the regional aquifer system in the Sierra de los Valles area west of the Laboratory.

10. Water levels were recorded at wells R-20, R-32, and R-22 for about one year following the aquifer test at well PM-2. These data are shown in Figure 30. These data are significant for several reasons. First, the water levels recorded in the five screens at R-22 reveal no influence of pumping from any municipal water supply well. Second, the water levels at R-20 and screens 2 and 3 at R-32 continued to respond to cyclical pumping at well PM-2 during the year following the aquifer test. However, the long-term water-level response at R32-1 was unexpected. During the PM-2 test, we concluded that screen 1 was not in hydraulic communication with PM-2. That conclusion is reaffirmed here. In addition, water levels in this screen are responding to some unknown municipal water supply well or wells. This connection to another water supply well is revealed by the 
water-level pattern shown in screen 1 because it closely resembles the pumping pattern for all combined Pajarito Plateau water supply wells shown in Figure 31. Based on increasing distances between R-32 and numerous water supply wells that were listed in Table 12, several possible candidates were identified. These include wells PM-4, PM-3, PM-1, PM-5, and combinations of wells (e.g., PM-4 and PM-2, or PM-4, PM-3 and PM2). Wells in the Buckman well field are unlikely candidates because of their long distances from R-32 and the lack of any confirmation responses at R-22. However, the Buckman wells have reversed the expected upward vertical hydraulic gradient at well R16 (McLin 2005c).

11. The regional aquifer below Pajarito Plateau is an extremely complex system. This point is succinctly illustrated by several important examples from the PM-2 aquifer test. First, the PM-2 cone of depression propagated radially outward for more than $8,800 \mathrm{ft}$, but it did not propagate vertically upward with similar ease. Hence, drawdown effects were recorded in wells PM-2, PM-4, PM-5, R-20, and R-32 but not in numerous other wells that were too shallow. Second, PM-2 pumping influences were documented by waterlevel changes recorded in screens 2 and 3 of R-32, while a second unknown supply well affected water levels in screen 1 . Had the PM-2 aquifer test analyses not been combined with long-term water-level observations, we might have incorrectly assumed that screen 1 was hydraulically connected to PM-2. Third, in the year following the PM-2 aquifer test, a cyclical (daily) pumping pattern was observed in R20-3. A similar but smoother pattern was also observed in screen 2 because high-frequency, pumping oscillations were dampened out by anisotropy. By the time we reached screen 1, this pumping pattern was almost completely obliterated, so that only a declining water-level trend remained. If water-level records had not been available from the two deeper screens, we might have incorrectly concluded that screen 1 was also not in direct hydraulic communication with PM-2. This behavior would not have been revealed without recording transducers in multiple-level screens. We conclude that the true hydraulic behavior of the regional aquifer system cannot be fully understood without multiple-level hydraulic monitoring. These vertically arrayed screens, when used in conjunction with dynamic spinner logs and aquifer tests, are essential if we are to understand vertical communication between alternating layers of high and low $K$ values in the regional system. By extension, we conclude that the regional aquifer system cannot be adequately monitored for water quality without multiple-level sampling and long-term water-level observations.

\section{ACKNOWLEDGMENTS}

This work was supported by the Groundwater Protection Program within the Environmental Stewardship Division at Los Alamos National Laboratory. Special thanks are extended to Timothy Glasco, deputy utility manager, and Charles Brown, water system superintendent, both of the Department of Public Utilities, County of Los Alamos, for their support and cooperation in conducting the aquifer test described here. This manuscript also benefited greatly from comments and suggestions provided by Velimir Vesselinov and David Broxton of the Hydrology, Geochemistry, and Geology Group (EES-6), Earth and Environmental Sciences Division, Los Alamos National Laboratory; Bruce Gallaher of the Water Quality and Hydrology Group (WQH), Environmental Stewardship Division, Los Alamos National Laboratory; and 
David Schafer of Schafer and Associates, Inc., Stillwater, Minnesota, for their invaluable discussions and critical reviews of this report. Special thanks are extended to David Broxton for providing Figures 1, 2, and 4; and to David Rogers for providing the data used in Figure 14. Finally, I would also like to thank William Stone for his encouragement and support during those dark days following the Cerro Grande wildfire, and for many discussions on plateau hydrogeology.

\section{REFERENCES}

Ball, T.T., M.C. Everett, P.A. Longmire, D.T. Vaniman, W.J. Stone, D. Larrsen, K.R. Greene, N. Clayton, and S. McLin, 2002. "Characterization of Well R-22 Completion Report," Los Alamos National Laboratory report LA-13893-MS, Los Alamos, NM.

Bouwer, H., 1978. Groundwater Hydrology. McGraw-Hill, New York, p. 480.

Bradbury, K.R., and E.R. Rothschild, 1985. "A Computerized Technique for Estimating Hydraulic Conductivity of Aquifers from Specific-Capacity Data." Ground Water, Vol. 23, No. 2, pp. 240-246.

Broxton, D.E., and D.T. Vaniman, 2005. "Geologic Framework of a Groundwater System on the Margin of a Rift Basin, Pajarito Plateau, North-Central New Mexico." Vadose Zone Journal (in press).

Broxton, D.E., and S.L. Reneau, 1996. "Buried Early Pleistocene Landscapes beneath the Pajarito Plateau, Northern New Mexico." New Mexico Geological Society, 47th Field Conference Guidebook to Jemez Mountains, New Mexico Bureau of Mines, Socorro, NM, pp. $325-334$.

Cushman, R.L., 1965. "An Evaluation of Aquifer and Well Characteristics of Municipal Well Fields in Los Alamos and Guaje Canyon near Los Alamos, New Mexico." U.S. Geological Survey, Water Supply Paper 1809-D, 50 p.

Driscoll, F.G., 1986. Groundwater and Wells. 2nd ed., Johnson Division, St. Paul, Minnesota.

Fetter, C.W., 1994. Applied Hydrology. 3rd edition, Prentice-Hall, New Jersey, 691 p.

Freeze, R.A., and J.A. Cherry, 1979. Groundwater. Prentice-Hall, New York, 604 p.

Griggs, R.L., 1964. "Geology and Ground-Water Resources of the Los Alamos Area, New Mexico," U.S. Geological Survey, Water Supply Report 1753, 107 p.

Hantush, M.S., 1960. "Modification of the Theory of Leaky Aquifers." Journal of Geophysical Research, Vol. 65, pp. 3713-3725.

Hantush, M.S., 1962. "Flow of Ground Water in Sands of Non-uniform Thickness; 3. Flow to Wells," Journal of Geophysical Research, Vol. 67, No. 4, pp. 1527-1534.

Hantush, M.S., 1964. "Hydraulics of Wells," in Advances in Hydroscience. V.T. Chow, Ed. Academic Press, New York, Vol. 1, pp. 281-442. 
Hantush, M.S., and C.E. Jacob, 1955. "Non-steady Radial Flow in an Infinite Leaky Aquifer," Transactions of the American Geophysical Union, Vol. 36, pp. 95-100.

Kelley, R., 2005. "Elevation of the Top of the Regional Aquifer for Los Alamos National Laboratory," Los Alamos National Laboratory document LA-UR-05-0455.

Koch, R.J., P. Longmire, D.B. Rogers, and K. Mullen, 1999. "Report of Testing and Sampling of Municipal Supply Well PM-4,” Los Alamos National Laboratory report LA-13648.

Koch, R.J., and D.B. Rogers, 2003. "Water Supply at Los Alamos, 1998-2001,” Los Alamos National Laboratory report LA-13985-PR.

LANL (Los Alamos National Laboratory), January 1996. "Groundwater Protection Management Program Plan," Environmental Restoration Project Report No. 70215, Los Alamos, New Mexico.

LANL (Los Alamos National Laboratory), September 1998. "Hydrogeologic Workplan," Environmental Restoration Project Report No. 59599, Los Alamos, New Mexico.

McLin, S.G., 1996. "Analysis of Water Level Fluctuations in Pajarito Plateau Wells." New Mexico Geological Society, 47th Field Conference Guidebook to Jemez Mountains, New Mexico Bureau of Mines, Socorro, NM, pp. 421-426.

McLin, S.G., 2005a. "Hydrologic Tests at Characterization Well R-20," Los Alamos National Laboratory report LA-14201-MS.

McLin, S.G., 2005b. "Estimating Transmissivity from Specific Capacity Using Matlab.” Ground Water (in press).

McLin, S.G., 2005c. "Hydrologic Tests at Characterization Well R-16," Los Alamos National Laboratory report LA-14183-MS.

McLin, S.G., W.D. Purtymun, and M.E. Maes, 1998. "Water Supply at Los Alamos during 1997,’ Los Alamos National Laboratory report LA-13548-PR.

McLin, S.G., and W.J. Stone, 2004a. "Hydrologic Tests at Characterization Wells R-9i, R-13, R19, R-22, and R-31, Revision 1,” Los Alamos National Laboratory report LA-14121-MS.

McLin, S.G., and W.J. Stone, 2004b. "Hydrologic Tests at Characterization Well R-32," Los Alamos National Laboratory report LA-14106-MS.

Moench, A.F., 1985. "Transient Flow to a Large Diameter Well in an Aquifer with Storative Semiconfining Layers," Water Resources Research, Vol. 21, No. 8, pp. 1121-1131.

Neuman, S.P., and P.A. Witherspoon, 1969. "Theory of Flow in a Confined Two Aquifer System," Water Resources Research, Vol. 5, No. 4, pp. 803-816.

Neuman, S.P., and P.A. Witherspoon, 1971. "Transient Flow of Ground Water to Wells in Multiple Aquifer Systems, in Sea-Water Intrusion: Aquitards in the Coastal Ground Water Basin of Oxnard Plain, Ventura County. P.A. Witherspoon and J.K. Mitchell (Eds.), California Department of Water Resources, Bulletin No. 63-4, Sacramento, CA. 
Pearson, S.G., 2003. "Characterization Well R-32 Completion Report," Los Alamos National Laboratory document LA-UR-03-3984.

Purtymun, W.D., 1995. "Geologic and Hydrologic Records of Observation Wells, Test Holes, Test Wells, Supply Wells, Springs, and Surface Water Stations in the Los Alamos Area," Los Alamos National Laboratory report LA-12883-MS.

Purtymun, W.D., and S. Johansen, 1974. "General Geohydrology of the Pajarito Plateau." New Mexico Geological Society, 25th Field Conference Guidebook to Ghost Ranch, New Mexico Bureau of Mines, Socorro, NM, pp. 347-349.

Purtymun, W.D., and A.K. Stoker, 1988. "Water Supply at Los Alamos: Current Status of Wells and Future Water Supply," Los Alamos National Laboratory report LA-11332-MS, Los Alamos, NM.

Rogers, D.B., A.K. Stoker, S.G. McLin, and B.M. Gallaher, 1996. "Recharge to the Pajarito Plateau Regional Aquifer System." New Mexico Geological Society, 47th Field Conference Guidebook to Jemez Mountains, New Mexico Bureau of Mines, Socorro, NM, pp. 407-412.

Schafer, D.C., 1979. "Casing Storage Can Affect Pumping Test Data," Johnson Driller's Journal, Jan.-Feb. 1979.

Theis, C.V., 1935. "The Relation Between the Lowering of the Piezometric Surface and the Rate and Duration of Discharge of a Well Using Groundwater Storage," American Geophysical Union Transactions, Vol. 16, pp. 519-524.

Theis, C.V., and C.S. Conover, 1962. "Pumping Tests in the Los Alamos Canyon Well Field near Los Alamos, New Mexico,” U.S. Geological Survey, Water Supply Paper 1619-I, p. 24.

Thompson, D., C. Schultz, P. Schuh, E. Tow, and R. Lawrence, 2003. "Characterization Well R20 Completion Report,” Los Alamos National Laboratory document LA-UR-03-1839.

Todd, D.K., 1980. Groundwater Hydrology. (2nd ed.), John Wiley and Sons, New York, 535 pp.

Vesselinov, V.V., and E.H. Keating, 2002. "Analysis of Capture Zones of the Buckman Well Field and a Proposed Horizontal Collector Well North of the Otowi Bridge," Los Alamos National Laboratory document LA-UR-02-2750.

Walton, W.C., 1970. Groundwater Resource Evaluation. McGraw-Hill Book Company, New York, $664 \mathrm{pp}$. 



\section{APPENDIX. MAP OF DATA FILES}

Table A-1 lists data files that are contained in the CD-ROM located in the inside back cover of this report. These drawdown and recovery data were collected from numerous wells during the aquifer test described in the report. Table A-1 describes the naming convention used to identify these data files. Each data file contains important data in tab-delimited, text format. The file name tells which well the data came from. For example, PM-2p.txt contains drawdown (or pumping) data from well PM-2. The first column in this file contains elapsed time (days) since pumping began; the second column contains drawdown (ft). Other data files contain simple recovery data (i.e., PM-2r.txt); however, all files are structured identically (i.e., time in Column 1 is time since recovery began and recovery in Column 2). Some files contain both drawdown and residual recovery data (i.e., PM-2pr.txt). These data are different from individual drawdown or recovery data files. These differences are explained in the report. Finally, some data files contain multiple-screen data (i.e., R32-all.txt). Here time (days) is in Column 1, while screens 1, 2, and 3 contain water-level data (ft) that are in Columns 2, 3, and 4, respectively. These data were simultaneously recorded.

Table A-1. Data Files Contained on the CD-ROM Included with This Report

\begin{tabular}{|c|c|c|}
\hline File Name & Well & Remarks \\
\hline PM-2p.txt & PM-2 & Drawdown data \\
\hline PM-2pr.txt & PM-2 & Drawdown and recovery data-continuous time \\
\hline PM-2r.txt & PM-2 & Recovery data \\
\hline PM-2tr.txt & PM-2 & Theis recovery data \\
\hline PM-4p.txt & PM-4 & Drawdown data \\
\hline PM-4pr.txt & PM-4 & Drawdown and recovery data-continuous time \\
\hline PM-4r.txt & PM-4 & Recovery data \\
\hline PM-5p.txt & PM-5 & Drawdown data \\
\hline PM-5pr.txt & PM-5 & Drawdown and recovery data-continuous time \\
\hline PM-5ps.txt & PM-5 & Drawdown data-smoothed \\
\hline PM-5r.txt & PM-5 & Recovery data \\
\hline R20-1p.txt & $\mathrm{R}-20$ & Drawdown data from screen 1 \\
\hline R20-1r.txt & $\mathrm{R}-20$ & Recovery data from screen 1 \\
\hline R20-2p.txt & $\mathrm{R}-20$ & Drawdown data from screen 2 \\
\hline R20-2r.txt & $\mathrm{R}-20$ & Recovery data from screen 2 \\
\hline R20-3p.txt & $\mathrm{R}-20$ & Drawdown data from screen 3 \\
\hline R20-3pr.txt & $\mathrm{R}-20$ & Drawdown and recovery data from screen 3 \\
\hline R20-3r.txt & $\mathrm{R}-20$ & Recovery data from screen 3 \\
\hline R32-all.txt & R-32 & Drawdown and recovery data from all screens \\
\hline R20wls.txt & $\mathrm{R}-201-\mathrm{yr}$ & Piezometric levels for $1-y r$ following test \\
\hline R22wls.txt & $\mathrm{R}-221-\mathrm{yr}$ & Piezometric levels for $1-y r$ following test \\
\hline R32wls.txt & $\mathrm{R}-321-\mathrm{yr}$ & Piezometric levels for $1-y r$ following test \\
\hline
\end{tabular}



This report has been reproduced directly from the best available copy. It is available electronically on the Web (http://www.doe.gov/bridge).

Copies are available for sale to U.S. Department of Energy employees and contractors from:

Office of Scientific and Technical Information

P.O. Box 62

Oak Ridge, TN 37831

(865) 576-8401

Copies are available for sale to the public from: National Technical Information Service

U.S. Department of Commerce

5285 Port Royal Road

Springfield, VA 22161

(800) 553-6847 


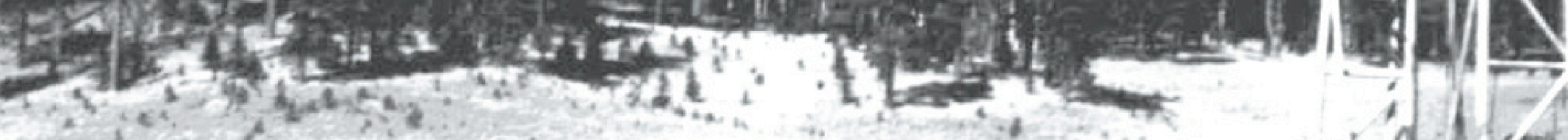

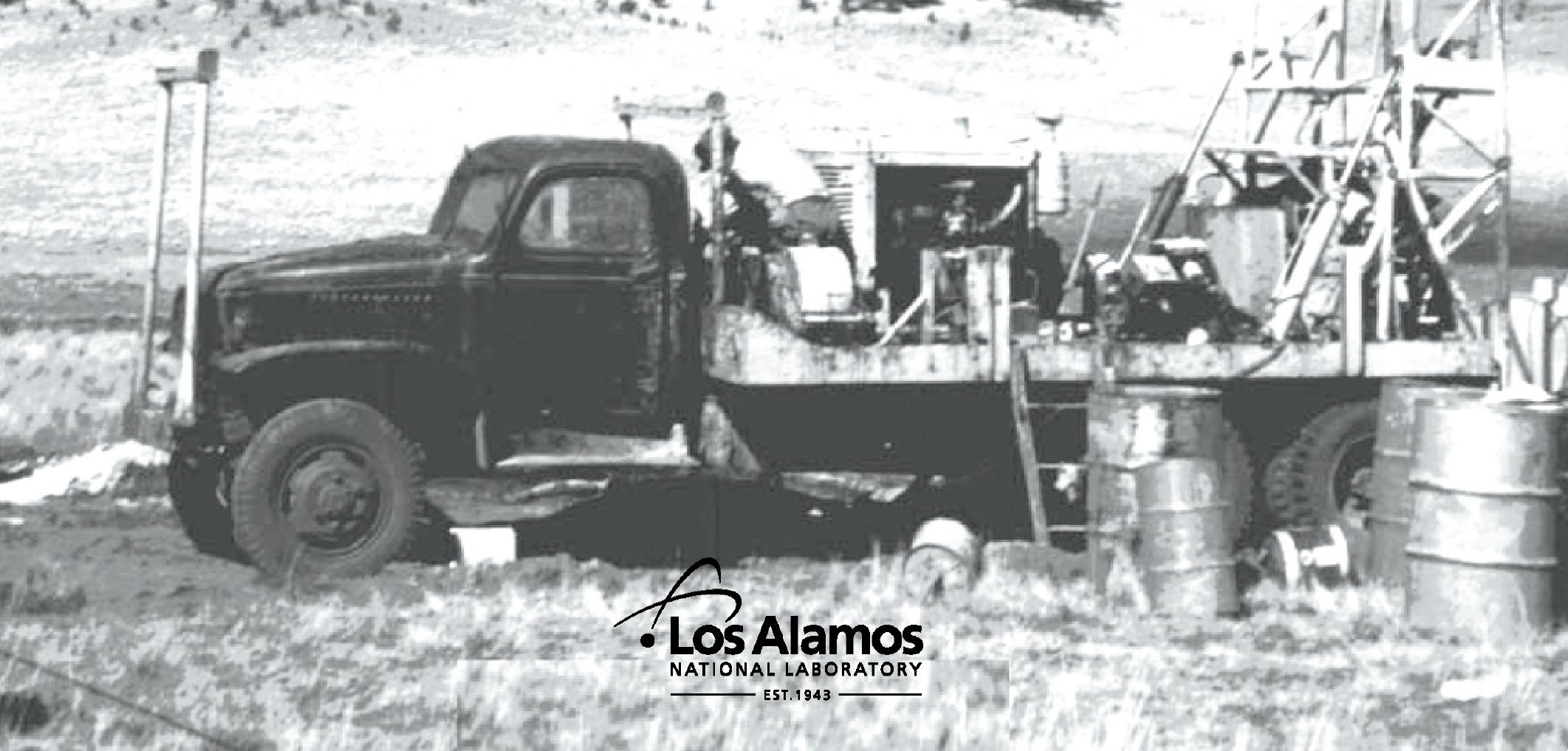

